\title{
INITIAL MOVEMENTS AND DISTURBANCE RESPONSE OF A NEWLY REINTRODUCED ELK HERD IN THE MISSOURI OZARKS
}

\author{
A Thesis \\ presented to
}

the Faculty of the Graduate School

at the University of Missouri-Columbia

In Partial Fulfillment
of the Requirements for the Degree
Master of Science
by
AMY BLEISCH
Joshua Millspaugh, Thesis Supervisor
MAY 2014


The undersigned, appointed by the dean of the Graduate School, have examined the thesis entitled

\section{INITIAL MOVEMENTS AND DISTURBANCE RESPONSE OF A NEWLY REINTRODUCED ELK HERD IN THE MISSOURI OZARKS}

presented by Amy Bleisch, a candidate for the degree of master of science, and hereby certify that, in their opinion, it is worthy of acceptance.

\begin{tabular}{c}
\hline Professor Joshua Millspaugh \\
\hline Professor Charles Nilon \\
\hline Professor Hong He \\
\hline
\end{tabular}

Lonnie Hansen 


\section{DEDICATION}

For my family:

My mother, Annette Bleisch,

My father, Daniel Bleisch,

My sister, Courtney Bleisch,

My fiancé, Lance Ennen.

Thank you for your love and support as I follow my dreams.

-Amy 


\section{ACKNOWLEDGMENTS}

I would like to thank my adviser, Dr. Joshua Millspaugh, for giving me the opportunity to pursue this research, his mentorship, support, and guidance, and providing an inspiring lab environment in which to grow. I have learned so much during my time in Missouri, academic and otherwise, and I owe it all to him.

I could not have finished this work without the help of our interagency colleagues. I would like to thank the Missouri Department of Conservation for providing innumerable resources and professional opportunities. Thank you especially to Lonnie Hansen for serving on my committee and challenging me to mature as an ecologist. Ron Dent, Scott McWilliams, Jacob Rieken, and Steve Crider helped coordinate the capture, care, and transport of elk for release. Ryan Houf, Preston Mabry, Marshall Price, Patti Vessels, and many other Peck Ranch staff provided a positive environment and logistical support for my research. Thank you to David Hasenbeck for his help establishing the project in the Ozarks. Thank you to Timothy Bixler, Jason Sumners, Joel Sartwell, Julie Fleming, and Philip Marley for extensive collar and database management contributions. Thank you to Terry Thompson and Rex Martensen for affording me a few days outside of the office. Thanks to the many, many Missouri Department of Conservation staff who allowed me to help capture elk in Kentucky in 2011, which was one of the most exciting experiences on the project.

Thank you to the Kentucky Department of Fish and Wildlife for their guidance and patience as we adapted to the translocation and reintroduction process. Thanks to the University of Kentucky, especially Aaron Hildreth, for 
sharing valuable data from the elk capture and holding periods in Kentucky. Thank you to the National Park Service employees at the Ozark National Scenic Riverways for their continued cooperation and support of the elk research project. Thank you to the Rocky Mountain Elk Foundation, particularly Tom Toman, for their enthusiastic support of elk reintroduction, research, and management.

I would like to thank my labmates for all of their help over the years. First, my project mates Dr. Barbara Keller and Trenton Smith helped manage data collection when I was away from the field site and provided vital insights into the project. Thomas Bonnot was very generous with his time and provided GIS and statistical support that made the completion of this work possible. Thanks to Drs. Robert Gitzen and Christopher Rota for lending their statistical coding expertise. Thanks to Aleshia Fremgen, Leslie Schreiber, and Jaymi LeBrun for providing welcome distractions, intellectual or otherwise. Finally, thank you to Stephanie Zimmer Shaffer for her many years of friendship and encouragement.

Thank you to the many others at the University of Missouri who helped make graduate school a positive experience. Thanks in particular to Karen Decker, who was instrumental in coordinating logistics to make our project run smoothly.

I would like to thank our many field technicians, whose hard work made mine possible: Seth Snow, Tanya Wolf, Tim Schrautemeier, Cari Sebright, Jacob Dillon, Jana Ashling, Dakota Neel, Stephanie Raiman, Jennifer Foggia, Jake Behrens, Matthew Thomas, Chloe Wright, Derek Payne, Damon Haan, Nick Oakley, Kourtney Stonehouse, Josh Leonard, Deanna Russell, and Sam Garrett McKee. 
Finally, I would like to thank my undergraduate mentor, Dr. Paul Curtis, and his colleagues Michael Ashdown and Dr. Jay Boulanger, for inspiring me to pursue wildlife ecology as a career, introducing me to ungulate research, and for all of the time and resources they invested to help me succeed in the field. 


\section{TABLE OF CONTENTS}

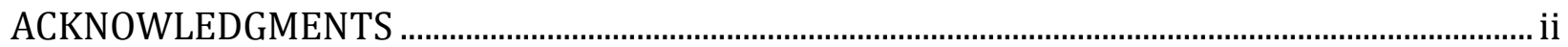

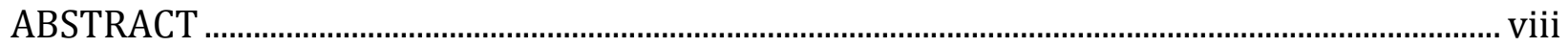

INITIAL MOVEMENTS OF REINTRODUCED ELK IN THE MISSOURI OZARKS.............................. 1

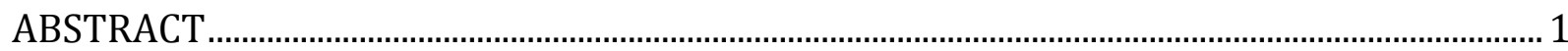

INTRODUCTION

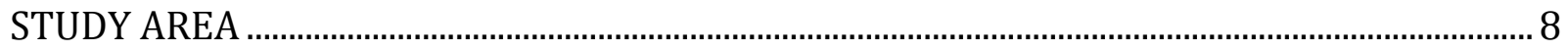

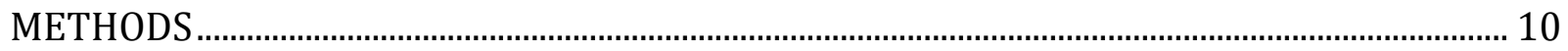

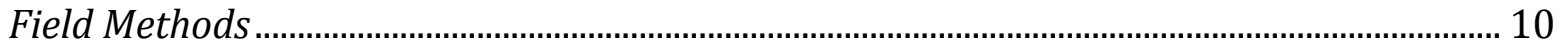

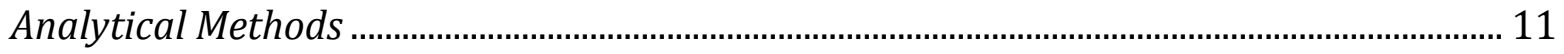

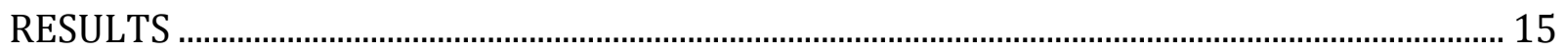

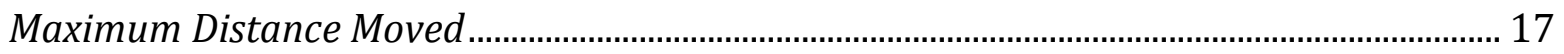

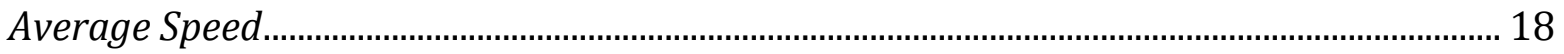

Utilization Distributions .................................................................................................................... 18

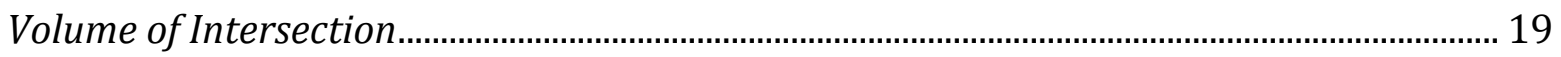

DISCUSSION

MANAGEMENT IMPLICATIONS..................................................................................................... 24

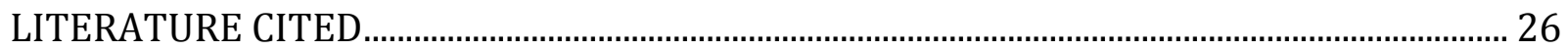

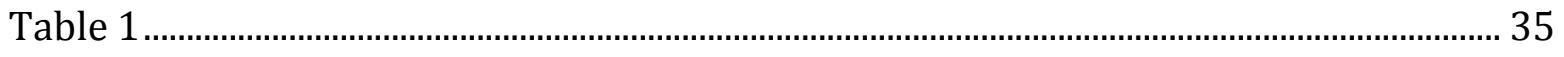

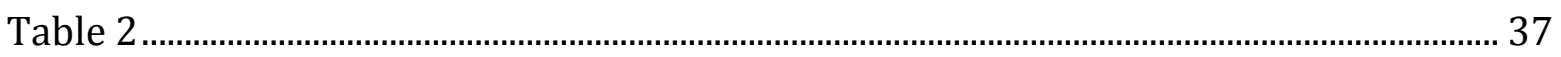

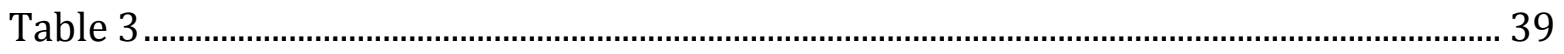




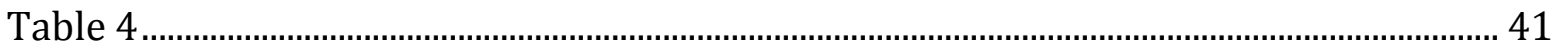

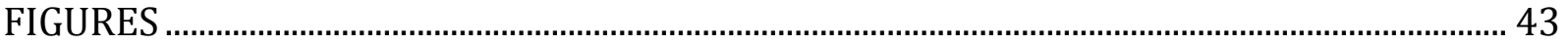

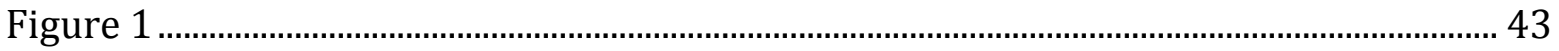

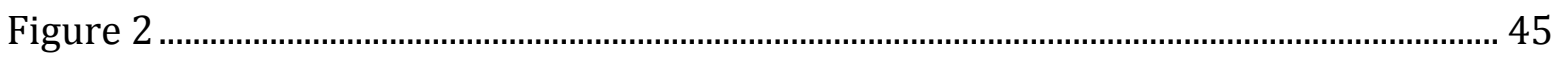

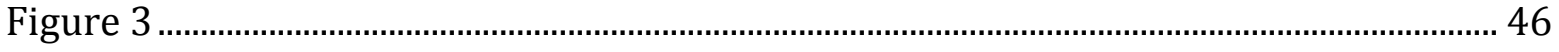

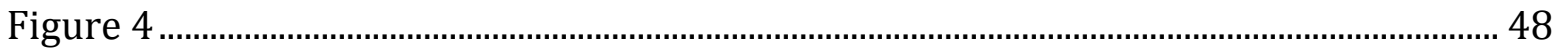

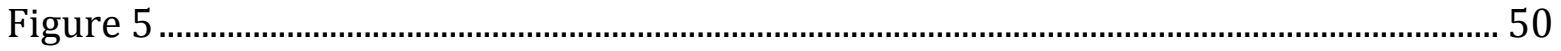

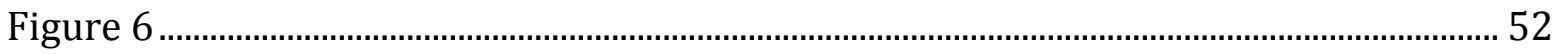

DISTURBANCE RESPONSE OF RECENTLY REINTRODUCED ELK IN THE MISSOURI OZARKS

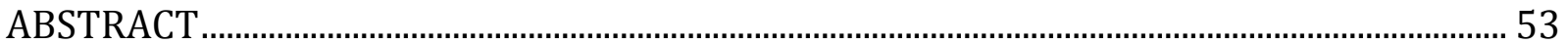

INTRODUCTION

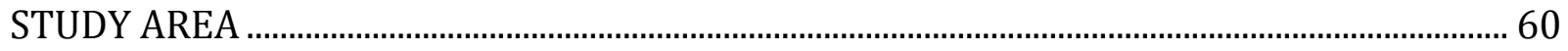

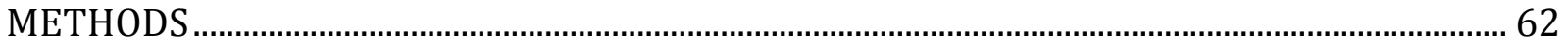

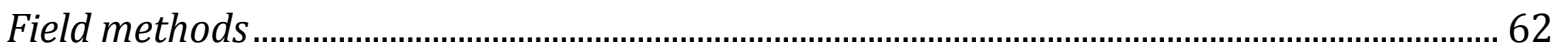

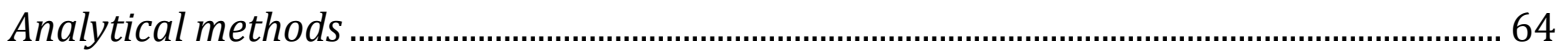

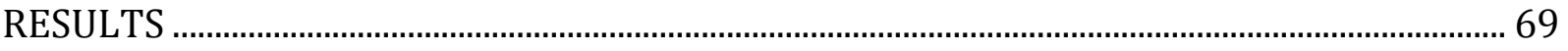

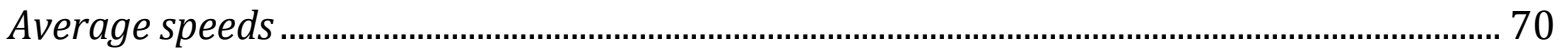

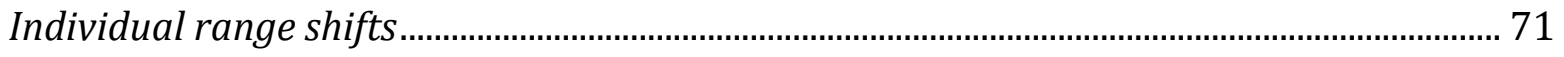

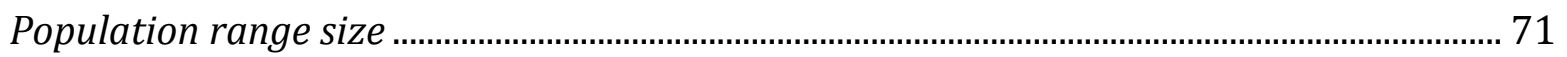

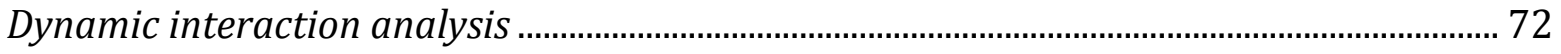

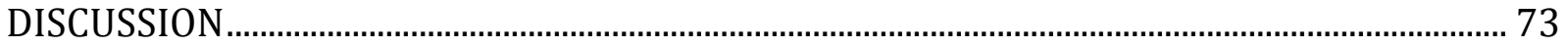

MANAGEMENT IMPLICATIONS................................................................................................... 75 
LITERATURE CITED ................................................................................................................................. 77

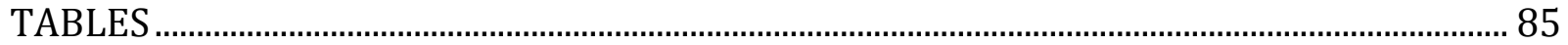

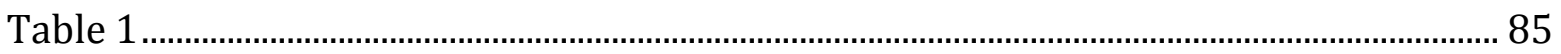

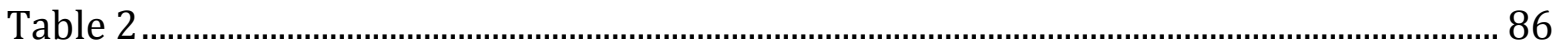

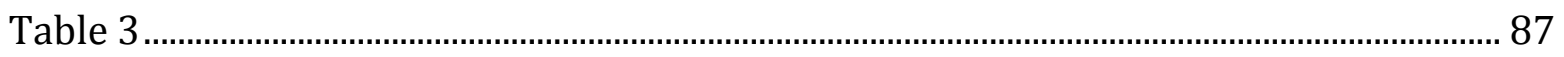

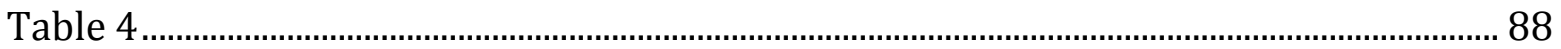

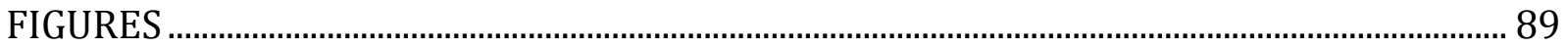

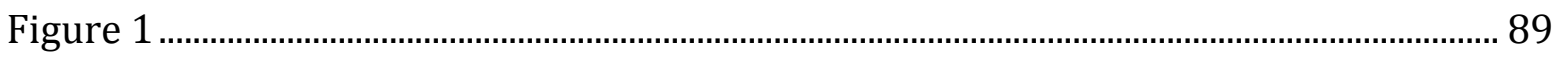

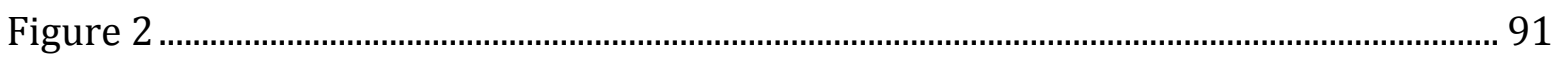

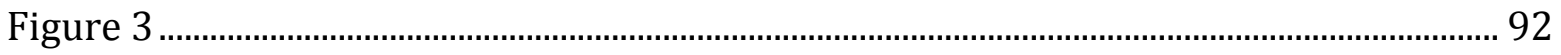

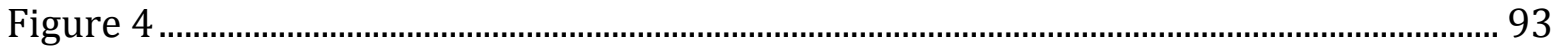

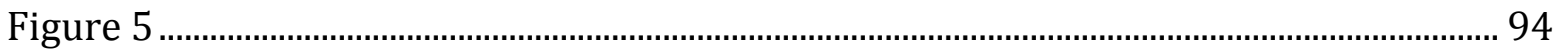

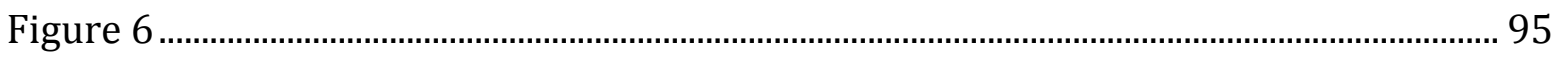

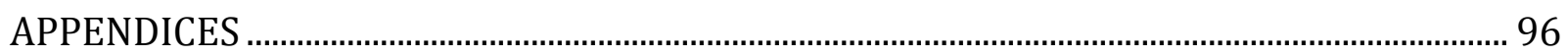

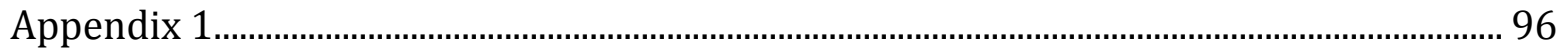

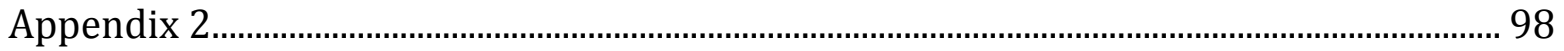

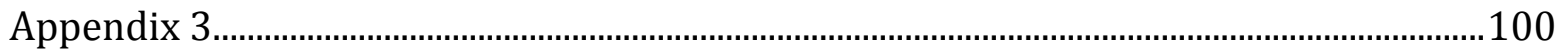




\section{ABSTRACT}

Initial movements of reintroduced wildlife populations can determine shortterm restoration success. Managers need ways to encourage animals to exhibit high release site fidelity so that they can mitigate suboptimal breeding, reduce mortality rates, and minimize human-wildlife conflicts that are sometimes associated with low site fidelity. We studied initial movement ecology of adult and yearling elk (Cervus elaphus) reintroduced to the Missouri Ozarks in $2011(n=32), 2012(n=21)$, and $2013(n=31)$ for the initial 6 months post-release. All released elk were fitted with GPS collars which obtained locations at 2-5 hour intervals. We assessed maximum displacement from the release site, range shifts, movement rates, and range size across 4 sequential time frames (0-10 days, 11-31 days, 32-62 days, and 62-183 days) for animals surviving the study duration. We fit repeated measures mixed models to assess the effects of sex, age, calf-rearing status, release site, and release year on movement responses. Elk acclimated to their environment in discrete phases, including 1) immediate departure from the release site and elevated movement rates, followed by 2) establishing a home range and gradually expanding their range using previously used area. Individual maximum distances from the release site were stable for 0-61 days, and somewhat higher for 62-183 days. Compared to other restorations in eastern North America, site fidelity was high, with maximum distance from the release site $62-183$ days post-release $\leq 10$ $\mathrm{km}$ for $94 \%$ of 2011 animals, 57\% of 2012 animals, and $97 \%$ of 2013 animals. The speed of elk movements declined slightly 10-61 days post-release, but were $30 \%$ higher in the last time frame. The average speed of individual elk across all time 
frames was $0.080 \pm 0.024 \mathrm{~km}$ per hour in the 2011 release group ( $n=32)$,

$0.101 \pm 0.026 \mathrm{~km}$ per hour in 2012 release groups $(n=21)$, and $0.091 \pm 0.025$ in the 2013 release group ( $n=31)$. Elk range sizes were similar for 0-61 days post-release and approximately twice as high for 62-183 days post-release. Even so, elk range sizes during 61-183 days post-release were small, averaging $17.6 \pm 5.4 \mathrm{~km} 2$ in the 2011 release group ( $n=32), 39.9 \pm 42.8 \mathrm{~km} 2$ in the 2012 release groups ( $n=21)$, and 13.9 \pm 17.2 for year 3 elk $(n=31)$. The average range overlap for individual elk in sequential time periods was $0.230 \pm 0.320(n=32)$ in $2011,0.290 \pm 0.323(n=21)$ in 2012, and 0.26 \pm 0.24 in 2013 ( $n=31$ ). Release site had the greatest influence on initial movements; one site used in 2012 was associated with higher release site displacement and range sizes. These results may be due to habitat differences, presence of conspecifics, and variation in demography between release groups. High site fidelity overall and small home ranges in elk recently restored to Missouri may be attributed to soft release, suitable habitat, and minimal human disturbance.

Although wildlife reintroductions are often intended to provide the public with recreational opportunities, human disturbance at the release site may compromise the reintroduction effort. Animals that are disturbed may demonstrate reduced reproduction and survival. Further, if disturbance causes animals to abandon the release site, human-wildlife conflict may result. We studied the response of reintroduced Missouri elk (Cervus elaphus) to managed deer hunts in $2011(n=29), 2012$ (n=36), and 2013 ( $n=43)$. All elk were fitted with GPS collars that obtained fixes every 2-5 hours. We measured elk speeds, range shifts, and range sizes. We fit mixed-effects repeated measures models to determine the 
impact of hunter numbers, hunt type, hunt duration, hunt year, number of hunts an individual experienced, timing relative to the hunt, sex, age, release site, and release year on disturbance response. We asked deer hunters to carry GPS units during the hunts in order to assess spatiotemporal elk-hunter interactions and conducted a dynamic interaction analysis to assess whether elk were attracted to or avoided hunters. Elk responded to deer hunter disturbance by using refugia. Eleven elk left during the first hunt. After the first hunt, only one other hunt caused $>3$ elk to leave the conservation area. During the hunts, speeds increased, ranges shifted, and range sizes decreased. Speeds increased by $11 \%$ during each hunt compared to before the hunt. Elk used only $32.2 \%$ of their pre-hunt range post-hunt. Elk range sizes were $11 \%$ smaller during muzzleloader hunts than youth hunts. These behaviors may indicate that elk identified a fraction of their range to use as refugia and made more directed movements to leave the immediate vicinity of deer hunters. We observed neither attraction nor avoidance between deer hunters and elk, possibly due to availability of refugia within the spatial extent of the disturbance. This study provides evidence that elk are adaptable to human-wildlife disturbance even shortly (4 months) after reintroduction, and that animal reintroductions do not preclude recreational use of public lands where both are management priorities. 


\section{INITIAL MOVEMENTS OF REINTRODUCED ELK IN THE MISSOURI OZARKS}

\section{ABSTRACT}

Initial movements of reintroduced wildlife populations can determine shortterm restoration success. Managers need ways to encourage animals to exhibit high release site fidelity so that they can mitigate suboptimal breeding, reduce mortality rates, and minimize human-wildlife conflicts that are sometimes associated with low site fidelity. We studied initial movement ecology of adult and yearling elk (Cervus elaphus) reintroduced to the Missouri Ozarks in 2011 ( $n=32), 2012$ ( $n=21)$, and 2013 ( $n=31)$ for the initial 6 months post-release. All released elk were fitted with GPS collars which obtained locations at 2-5 hour intervals. We assessed maximum displacement from the release site, range shifts, movement rates, and range size across 4 sequential time frames (0-10 days, 11-31 days, 32-62 days, and 62-183 days) for animals surviving the study duration. We fit repeated measures mixed models to assess the effects of sex, age, calf-rearing status, release site, and release year on movement responses. Elk acclimated to their environment in discrete phases, including 1) immediate departure from the release site and elevated movement rates, followed by 2) establishing a home range and gradually expanding their range using previously used area. Individual maximum distances from the release site were stable for 0-61 days, and somewhat higher for 62-183 days. Compared to other restorations in eastern North America, site fidelity was high, with maximum distance from the release site $62-183$ days post-release $\leq 10$ km for $94 \%$ of 2011 animals, 57\% of 2012 animals, and $97 \%$ of 2013 animals. The 
speed of elk movements declined slightly 10-61 days post-release, but were $30 \%$ higher in the last time frame. The average speed of individual elk across all time frames was $0.080 \pm 0.024 \mathrm{~km}$ per hour in the 2011 release group ( $n=32)$, $0.101 \pm 0.026 \mathrm{~km}$ per hour in 2012 release groups $(n=21)$, and $0.091 \pm 0.025$ in the 2013 release group ( $n=31$ ). Elk range sizes were similar for 0-61 days post-release and approximately twice as high for 62-183 days post-release. Even so, elk range sizes during 61-183 days post-release were small, averaging $17.6 \pm 5.4 \mathrm{~km}^{2}$ in the 2011 release group ( $n=32), 39.9 \pm 42.8 \mathrm{~km}^{2}$ in the 2012 release groups $(n=21)$, and 13.9 \pm 17.2 for year 3 elk $(n=31)$. The average range overlap for individual elk in sequential time periods was $0.230 \pm 0.320(n=32)$ in $2011,0.290 \pm 0.323(n=21)$ in 2012, and 0.26 \pm 0.24 in 2013 ( $n=31$ ). Release site had the greatest influence on initial movements; one site used in 2012 was associated with higher release site displacement and range sizes. These results may be due to habitat differences, presence of conspecifics, and variation in demography between release groups. High site fidelity overall and small home ranges in elk recently restored to Missouri may be attributed to soft release, suitable habitat, and minimal human disturbance. 


\section{INTRODUCTION}

Although animal reintroductions have been commonplace in the United States since the turn of the $20^{\text {th }}$ century (Enochs 1998), most attempts to restore wild populations fail (Rodriguez et al. 1995, Clark et al. 2002, Teixeira et al. 2007, Jachowski et al. 2011). As restoration efforts are expensive and time-intensive (Spinola et al. 2008), we must optimize protocols to maximize success.

Reintroduced wildlife face many challenges post-release, including predation, habitat and food shortages, disease, and human conflicts (Banks et al. 2002, Collazo et al. 2003, Vandel et al. 2006, Benson and Chamberlain 2007, Spinola et al. 2008, Jachowski et al. 2011, Yott et al. 2011). Additionally, acquisition of enough founding animals is an issue for rare species or when genetically sound and disease-free populations are scarce (Missouri Department of Conservation 2010, Armstrong and Wittmer 2011). Elk (Cervus elaphus) restorations in the eastern United States face similar challenges to other wildlife reintroductions. Early attempts to restore elk often failed due to habitat constraints, legal or illegal harvest, agrarian conflicts, or meningeal worm (Parelaphostrongylus tenuis) infections (Virginia Department of Game and Inland Fisheries 2010). Obtaining founding animals is also problematic. Although elk are locally abundant, concerns about emerging diseases such as chronic wasting disease limit the number of potential donor states (Missouri Department of Conservation 2010, Virginia Department of Game and Inland Fisheries 2010). As game animals, donor states may be reluctant to part with quality mature individuals (Larkin et al. 2002). The challenges to translocated 
wildlife, potential lack of available animals, and cost of reintroduction programs call for a complete understanding of factors contributing to restoration success.

Initial movements of reintroduced animals play an important role in population growth and therefore restoration success. Dispersal from the release site decreases population growth because animals may fail to reproduce or die (Hardman and Moro 2006, Devineau et al. 2010). It is critical for small populations to remain at a density that provides resiliency against stochastic events, protection against inbreeding, and prevents temporary Allee effects (Komers and Curman 2000, Larkin et al. 2002, Moehrenschlager and Macdonald 2003, Vandel et al. 2006, Spinola et al. 2008, Armstrong and Wittmer 2011, Yott et al. 2011). However, large mammals often leave release sites quickly and are capable of making extensive movements (Fritts et al. 1984, Ruth et al. 1998, Moehrenschlager and Macdonald 2003, Spinola et al. 2008, Yott et al. 2011). Elk and other large mammals that disperse long distances often experience high mortality rates (Ruth et al. 1998, Moehrenschlager and Macdonald 2003, Benson and Chamberlain 2007, Haydon et al. 2008, Spinola et al. 2008, Devineau et al. 2010). In contrast to smaller vertebrates (Banks et al. 2002, Collazo et al. 2003, Hardman and Moro 2006), large animals may be more likely to die from human-wildlife interactions associated with dispersal than predation (Benson and Chamberlain 2007, Spinola et al. 2008, Yott et al. 2011). Because adult survival is key to the population growth of long-lived species (Devineau et al. 2010), large mammal restorations should be structured to encourage animals to remain near the release site. 
Because encouraging reintroduced vertebrates to stay near the release site is a key component for project restoration success (Yott et al. 2011), it is important to determine which factors affect movement ecology. Sex, age, presence of young, release site, and release year may all be predictors of post-release movements in translocated mammals. Typically, males disperse farther than females in mammal reintroductions (Moehrenschlager and Macdonald 2003, Hardman and Moro 2006, Spinola et al. 2008, Devineau et al. 2010, Ryckman et al. 2010), although sex is not always an influential variable in elk movements after reintroduction (Larkin et al. 2004). Age is also an important factor in mammalian post-translocation movements, with older individuals usually traveling farther than younger ones (Fritts et al. 1984, Ruth et al. 1998, Clark et al. 2002, Moehrenschlager and Macdonald 2003, Larkin et al. 2004, Ryckman et al. 2010). However, this is not always true (Vandel et al. 2006). Maternal females may restrict movements postrelease when compared to individuals without dependent offspring (Clark et al. 2002). This may be especially true for maternal cow elk and other ungulates that reduce movement post-parturition to tend hiding young (Vore and Schmidt 2001). Release site and release year can also be predictors of post-release movement and spatial ecology in elk and other large mammals (Larkin et al. 2004, Benson and Chamberlain 2007, Devineau et al. 2010). Studies attempting to relate biological factors to post-release movements in elk have yielded inconsistent results. For this reason, it is important to conduct site-specific studies to determine why these inconsistencies might exist. 
As elk reintroductions to eastern North America become more widespread, site-specific studies of factors influencing initial movements are needed to maximize success. Elk reintroduction programs have enjoyed renewed interest the past 2 decades (Virginia Department of Game and Inland Fisheries 2010). Of the 20 eastern states and provinces that have implemented elk restoration efforts, $7^{*}$ have released elk in the past 20 years (Alabama, Arkansas, the District of Columbia, Florida, Indiana, Kansas, Kentucky*, Louisiana, Michigan, Minnesota, Missouri*, New Hampshire, New York, North Carolina*, Oklahoma, Ontario*, Pennsylvania, Tennessee*, Virginia*, and Wisconsin*) (O'Gara and Dundas 2002, Conard et al. 2006, Virginia Department of Game and Inland Fisheries 2010, Rosatte et al. 2007, Missouri Department of Conservation 2010). We studied the movement ecology of elk reintroduced to Missouri in 2011-2013 to inform future releases. Understanding factors influencing elk movements post-release would allow managers to optimize protocols for initial population growth (Komers and Curman 2000), select areas with an appropriate landscape structure (Larkin et al. 2004, Ryckman et al. 2010), provide supplementary food sources (Ryckman et al. 2010), mitigate human disturbance on the site (Larkin et al. 2004), and attempt to reduce elk-human conflict in agrarian areas (Rosatte et al. 2007), each of which is thought to increase the success of elk restorations.

Our objectives were to study the initial movements of elk reintroduced to Missouri by assessing 2 site fidelity metrics, maximum distances moved and range shifts, and 2 additional space use responses, movement rates and range size. Because disorientation subsides and translocated mammals establish long-term 
space use habits at 5-156 days post-release (Ruth et al. 1998, Moehrenschlager and Macdonald 2003), we evaluated each of the 4 movement responses across 4 sequential time frames during the first 6 months (183 days) post-release. We hypothesized that site fidelity would be high because the Missouri elk restoration was not at the historic range limit of the species, released elk in suitable habitat surrounded by a landscape with minimal open areas, and minimized human disturbance in the area immediately post-release (Larkin et al. 2004). Also, the Missouri elk restoration used a soft release by holding animals in pens to form social bonds and acclimate to their new environment after transport (Rosatte et al. 2007, Missouri Department of Conservation 2010, Ryckman et al. 2010, Armstrong and Wittmer 2011). Each of these factors is thought to increase fidelity to the release site in translocated elk. Since the primary Missouri elk release site provided open land and low disturbance from roads and residences, we predicted that animals released there would demonstrate high site fidelity. Transient or exploring individuals are thought to move faster than those who are resident or encamped (Delgado et al. 2009, Morales et al. 2004, Turchin 1998). Because of conditions at and surrounding the release sites, we hypothesized that movement rates would be highest immediately post-release and decrease over time, resulting in range sizes that would decrease over time. We also predicted initial movement responses would vary by sex (Ryckman et al. 2010), age (Larkin et al. 2004, Ryckman et al. 2010), calf-rearing status, release site, and release year. 


\section{STUDY AREA}

Elk were reintroduced to an $896 \mathrm{~km}^{2}$ Elk Restoration Zone (ERZ, Figure 1) in parts of Carter, Shannon, and Reynolds Counties in the southeastern Missouri Ozarks $\left(91^{\circ} 24^{\prime}\right.$ to $90^{\circ} 58^{\prime} \mathrm{W}$ and $37^{\circ} 0^{\prime}$ to $\left.37^{\circ} 19^{\prime} \mathrm{N}\right)$. The Missouri Department of Conservation (MDC), National Park Service, and United States Forest Service manage $49 \%$ of the ERZ. The Nature Conservancy owns $3 \%$ of the ERZ, and an additional $27 \%$ is held by the L-A-D Foundation, a sustainable forest products initiative (Missouri Department of Conservation 2010). Combined, 79\% of the ERZ is publicly accessible for recreation and hunting. Small (population $<1,400$ ) communities in the ERZ are networked by $53.1 \mathrm{~km}$ of paved highways (United States Census Bureau 2013, Missouri Department of Conservation 2010). These roads include State Highways 19 and 106, as well as State Routes H, D, and B. Traffic volume on these roads is light, averaging 245-464 vehicles per day in 2008 (Missouri Department of Conservation 2010).

The ERZ is comprised largely of forest and woodland habitat (93\%, Missouri Department of Conservation 2010). Oak (Quercus alba, Q. stellata, Q. coccinea, Q. velutina), hickory (Carya tomentosa, C. texana, C. glabra), and shortleaf pine (Pinus echinata) dominate the mature, second-growth forests of the region (Brookshire and Dey 2000, Shifley et al. 2000). Sparse open lands (5\%) are held mostly in pasturelands and food plots, rather than cropland (0.1\%). MDC has restored and maintained glades and woodlands on their ERZ lands through the use of landscapelevel prescribed burns (Missouri Department of Conservation 2005, Missouri Department of Conservation 2010, Tousignant 2011). MDC forests are managed in a 
matrix of even-aged, uneven-aged, and no harvest tracts for forest products, wildlife habitat, and recreation (Wallendorf et al. 2006). Other large mammals occurring in the region include white-tailed deer (Odocoileus virginianus), black bears (Ursus americanus), coyotes (Canis latrans), bobcats (Lynx rufus), and transient cougars (Puma concolor).

Elk were released on MDC's Peck Ranch Conservation Area (Peck Ranch, 2011 and 2012) and The Nature Conservancy's Chilton Creek Preserve (Chilton Creek, 2012) within the ERZ (Figure 1). Although the release sites are approximately $7.6 \mathrm{~km}$ apart, the Chilton Creek release site is only $2.5 \mathrm{~km}$ from the Peck Ranch border. The 9,327 hectare Peck Ranch is made up of 8,445 forested hectares, 662 hectares of glades, savannah, old fields, and wetlands, and 151 food plots totaling 221 hectares. Ridge elevation ranges between 274.3 to $304.8 \mathrm{~m}$ above sea level, but the maximum elevation on Peck Ranch is Stegall Mountain at $410.9 \mathrm{~m}$ above sea level. Rogers Creek and Mill Creek, tributaries of the Current River, are located on Peck Ranch. Other water sources include an intermittent stream and over 119 small ponds (Missouri Department of Conservation 2009). The southern boundary of Peck Ranch aligns with part of the southern boundary of the Elk Restoration Zone (Missouri Department of Conservation 2010). The almost entirely forested 2,277 hectare Chilton Creek Preserve borders Peck Ranch Conservation Area and the Current River (The Nature Conservancy 2013) (Figure 1). 
METHODS

Field Methods

We captured elk in January 2011 (year 1), 2012 (year 2), and 2013 (year 3) using corral traps or darting near Stoney Fork, Kentucky. We outfitted all elk with metal ear tags (Salt Lake Stamp Company, Salt Lake City, UT), PIT tags (LifeChip Permanent Identification, Destron Fearing, South St. Paul, MN; preloaded sterile GPT12, Biomark, Boise, ID), and GPS-PPT/VHF collars with blow-off devices (RASSL 3D cell collar, North Star Science and Technology, LLC, King George, VA; G2110E Iridium/GPS series model, Advanced Telemetry Systems, Insanti, MN). We held elk in Kentucky 102-116 (year 1), 105-129 days (year 2), and 107-128 days (year 3) to complete health testing. We transported them to Missouri overnight on a commercial stock trailer and held them for 27 (year 1), 32-34 days (year 2), and 19 days (year 3) at Peck Ranch before release. In year 1, we released all animals ( $n=34$, 15 adult female, 6 adult male, 5 yearling female, 8 yearling male) at Peck Ranch on June 1. In year 2, we released gestating and post-parturient cows on Peck Ranch on June 19 ( $n=19$ adult female); we transported all other animals ( $n=14,3$ adult female, 4 adult male, 3 yearling female, 4 yearling male) to Chilton Creek on June 21 and held them there until release on June 23. In year 3, we released all animals ( $n=39$, 20 adult female, 16 yearling female, 3 yearling male) at Peck Ranch on June 7 . We captured calves born pre-release in the quarantine pens and calves born postrelease using ground search methods. We fitted calves with expandable VHF collars (custom M4200 series model, Advanced Telemetry Systems, Isanti, MN) and PIT tags. To reduce human disturbance, MDC closed Peck Ranch to the public during 
quarantine and immediately following release. Managers opened a public driving tour on select roads on July 1 each year. Although The Nature Conservancy land is open to the public, managers selected a remote release site at Chilton Creek to discourage human activity near newly released animals. Elk locations were collected using the GPS-PTT collars at $2.5(n=3), 3(n=41), 4(n=2)$, and $5(n=46)$ hour intervals. We downloaded locations from the internet or internal collar storage when we retrieved collars before the study ended. All elk use was approved by University of Missouri Animal Care and Use Committee protocol 6909.

\section{Analytical Methods}

Because animal movements immediately post-release are critical to survivorship and reproductive success, we characterized movement patterns over the initial 6 months (183 days) post-release for animals surviving that time. To capture the effect of release on animal movements, we evaluated time frames based on days post-release rather than biological seasons. An apparent change in behavior occurred at approximately 10 days post-release; we based other time frames on the literature (Larkin et al. 2004, Yott et al. 2011). Thus, we evaluated responses for each elk 0-10 days, 11-30 days, 31-61 days, and 62-183 days post release. For brevity, hereafter we use the term elk-period to denote 1 time frame for 1 elk.

We calculated maximum distances traveled, average movement rates (elk speed), range size, and range shifts for each elk-period. We calculated maximum distances traveled from the release site per elk-period using the Near function in ArcInfo 10.2 (ESRI, Redlands, CA). We calculated movement rates, defined as the 
straight-line distance traveled per hour (km/hr, White and Garrott 1990), using the Tracking Analyst function in ArcInfo 10.2 (ESRI, Redlands, CA). We recorded average movement rates for each elk-period. To assess range size and shifts, we created fixed kernel utilization distributions (UDs) for each elk-period (Van Winkle 1975, Seaman et al. 1999) in program R using packages KernSmooth, ks, and mvtnorm (R Version 2.10.0, www.r-project.org, Accessed 26 Jan 2012). We selected bandwidths using plug-in methods (Gitzen et al. 2006). We evaluated range shifts by comparing UD volume overlap for all within-individual elk-periods (UDs from each time frame compared to UDs from each other time frame for each individual, e.g., $0-10$ vs. $11-30$ days, $0-10$ vs. 31-61 days, $0-10$ vs. $62-183$ days) using Seidel's (1992) Volume of Intersection Index (V) (Millspaugh et al. 2004b). This statistic yields a number ranging from 0 to 1 , which indicates the proportion volume overlap between UD pairs (Millspaugh et al. 2000). We used 100\% volume UDs to calculate the $\mathrm{V}$ in order to capture peripheral range overlap. We used 95\% volume UDs to assess range size, which is the standard for home range analyses.

We developed 18 candidate models representing different hypotheses explaining differences in reintroduced elk movement patterns (Table 1). We constructed models using the variables sex (Ryckman et al. 2010), age (Larkin et al. 2004, Ryckman et al. 2010), calf rearing status, release site, and release year. For coding purposes, we considered cows to be maternal for the elk-periods in which their captured calves were born and survived. Because cows were observed to alter their movement patterns following the death of a calf, we considered cows calfless for the entire time frame during which a calf died. We noted elk ages as yearling or 
adult. One candidate model was a global model that assumed all five variables as well as time post-release contributed to movement patterns (Hypothesis 1, Table 1). We also included univariate models that assumed movement responses were not influenced by time post-release (Hypotheses 2-6, Table 1) and univariate models that assumed movement responses were influenced by time post-release (Hypotheses 7-11, Table 1) to determine if a single factor drives movement patterns and to confirm observations that time post-release affected movement patterns. Because time frames were in part selected based on these observations, we suspected time post-release would have an effect, and all subsequent models accounted for time post-release. Additional models tested the hypotheses that movement patterns were driven by structural factors release year and release site (Hypothesis 12, Table 1), demographic factors sex and age (Hypothesis 13, Table 1), and biological factors including demographic factors and calf rearing status (Hypothesis 14, Table 1). After plotting the data, we included 3 multivariate models that combined structural factors with one demographic factor or demographic factors with one structural factor that had an apparent impact on movement patterns (Hypotheses 15-17, Table 1). Finally, we included one model comprised of the apparent single most important biological and structural factors, sex and release site (Hypotheses 18, Table 1) to determine if just those two factors were responsible for movement outcomes. We fit each of the 18 resultant models to each of the 4 movement response variables.

We used an information theoretic approach (Burnham and Anderson 2002) to rank candidate models. We fit repeated measures, mixed-effects models for each 
movement response using the MIXED procedure in SAS 9.3 (SAS Institute, Inc., Cary, NC). We used Akaike's Information Criterion corrected for small sample sizes (AICc) to evaluate support for each model (Burnham and Anderson 2002). We considered 3 possible covariance structures for each of our 4 measured responses: unstructured covariance, which assumes independence among data; compound symmetry, which assumes dependence among data; and autoregressive structure, which accounts for the potential for our data to be temporally autocorrelated (Littell et al. 2006, Bonnot et al. 2011). Based on AIC $C_{C}$ values from restricted maximum likelihood global models of each response variable, an unstructured covariance structure was the best fit for maximum distance moved, range shifts, and movement rate models, while compound symmetry was the best fit for range size models. Hereafter, we fit models for each response using its respective best fit covariance structure.

We used a two-step process to find parameter estimates (Bonnot et al. 2011). First, we fit candidate models using maximum likelihood methods to achieve AICC values comparable across models with varying fixed effects. Models that had at least $1 / 8^{\text {th }}$ of the relative support of the top model in the set as (equation 1 ):

$$
\text { Relative support for any model }=e^{-1 / 2 \triangle A I C c i}
$$

where $\Delta \mathrm{AIC}_{\mathrm{ci}}$ is the difference in $\mathrm{AIC}_{\mathrm{C}}$ between the top model and model $i$ in the set were it included in the confidence set for each response (Burnham and Anderson 2002:171, Bonnot et al. 2011). Second, we refit models using restricted maximum likelihood to achieve unbiased estimates and standard errors for the fixed effects. When there was at least one model with $1 / 8^{\text {th }}$ of the relative support of the top 
model, we model-averaged using the maximum likelihood Akaike weights $w_{i}$, where $w_{i}$ is the probability of a candidate model providing the best fit of all models ranked, and the equation (2):

$$
\widehat{\bar{\beta}}=\sum_{i=1}^{R} w_{i} \widehat{\beta}_{l},
$$

where $\widehat{\bar{\beta}}$ is the model averaged estimate of a given coefficient, $w_{i}$ is the Akaike weight computed from AIC $\mathrm{C}$ values for $R$ models in the confidence set containing a given predictor variable, and $\widehat{\beta}_{l}$ is the estimate of the coefficient for a given variable in model $i$ (Burnham and Anderson 2002, Bonnot et al. 2008). Finally, we calculated unconditional variance estimates using the equation (3):

$$
\left.\widehat{\operatorname{var}}(\widehat{\bar{\beta}})=\left[\sum_{i=1}^{R} w_{i} \sqrt{\left[\widehat{\operatorname{var}}\left(\widehat{\beta}_{l}\right)+\left(\widehat{\beta}_{l}-\widehat{\bar{\beta}}_{l}\right)^{2}\right.}\right]\right]^{2}
$$

(Burnham and Anderson 2002, Bonnot et al. 2011, Bonnot et al. 2008). Confidence intervals were constructed from the unconditional variance estimates (Figures 4-7).

\section{RESULTS}

We collected 69,209 locations on 32 surviving elk in year $1(n=26,715), 21$ surviving elk in year $2(n=15,621)$, and 31 elk surviving in year $3(n=26,873)$. In year 1, 2 adult females died and were censured from the analysis. In year 2, 9 adult females, 1 yearling female, and 1 yearling male died and were censored from the analysis. We censored one yearling male due to collar failure in year 2 . We censored 3 adult and 2 yearling females that died, 1 adult female that dropped her collar, and 1 adult and 1 yearling female for collar failure in year 3 . We captured 4 year 1, 12 year 2 calves, and 10 year 3 calves from cows surviving the initial 6 
months post-release. One cow in year 1, 4 cows in year 2, and 6 cows in year 3 lost their calves during the study period. One calf dropped its collar in year 3 and was right-censored.

Elk displayed distinctly different initial movement behavior in each of the four releases (Figure 2). Variation in behavior among release groups may have been influenced by release group demography, as we released elk during calving season and calf-rearing status contributed to differing movement responses (Figure 3). Immediately following the year 1 Peck Ranch release, we observed several nonmaternal animals traveling southwest together approximately $9.8 \mathrm{~km}$ from the release site; all animals returned to Peck Ranch within 4 days. By contrast, maternal elk remained near the release site. After the year 2 Peck Ranch release, elk did not make extensive initial movements; only two individuals left Peck Ranch within the first 10 days post-release for this group. Animals in the year 2 Chilton Creek release group divided into subgroups and solitary individuals, each of which traveled in a separate direction. Three small groups of Chilton Creek elk traveled 2.6, 4.1, and 8.2 $\mathrm{km}$ from the release site within 10 days post-release. Within 6 months, all of the surviving Chilton Creek elk joined other elk on Peck Ranch. In year 3, elk left the release site more gradually than in in previous releases. One group of 8 nonmaternal elk left Peck Ranch $400 \mathrm{~m}$ to the east one day after release, but returned to Peck Ranch the same day. No other year 3 release group elk left Peck Ranch during the first 10 days post-release. 


\section{Maximum Distance Moved}

As predicted, reintroduced elk stayed near the release site through 6 months post-release. The maximum distance moved from the release site was $\leq 10 \mathrm{~km}$ for 94\% of year 1 animals 62-183 days ( 6 months) post-release. Although this number dropped to $57 \%$ for the year 2 release groups, this is likely because animals released at Chilton Creek in year 2 either were still making extensive movements during this time frame or joined other elk at Peck Ranch and instead demonstrated fidelity to that site. No year 2 Peck Ranch release group elk moved $>10 \mathrm{~km}$ from the release site within 6 months post-release, but all Chilton Creek elk did. In year 3, 97\% of elk remained $\leq 10 \mathrm{~km}$ during $62-183$ days post-release. The mean maximum displacement for each animal in any time frame was $6.1 \pm 4.0 \mathrm{~km}$ in year $1(n=32$, range $=0.4-11.8 \mathrm{~km}), 10.4 \pm 12.2 \mathrm{~km}$ in year $2(n=21$, range $=0.6-37.0 \mathrm{~km})$, and $8.0 \pm 10.6$ in year $3(n=31$, range $=3.7-31.2 \mathrm{~km})$. Cows with calves stayed closer to the release site immediately following release than nonmaternal elk. Nonmaternal elk were twice as far away from the release site than maternal elk for the first 10 days, and daily average displacement was first equal between maternal and nonmaternal elk at 21 days post release (Figure 3).

Individual maximum distances from the release site were stable for the first three elk-periods, and somewhat higher for the final elk-period (Figure 4). Compared to 0-10 days post-release, maximum displacement was $9 \%$ higher for days $11-31,5 \%$ higher for days 32-61, and 38\% higher for days 62-183. Supported models contained all five covariates (Table 2). Confidence intervals overlapped for predicted results based on age, calf-rearing status, and year. However, females were 
predicted to be $1084 \mathrm{~m}$ closer to the release site than males in each elk-period, and animals released at Peck Ranch were predicted to achieve 3778 m lower maximum distances per elk-period than those released at Chilton Creek. Average Speed

Average speeds per elk-period varied by period and other variables. The average speed of individual elk across all time frames was $0.080 \pm 0.024 \mathrm{~km}$ per hour in year $1(n=32), 0.101 \pm 0.026 \mathrm{~km}$ per hour in year $2(n=21)$, and $0.091 \pm 0.025 \mathrm{in}$ year $3(n=31)$. All five covariates were included in the top supported models (Table 3). We predicted elk speeds to decrease steadily for the first three periods, then jump 30\% between the 32-61 and 62-183 day periods (Figure 5). We did not detect differences in speed predictions based on age, calf presence, and site. We predicted year 2 elk to move $0.017 \mathrm{~km}$ per hour faster than year 1 elk in each elk-period and year 3 elk to move $0.011 \mathrm{~km}$ per hour faster than year 2 elk in each elk period. We also predicted males to move $11 \%$ faster than females in all time periods. Although calf-rearing status was not an important predictor of differing speeds in our model, nonmaternal elk moved $66 \%$ faster than maternal elk on average during the first 10 days post-release. Maternal and nonmaternal elk movement rate patterns were otherwise similar.

\section{Utilization Distributions}

Predicted range sizes for all elk were stable for the first two periods and increased over the last three periods; range sizes for 62-183 days post-release were roughly twice as large as the first period. Average range sizes for $62-183$ days postrelease were $17.6 \pm 5.4 \mathrm{~km}^{2}$ for year 1 elk ( $\left.n=32\right), 25.2 \pm 11.0 \mathrm{~km}^{2}$ for year 2 Peck 
Ranch elk ( $n=12), 59.5 \pm 60.4 \mathrm{~km}^{2}$ for year 2 Chilton Creek elk ( $\left.n=9\right)$, and $13.9 \pm 17.2$ for year 3 elk ( $n=31)$. All predictor variables were in the confidence set (Table 4); all models included site. Confidence intervals overlapped for predicted range size based on sex, age, and calf-rearing status (Figure 6). Site emerged as an important determinant of range size, likely due to movements by Chilton Creek elk prior to finding Peck Ranch. Elk released at Chilton Creek had $17.9 \mathrm{~km}^{2}$ larger predicted range sizes than elk released at Peck Ranch. Compared to predicted ranges for Chilton Creek elk during the first 2 elk-periods $\left(18.9 \pm 1.2 \mathrm{~km}^{2}\right.$ and $\left.17.0 \pm 1.2 \mathrm{~km}^{2}\right)$, predicted ranges for Peck Ranch elk were small $\left(4.2 \pm 4.5 \mathrm{~km}^{2}\right.$ and $\left.4.3 \pm 6.7 \mathrm{~km}^{2}\right)$. Notably, when the impact of year was considered alone, year 3 elk used $46 \%$ larger range sizes than year 1 elk and 29\% larger range sizes than year 2 elk.

\section{Volume of Intersection}

We found that reintroduced elk used at least some previously explored range over sequential time periods during the course of the first 6 months post-release. The mean $V$ for successive time periods for year 1 elk was $0.230 \pm 0.320(n=32)$, the mean for year 2 elk was $0.290 \pm 0.323(n=21)$, and the mean for year 3 elk was $0.26 \pm 0.24(n=31)$. Just 9 of 252 (4\%) consecutive elk-period UD pairs yielded a V of $0(\leq 0.0)$, indicating a lack of any space sharing over time. However, our model failed and we were unable to obtain reasonable predicted $\mathrm{V}$ scores.

\section{DISCUSSION}

Missouri elk exhibited a multiphasic movement strategy post-release and quickly settled in their new habitat. Elk appeared to acclimate to their environment 
in discrete phases, including 1) immediate departure from the release site and elevated movement rates, followed by 2) establishing a home range and gradually expanding their range using previously used area as a base. Multiphasic movement patterns have previously been observed in translocated raccoons (Procyon lotor), swift foxes (Vulpes velox), and cougars (Puma concolor) (Ruth et al. 1998, Mosillo et al. 1999, Moehrenschlager and Macdonald 2003). While previous studies found that reintroduced elk took 3 years to transition from a dispersive to a home range phase (Fryxell et al. 2008), Missouri elk acclimated to their surroundings on a much shorter time scale. In our study, elk speeds decreased from 0-10 days to 11-31 days and again from 32-61 days. Combined with similar displacement levels and range sizes for the first 3 time frames, this pattern may indicate that elk were transient for just 10 days before settling into a home range phase. After 10 days, elk established a range and expanded it over time, as evidenced by the fact that speeds, range sizes, and maximum displacement were largest for days 62-183, but $\mathrm{V}$ scores remained nonzero. During days 11-183 post-release, animals were observed to use and reuse different food plots dispersed over Peck Ranch daily. Thus, our study may provide evidence that, following transition from a dispersive to a home range phase, movement rates may increase as reintroduced animals learn to move between resource-rich patches in a heterogeneous landscape. In this case, animals are demonstrating site fidelity to their established range, but movement between resource-rich patches manifests similarly (elevated movement rates) whether animals are learned or naïve. Alternatively, movement rates may have increased as a result of exploring new habitat on the periphery of their range, or as a response to 
increased disturbance on the site or decreasing food availability during fall and winter, although the latter seems doubtful given only 3 isolated weekends of elevated disturbance from deer hunts and a mild winter in 2011-2012.

Site was an important factor contributing to movement patterns in reintroduced elk. Chilton Creek elk moved farther and had larger ranges, indicating that they may have been transient longer than Peck Ranch elk (Turchin 1998). Chilton Creek elk movement responses may be due to differences in habitat, presence of conspecifics, demography of the release-group, or release strategy. Previous studies have suggested that reintroduced elk demonstrate higher release site fidelity when release areas have higher edge densities (Larkin et al. 2004) and forage-rich open land habitats (Ryckman et al. 2010). Our results were consistent with these findings. Peck Ranch contains hundreds of open areas and associated edge habitat; Chilton Creek lacks both. The presence of conspecifics has also been thought to be a potential factor in elk release site fidelity (Ryckman et al. 2010). Our study supports this claim. Two groups were released at sites without other elk (Peck Ranch 2011 and Chilton Creek 2012); both immediately left. One group did not find conspecifics and returned to the release site (Peck Ranch 2011). The other found conspecifics and did not return to the release site (Chilton Creek 2012). Most elk released in the presence of other elk never left at all (Peck Ranch 2012, 2013). Alternatively, Chilton Creek elk may have demonstrated different behavior due to demographic characteristics of the group. The release group was predominantly young bulls, who may disperse large distances even without translocation (Ryckman et al. 2010). The remaining animals were open cows, whose reproductive 
status may indicate that they were lower quality or sick individuals. Only 2 Chilton Creek females survived for 6 months post-release. Because elk herds are structured by dominant cows (Millspaugh et al. 2004a), a lack of healthy, mature females at the release site may have contributed to the immediate disbanding of the Chilton Creek elk gang into small groups and lone individuals. Other studies have indicated that reintroduced elk travel farther when solitary (Haydon et al. 2008), which may have exacerbated differences between release sites. Finally, elk relocated to Chilton Creek were held together for just 2 more days after transport. This process may have interrupted social bonds and led to diffusion of individuals across the landscape. Mortality rates for each release group were 2/32 (6\%) for Peck Ranch in year 1, 7/19 (37\%) for Peck Ranch in year 2, $4 / 14$ (29\%) for Chilton Creek in year 2, and 5/39 (13\%) for Peck Ranch in year 3. Higher transience in Chilton Creek elk did not lead to higher mortality than their Peck Ranch counterparts in year 2. However, it is important to note that drought conditions coupled with the energetic demands of reproduction led to increased mortality in year 2 Peck Ranch elk, which may have concealed this effect if it existed.

Our study provides additional evidence that large mammals are more likely to remain at the release site if they are transported while pregnant and released prior to bearing young (Clark et al. 2002). In some species, this effect is presumably caused by lower mobility of young offspring; in elk, this may be due to hiding behavior of calves. During the first few days post-release, maternal elk stayed near release sites while nonmaternal elk made more extensive initial movements. It was not until 21 days post-release that average maximum displacement was first equal 
between maternal and nonmaternal elk (Figure 3). Although calf-rearing status was not strongly supported, its impact may have been understated. We were aware of, but unable to capture, 2 year 1 calves, 6 year 2 calves, and 1 year 3 calf. Because we could not capture them, and therefore could not confirm maternity or determine if a calf died and a cow transitioned from having a calf to not having a calf, we chose to treat mothers of uncollared calves as nonmaternal in the analysis.

Although previous studies found sex and age to be important influences on reintroduced elk movements (Larkin et al. 2004, Ryckman et al. 2010), our study only found sex to contribute to movement patterns. Age impacts were supported, but were never measurably different over time. However, sex contributed to both maximum distances moved and movement rates. These results may indicate that elk demonstrated typical social behavior within 6 months post-release. Male elk were observed forming bachelor herds, which do not vary by age. Also, it is normal for young male elk to disperse, and most translocated male elk were yearlings at the time of release. These bonds may have been encouraged by Missouri's release strategy. We held elk for an extended time at the source site and again at the release site, and during the holding period at the release site, elk were separated into samesex pens. This soft release strategy may have helped to build stronger social bonds between same-sex individuals and encouraged them to maintain those groups postrelease. 


\section{MANAGEMENT IMPLICATIONS}

Release site fidelity is critical for reintroduced animals to reproduce, avoid mortality associated with human-wildlife conflict, and improve initial population growth. To encourage elk to remain near the release site, we recommend careful release site selection, considering a soft release, choosing appropriate release groups, and recognizing that multiphasic movement patterns might occur. In our study, one release site was associated with increased transience. There were several differences that likely contributed to this effect. The two release sites were located in markedly different habitat. The release site with lower transience had higher edge densities and numerous, well-managed open areas. It is well known that elk are attracted to edge habitats (Larkin et al. 2004, Telesco et al. 2007, Missouri Department of Conservation 2010); for elk reintroductions in heavily forested environments like the Missouri Ozarks, managers can expect animals to consistently seek open lands. Another difference between release sites in the second and third years was presence of conspecifics at the site associated with lower transience. As previous studies have also indicated that elk are attracted to other elk (Ryckman et al. 2010), managers may wish to select release sites with conspecifics for elk and other social species where possible. In addition, animals released at the site associated with higher transience were relocated a second time and held just 2 days before release. This process may have compromised any benefits associated with soft release.

Also likely contributing to differences in release site in our study were the individuals chosen for the each release site. Only bulls and nonmaternal female elk 
were released at the site associated with higher transience. Including healthy adult females in release groups for species like elk with matrilineal social structures and male-dominated dispersal may help keep the release group together and limit extensive movements. Complicating the issue of founding individual selection is maternal status of females. Maternal females appear to remain closer to the release site, but the stress of transport likely has ill effects on both mother and offspring (Shelton and Huston 1968, Braastad 1998, Couret et al. 2009, Dickens et al. 2010). As a result, mortality or decreased productivity due to translocating or holding animals close to the parturition date must therefore be weighed against suboptimal population growth due to lower release site fidelity.

Finally, we recommend that managers keep in mind the potential for multiphasic movement patterns. Animal movement patterns are nonlinear, and temporary long-range movements do not necessarily require intervention. Released animals may leave the release site, but they also may return if the site provides adequate resources and protection from human disturbance. This is especially true for animals that are sensitive to disturbance, such as elk (Schultz and Bailey 1978, Knight 1980, Edge and Marcum 1985, Cassirer et al. 1992, Cole et al. 1997, Phillips and Alldredge 2000, Larkin et al. 2004, Naylor et al. 2009). Elk movement rates may increase as they explore the periphery of their ranges, but that does not preclude site fidelity to their current range. As movement rates had not plateaued after 6 months, managers may expect changes in movement patterns for at least as long. 


\section{LITERATURE CITED}

Armstrong, D., and H. Wittmer. 2011. Incorporating Allee effects into reintroduction strategies. Ecological Research 26(4):687-695.

Banks, P. B., K. Norrdahl, and E. Korpimäki. 2002. Mobility decisions and the predation risks of reintroduction. Biological Conservation 103(2):133-138.

Benson, J. F., and M. J. Chamberlain. 2007. Space use, survival, movements, and reproduction of reintroduced Louisiana black bears. The Journal of Wildlife Management 71(7):2393-2403.

Bonnot, T.W., J.H. Schulz, and J.J. Millspaugh. 2011. Factors affecting mourning dove harvest in Missouri. Wildlife Society Bulletin 9999(xx):1-9.

Bonnot, T.W., M.A. Rumble, and J.J. Millspaugh. 2008. Nest success of black-backed woodpeckers in the forests with mountain pine beetle outbreaks in the Black Hills, South Dakota. The Condor 110(3):450—457.

Braastad, B.O. 1998. Effects of prenatal stress on behavior of offspring of laboratory and farmed mammals. Applied Animal Behavior Science 61(2):159—180.

Brookshire, B.L. and D.C. Dey. 2000. Establishment and data collection of vegetationrelated studies on the Missouri Ozark Ecosystem Project study sites. Pages 1-18 in S.R. Shifley and B.L. Brookshire, editors. Missouri Ozark Forest Ecosystem Project site history, soils, landforms, woody and herbaceous vegetation, down wood, and inventory methods for the landscape experiment. 
Burnham, K.P., and D.R. Anderson. 2002. Model selection and multi-model inference: a practical information-theoretic approach. Second edition. Springer, New York, New York, USA.

Cassirer, E.F., D.J. Freddy, and E.D. Ables. 1992. Elk responses to disturbance by cross-country skiers in Yellowstone National Park. Wildlife Society Bulletin $20(4): 375-381$.

Clark, J. D., D. Huber, and C. Servheen. 2002. Bear reintroductions: Lessons and challenges: Invited paper. Ursus 13:335-345.

Cole, E.K., M.D. Pope, and R.G. Anthony. 1997. Effects of road management on movement and survival of Roosevelt elk. Journal of Wildlife Management 61(4):1115-1126.

Collazo, J. A., T. H. W. Jr, F. J. Vilella, and S. A. Guerrero. 2003. Survival of captivereared Hispaniolan parrots released in Parque Nacional del Este, Dominican Republic. The Condor 105(2):198-207.

Conard, J.M., P.S. Gipson, and M. Peek. 2006. Historical and current status of elk in Kansas. Pages 307-312 in Prairie invaders: Proceedings of the 20th North American Prairie Conference. J.T. Springer and E.C. Springer, editors. July 23-26 2006, University of Nebraska at Kearney, Kearney, Nebraska.

Couret, D., A. Prunier, A. Mounier, F. Thomas, I. Oswald, and E. Merlot. 2009. Comparative effects of a prenatal stress occurring during early or late gestation on pig immune response. Physiology and Behavior 98(4):498504. 
Delgado, M.M., V. Penteriani, V. O. Nams, and L. Campioni. 2009. Changes of movement patterns from early dispersal to settlement. Behav Ecol Sociobiol $64: 35-43$.

Devineau, O., T. M. Shenk, G. C. White, P. F. Doherty Jr, P. M. Lukacs, and R. H. Kahn. 2010. Evaluating the Canada lynx reintroduction programme in Colorado: patterns in mortality. Journal of Applied Ecology 47(3):524-531.

Dickens, M. J., D. J. Delehanty, and L. Michael Romero. 2010. Stress: An inevitable component of animal translocation. Biological Conservation 143(6):13291341.

Edge, W.D., and C.L. Marcum. 1985. Movements of elk in relation to logging disturbance. Journal of Wildlife Management, 49(4):926-930.

Enochs, C.R. 1998. Here today, gone tomorrow: policies and issues surrounding wildlife reintroduction. West Northwest Journal of Environmental Law and Policy 1996-1998:91-106.

Fritts, S. H., W. J. Paul, and L. D. Mech. 1984. Movements of translocated wolves in Minnesota. The Journal of Wildlife Management 48(3):709-721.

Fryxell, J.M., M. Hazell, L. Borger, B.D. Dalziel, D.T. Haydon, J.M. Morales, T. McIntosh, and R.C. Rosatte. 2008. Multiple movement modes by large herbivores at multiple spatiotemporal scales. PNAS 105(49):19114-19119.

Gitzen, R. A., J. J. Millspaugh, and B. J. Kernohan. 2006. Bandwidth selection for fixedkernel analysis of animal utilization distributions. The Journal of Wildlife Management 70(5):1334-1344. 
Hardman, B. and D. Moro. 2006. Optimising reintroduction success by delayed dispersal: Is the release protocol important for hare-wallabies? Biological Conservation 128(3):403-411.

Haydon, D.T., J.M. Morales, A. Yott, D.A. Jenkins, R. Rosatte, and J.M. Fryxell. 2008. Socially informed random walks: incorporating group dynamics into models of population spread and growth. Proceedings of the Royal Society B 275:1101-1109.

Jachowski, D. S., R. A. Gitzen, M. B. Grenier, B. Holmes, and J. J. Millspaugh. 2011. The importance of thinking big: Large-scale prey conservation drives blackfooted ferret reintroduction success. Biological Conservation 144(5):1560— 1566.

Knight, J.E. 1980. Effect of hydrocarbon development on elk movements and distribution in northern Michigan. Ph.D. University of Michigan.

Komers, P. E., and G. P. Curman. 2000. The effect of demographic characteristics on the success of ungulate re-introductions. Biological Conservation 93(2):187-193.

Larkin, J.L., D.S. Maehr, J.J. Cox, M.W. Wichrowski, and R.D. Crank. 2002. Factors affecting reproduction and population growth in a restored elk Cervus elaphus nelsoni population. Wildlife Biology 8(1):49-54.

Larkin, J. L., J. J. Cox, M. W. Wichrowski, M. R. Dzialak, and D. S. Maehr. 2004. Influences on release-site fidelity of translocated elk. Restoration Ecology 12(1):97-105. 
Littell, R., G. Milliken, W. Stroup, R. Wolfinger, and O. Schabenberger. 2006. SAS® for mixed models. SAS Institute, Cary, North Carolina, USA.

Millspaugh, J. J., G. C. Brundige, R. A. Gitzen, and K. J. Raedeke. 2000. Elk and hunter space-use sharing in South Dakota. The Journal of Wildlife Management 64(4):994-1003.

Millspaugh, J.J., G.C. Brundige, R.A. Gitzen, and K.J. Raedeke. 2004a. Herd organization of cow elk in Custer State Park, South Dakota. Wildlife Society Bulletin 32(2):506-514.

Millspaugh, J.J., R.A. Gitzen, B.J. Kernohan, M.A. Larson, and C.L. Clay. 2004b. Comparability of three analytical techniques to assess joint space use. Wildlife Society Bulletin 32(1):148-157.

Missouri Department of Conservation. 2010. Elk restoration in Missouri.

Missouri Department of Conservation. 2009. Peck Ranch Conservation Area. <http://mdc4.mdc.mo.gov/applications/moatlas/AreaSummaryPage.aspx?tx tAreaID $=5203>$

Missouri Department of Conservation. 2005. Current River Hills Conservation Opportunity Area.

Moehrenschlager, A., and D. W. Macdonald. 2003. Movement and survival parameters of translocated and resident swift foxes Vulpes velox. Animal Conservation 6(3):199-206.

Morales, J.M., D.T. Haydon, J. Frair, K.E. Holsinger, J.M. Fryxell. 2004. Extracting more out of relocation data: building movement models as mixtures of random walks. Ecology 85(9):2436-2445. 
Mosillo, M., E. J. Heske, and J. D. Thompson. 1999. Survival and movements of translocated raccoons in northcentral Illinois. The Journal of Wildlife Management 63(1):278-286.

Naylor, L.M., M.J. Wisdom, and R.G. Anthony. 2009. Behavioral responses of North American elk to recreational activity. Journal of Wildlife Management 73(3):328-338.

Nature Conservancy, The. 1997. The Nature Conservancy's Chilton Creek Management Area: A case study of the effects of fire-based ecosystem management in the Missouri Ozarks. Missouri Ozarks Office, Van Buren, Missouri.

O'Gara, B.W. and R. G. Dundas. 2002. Distribution: Past and Present. Pages 67-119 in Toweill, D.E. and J.W. Thomas, editors. North American Elk: Ecology and Management. Smithsonian Institution Press, Washington, D.C.

Phillips, G.E. and A.W. Alldredge. 2000. Reproductive success of elk following disturbance by humans during calving season. Journal of Wildlife Management 64(2):521-530.

Rodriguez, A., L. Barrios, and M. Delibes. 1995. Experimental release of an Iberian lynx (Lynx pardinus). Biodiversity \& Conservation 4(4):382-394.

Rosatte, R., J. Hamr, J. Young, I. Filion, and H. Smith. 2007. The restoration of elk (Cervus elaphus) in Ontario, Canada: 1998-2005. Restoration Ecology 15(1):34-43. 
Ruth, T. K., K. A. Logan, L. L. Sweanor, M. G. Hornocker, and L. J. Temple. 1998. Evaluating cougar translocation in New Mexico. The Journal of Wildlife Management 62(4):1264-1275.

Ryckman, M. J., R. C. Rosatte, T. McIntosh, J. Hamr, and D. Jenkins. 2010. Postrelease dispersal of reintroduced elk (Cervus elaphus) in Ontario, Canada. Restoration Ecology 18(2):173-180.

Schultz, R.D. and J.A. Bailey. 1978. Responses of National Park elk to human activity. Journal of Wildlife Management 42(1):91-100.

Seaman, D.E., J.J. Millspaugh, B.J. Kernohan, G.C. Brundige. 1999. Effects of sample size on kernel home range estimates. Journal of Wildlife Management 63(2): 739-747.

Seidel, K.D. 1992. Statistical properties and applications of a new measure of joint space use for wildlife. Thesis, University of Washington, Seattle, USA.

Shelton, M. and J.E. Huston. 1968. Effects of high temperature stress during gestation on certain aspects of reproduction in the ewe. Journal of Animal Science 27(1):153-158.

Shifley, S.R., L.M. Roovers, R.G. Jensen, and D.R. Larsen. 2000. Composition and structure of woody forest vegetation in the Missouri Ozarks. Pages 71-106 in S.R. Shifley and B.L. Brookshire, editors. Missouri Ozark Forest Ecosystem Project site history, soils, landforms, woody and herbaceous vegetation, down wood, and inventory methods for the landscape experiment. 
Spinola, R. M., T. L. Serfass, and R. P. Brooks. 2008. Survival and post-release movements of river otters translocated to western New York. Northeastern Naturalist 15(1):13-24.

Teixeira, C. P., C. S. de Azevedo, M. Mendl, C. F. Cipreste, and R. J. Young. 2007(1). Revisiting translocation and reintroduction programmes: the importance of considering stress. Animal Behaviour 73:1-13.

Telesco, R.L, F.T. Van Manen, J.D. Clark, and M.E. Cartwright. 2007. Identifying sites for elk restoration in Arkansas. Journal of Wildlife Management 71(5):1393-1403.

Tousignant, J. 2011. The Current River Hills of Southern Missouri: A CCPI EQIP Proposal.

Turchin, P. 1998. Quantitative analysis of movement: measuring and modeling population redistribution in animals and plants. Sinauer Associates, Sunderland, Massachusetts.

United States Census Bureau. 2013. American FactFinder. <http://factfinder2.census.gov/faces/nav/jsf/pages/community_ facts.xhtml>

Van Winkle, W. 1975. Comparison of several probabilistic home-range models. Journal of Wildlife Management. 39(1):118-123.

Vandel, J.-M., P. Stahl, V. Herrenschmidt, and E. Marboutin. 2006. Reintroduction of the lynx into the Vosges mountain massif: From animal survival and movements to population development. Biological Conservation 131(3):370-385. 
Virginia Department of Game and Inland Fisheries. 2010. Elk restoration and management options for southwest Virginia.

Vore, J. M., and E. M. Schmidt. 2001. Movements of female elk during calving season in northwest Montana. Wildlife Society Bulletin 29(2):720-725.

Wallendorf, M.J., P.A. Porneluzi, W.K. Gram, R.L. Clawson, and J. Faaborg. 2006. Bird response to clear cutting in Missouri Ozark forests. Journal of Wildlife Management 71(6):1899-1905.

White, G.C. and R.A. Garrott. 1990. Analysis of wildlife radio-tracking data. Academy Press Inc., San Diego, California.

Yott, A., R. Rosatte, J. A. Schaefer, J. Hamr, and J. Fryxell. 2011. Movement and spread of a founding population of reintroduced elk (Cervus elaphus) in Ontario, Canada. Restoration Ecology 19:70-77. 


\section{TABLES}

Table 1. Candidate models used to assess the relative importance of release site, release year, sex, age, and calf rearing status on maximum displacement from the release site per elk-period, average movement rates per elk-period, range size per elk-period, and volume of intersection indices of all within-individual elk-period range pairs for elk reintroduced to south-central Missouri 2011-2013.

\begin{tabular}{ll}
\hline Hypothesis & Model Structure \\
\hline Global Model: Intercept, period, release & $\beta_{0}+\beta_{1}($ Period $)+\beta_{2}($ Year $)+\beta_{3}($ Site $)+$ \\
year, release site, sex, age, and calf rearing & $\beta_{4}($ Sex $)+\beta_{5}($ Age $)+\beta_{6}($ Calf $)$ \\
status & \\
Only sex influences response patterns & $\beta_{0}+\beta_{4}($ Sex $)$ \\
Only age influences response patterns & $\beta_{0}+\beta_{5}($ Age $)$ \\
Only calf rearing status influences response & $\beta_{0}+\beta_{6}($ Calf $)$ \\
patterns & \\
Only release site influences response & $\beta_{0}+\beta_{3}$ (Site) \\
patterns & \\
Only release year influences response & $\beta_{0}+\beta_{2}($ Year $)$ \\
patterns & \\
Sex and period influence response patterns & $\beta_{0}+\beta_{1}($ Period $)+\beta_{4}($ Sex $)$ \\
Age and period influence response patterns & $\beta_{0}+\beta_{1}($ Period $)+\beta_{5}($ Age $)$ \\
Calf rearing status and period influence & $\beta_{0}+\beta_{1}($ Period $)+\beta_{6}($ Calf $)$ \\
response patterns &
\end{tabular}


Release site and period influence response $\quad \beta_{0}+\beta_{1}($ Period $)+\beta_{3}($ Site $)$

patterns

Release year and period influence response $\quad \beta_{0}+\beta_{1}($ Period $)+\beta_{2}$ (Year)

patterns

Structural factors (release year and release $\beta_{0}+\beta_{1}($ Period $)+\beta_{2}($ Year $)+\beta_{3}($ Site $)$

site) and period influence response

patterns

Demographic factors (sex and age) and $\quad \beta_{0}+\beta_{1}($ Period $)+\beta_{4}($ Sex $)+\beta_{5}($ Age $)$

period influence response patterns

Biological factors (sex, age, and calf rearing $\beta_{0}+\beta_{1}($ Period $)+\beta_{4}($ Sex $)+\beta_{5}$ (Age) $+\beta_{6}$ (Calf)

status) and period influence response

patterns

Structural factors, sex, and period influence $\quad \beta_{0}+\beta_{1}($ Period $)+\beta_{2}($ Year $)+\beta_{3}($ Site $)+$

response patterns

$\beta_{4}(\operatorname{Sex})$

Demographic factors, release site, and

$\beta_{0}+\beta_{1}($ Period $)+\beta_{3}($ Site $)+\beta_{4}($ Sex $)+\beta_{5}($ Age $)$

period influence response patterns

Demographic factors, release year, and

$\beta_{0}+\beta_{1}($ Period $)+\beta_{2}($ Year $)+\beta_{4}($ Sex $)+$

period influence response patterns

$\beta_{5}$ (Age)

Only sex, release site, and period influence

$\beta_{0}+\beta_{1}($ Period $)+\beta_{3}($ Site $)+\beta_{4}($ Sex $)$ response patterns 
Table 2. Model selection results for factors influencing maximum displacement from the release site achieved in 4 sequential time periods (0-10, 11-31, 32-61, and 62-183 days post-release) for elk reintroduced to south-central Missouri 2011-2013. We report log likelihood (LL), number of parameters (K), Akaike Information Criterion (AIC), AIC corrected for small sample sizes $\left(\mathrm{AIC}_{\mathrm{C}}\right)$, and the difference in $\mathrm{AIC}_{\mathrm{C}}$ from the most supported model $\left(\Delta \mathrm{AIC}_{\mathrm{C}}\right)$.

\begin{tabular}{|c|c|c|c|c|c|c|c|c|}
\hline Rank & Model No. & Model & $\mathbf{L L}$ & $\mathbf{K}$ & AIC & $\mathrm{AIC}_{\mathrm{C}}$ & $\Delta$ AIC $_{\mathrm{C}}$ & $w_{i}$ \\
\hline 1 & 16 & PERIOD SITE SEX AGE & 6276.64 & 17 & 6310.64 & 6312.56 & 0 & 0.36119 \\
\hline 2 & 18 & PERIOD SITE SEX & 6279.46 & 16 & 6311.46 & 6313.16 & 0.5979 & 0.26786 \\
\hline 3 & 15 & PERIOD YEAR SITE SEX & 6276.32 & 18 & 6312.32 & 6314.48 & 1.9175 & 0.13847 \\
\hline 4 & 1 & GLOBAL & 6272.85 & 20 & 6312.85 & 6315.51 & 2.9518 & 0.08256 \\
\hline 5 & 2 & SEX & 6272.85 & 20 & 6312.85 & 6315.51 & 2.9518 & 0.08256 \\
\hline 6 & 12 & PERIOD SITE YEAR & 6281.66 & 17 & 6315.66 & 6317.58 & 5.0206 & 0.02934 \\
\hline 7 & 10 & PERIOD SITE & 6286.48 & 15 & 6316.48 & 6317.98 & 5.4167 & 0.02407 \\
\hline 8 & 14 & PERIOD YEAR SITE AGE & 6280.91 & 18 & 6316.91 & 6319.07 & 6.5093 & 0.01394 \\
\hline 9 & 17 & PERIOD YEAR SEX AGE & 6304.07 & 18 & 6340.07 & 6342.23 & 29.6624 & 0 \\
\hline 10 & 5 & SITE & 6317.77 & 12 & 6341.77 & 6342.74 & 30.1781 & 0 \\
\hline
\end{tabular}




\begin{tabular}{llllllllll}
\hline $\mathbf{1 1}$ & 7 & PERIOD SEX & 6321.77 & 15 & 6351.77 & 6353.27 & 40.7064 & 0 \\
$\mathbf{1 2}$ & 13 & PERIOD SEX AGE & 6321.45 & 16 & 6353.45 & 6355.16 & 42.5943 & 0 \\
$\mathbf{1 3}$ & 11 & PERIOD YEAR & 6324.31 & 16 & 6356.31 & 6358.01 & 45.4499 & 0 \\
$\mathbf{1 4}$ & 9 & PERIOD CALF & 6333.53 & 15 & 6363.53 & 6365.03 & 52.4637 & 0 \\
$\mathbf{1 5}$ & 8 & PERIOD AGE & 6337.87 & 15 & 6367.87 & 6369.37 & 56.8038 & 0 \\
$\mathbf{1 6}$ & 6 & YEAR & 6355.6 & 13 & 6381.6 & 6382.73 & 70.1706 & 0 \\
$\mathbf{1 7}$ & 4 & CALF & 6362.73 & 12 & 6386.73 & 6387.69 & 75.1301 & 0 \\
$\mathbf{1 8}$ & 3 & AGE & 6369.16 & 12 & 6393.16 & 6394.13 & 81.5653 & 0 \\
\hline
\end{tabular}


Table 3. Model selection results for factors influencing average movement rates recorded in 4 sequential time periods $(0-10$, 11-31, 32-61, and 62-183 days post-release) for elk reintroduced to south-central Missouri 2011-2013. We report log likelihood (LL), number of parameters (K), Akaike Information Criterion (AIC), AIC corrected for small sample sizes (AICC), and the difference in $\mathrm{AIC}_{\mathrm{C}}$ from the most supported model $\left(\Delta \mathrm{AIC}_{\mathrm{C}}\right)$.

\begin{tabular}{lllllllll}
\hline Rank & Model No. & Model & LL & K & AIC & AICc & $\Delta$ AICc & $w_{i}$ \\
\hline $\mathbf{1}$ & 17 & PERIOD YEAR SEX AGE & -1557.74 & 18 & -1521.74 & -1519.59 & 0 & 0.42453 \\
$\mathbf{2}$ & 15 & PERIOD YEAR SITE SEX & -1557.53 & 18 & -1521.53 & -1519.37 & 0.213 & 0.38164 \\
$\mathbf{3}$ & 1 & GLOBAL & -1559.3 & 20 & -1519.3 & -1516.64 & 2.948 & 0.09722 \\
$\mathbf{4}$ & 14 & PERIOD YEAR SITE AGE & -1553.59 & 18 & -1517.59 & -1515.43 & 4.1586 & 0.05307 \\
$\mathbf{5}$ & 12 & PERIOD SITE YEAR & -1550.57 & 17 & -1516.57 & -1514.64 & 4.9423 & 0.03587 \\
$\mathbf{6}$ & 11 & PERIOD YEAR & -1545.26 & 16 & -1513.26 & -1511.55 & 8.0311 & 0.00766 \\
$\mathbf{7}$ & 10 & PERIOD SITE & -1529.59 & 15 & -1499.59 & -1498.09 & 21.4991 & 0.00001 \\
$\mathbf{8}$ & 18 & PERIOD SITE SEX & -1529.6 & 16 & -1497.6 & -1495.89 & 23.6953 & 0 \\
$\mathbf{9}$ & 16 & PERIOD SITE SEX AGE & -1530.38 & 17 & -1496.38 & -1494.46 & 25.1263 & 0 \\
$\mathbf{1 0}$ & 8 & PERIOD AGE & -1516.41 & 15 & -1486.41 & -1484.91 & 34.6804 & 0 \\
\hline
\end{tabular}




\begin{tabular}{llllllllll}
\hline $\mathbf{1 1}$ & 7 & PERIOD SEX & -1516.04 & 15 & -1486.04 & -1484.54 & 35.0452 & 0 \\
$\mathbf{1 2}$ & 9 & PERIOD CALF & -1515.81 & 15 & -1485.81 & -1484.31 & 35.2773 & 0 \\
$\mathbf{1 3}$ & 13 & PERIOD SEX AGE & -1516.58 & 16 & -1484.58 & -1482.88 & 36.7064 & 0 \\
$\mathbf{1 4}$ & 6 & YEAR & -1479.73 & 13 & -1453.73 & -1452.6 & 66.9909 & 0 \\
$\mathbf{1 5}$ & 5 & SITE & -1464.05 & 12 & -1440.05 & -1439.09 & 80.4997 & 0 \\
$\mathbf{1 6}$ & 3 & AGE & -1450.87 & 12 & -1426.87 & -1425.9 & 93.681 & 0 \\
$\mathbf{1 7}$ & 2 & SEX & -1450.51 & 12 & -1426.51 & -1425.54 & 94.0457 & 0 \\
$\mathbf{1 8}$ & 4 & CALF & -1450.19 & 12 & -1426.19 & -1425.22 & 94.3651 & 0 \\
\hline
\end{tabular}


Table 4. Model selection results for factors influencing 95\% volume utilization distribution (UD) range sizes in 4 sequential time periods (0-10, 11-31, 32-61, and 62-183 days post-release) for elk reintroduced to south-central Missouri 2011-2013. We report log likelihood (LL), number of parameters (K), Akaike Information Criterion (AIC), AIC corrected for small sample sizes $\left(\mathrm{AIC}_{\mathrm{C}}\right)$, and the difference in $\mathrm{AIC}_{\mathrm{C}}$ from the most supported model $\left(\Delta \mathrm{AIC}_{\mathrm{C}}\right)$.

\begin{tabular}{lllllllll}
\hline Rank & Model No. & Model & LL & K & AIC & AIC & \multicolumn{1}{c}{$\Delta$ AIC } & $w_{i}$ \\
\hline $\mathbf{1}$ & 14 & PERIOD YEAR SITE AGE & 12108.9 & 10 & 12128.9 & 12129.58 & 0 & 0.41855 \\
$\mathbf{2}$ & 12 & PERIOD SITE YEAR & 12111.26 & 9 & 12129.26 & 12129.81 & 0.228 & 0.37354 \\
$\mathbf{3}$ & 15 & PERIOD YEAR SITE SEX & 12111.22 & 10 & 12131.22 & 12131.9 & 2.32 & 0.13123 \\
$\mathbf{4}$ & 1 & GLOBAL & 12108.5 & 12 & 12132.5 & 12133.47 & 3.889 & 0.05986 \\
$\mathbf{5}$ & 10 & PERIOD SITE & 12123.23 & 7 & 12137.23 & 12137.57 & 7.988 & 0.00771 \\
$\mathbf{6}$ & 18 & PERIOD SITE SEX & 12121.54 & 8 & 12137.54 & 12137.98 & 8.398 & 0.00628 \\
$\mathbf{7}$ & 16 & PERIOD SITE SEX AGE & 12121.09 & 9 & 12139.09 & 12139.64 & 10.06 & 0.00274 \\
$\mathbf{8}$ & 11 & PERIOD YEAR & 12130.92 & 8 & 12146.92 & 12147.36 & 17.783 & 0.00006 \\
$\mathbf{9}$ & 17 & PERIOD YEAR SEX AGE & 12127.96 & 10 & 12147.96 & 12148.64 & 19.058 & 0.00003 \\
$\mathbf{1 0}$ & 8 & PERIOD AGE & 12148.72 & 7 & 12162.72 & 12163.06 & 33.483 & 0 \\
$\mathbf{1 1}$ & 7 & PERIOD SEX & 12149.05 & 7 & 12163.05 & 12163.39 & 33.813 & 0 \\
\hline & & & & & & & & \\
\hline
\end{tabular}




\begin{tabular}{llllllllll}
\hline $\mathbf{1 2}$ & 9 & PERIOD CALF & 12149.16 & 7 & 12163.16 & 12163.5 & 33.917 & 0 \\
$\mathbf{1 3}$ & 13 & PERIOD SEX AGE & 12148.49 & 8 & 12164.49 & 12164.93 & 35.351 & 0 \\
$\mathbf{1 4}$ & 5 & SITE & 12204.59 & 4 & 12212.59 & 12212.71 & 83.134 & 0 \\
$\mathbf{1 5}$ & 6 & YEAR & 12210.55 & 5 & 12220.55 & 12220.74 & 91.155 & 0 \\
$\mathbf{1 6}$ & 4 & CALF & 12223.5 & 4 & 12231.5 & 12231.62 & 102.038 & 0 \\
$\mathbf{1 7}$ & 3 & AGE & 12224.15 & 4 & 12232.15 & 12232.27 & 102.686 & 0 \\
$\mathbf{1 8}$ & 2 & SEX & 12224.39 & 4 & 12232.39 & 12232.52 & 102.934 & 0 \\
\hline
\end{tabular}


FIGURES

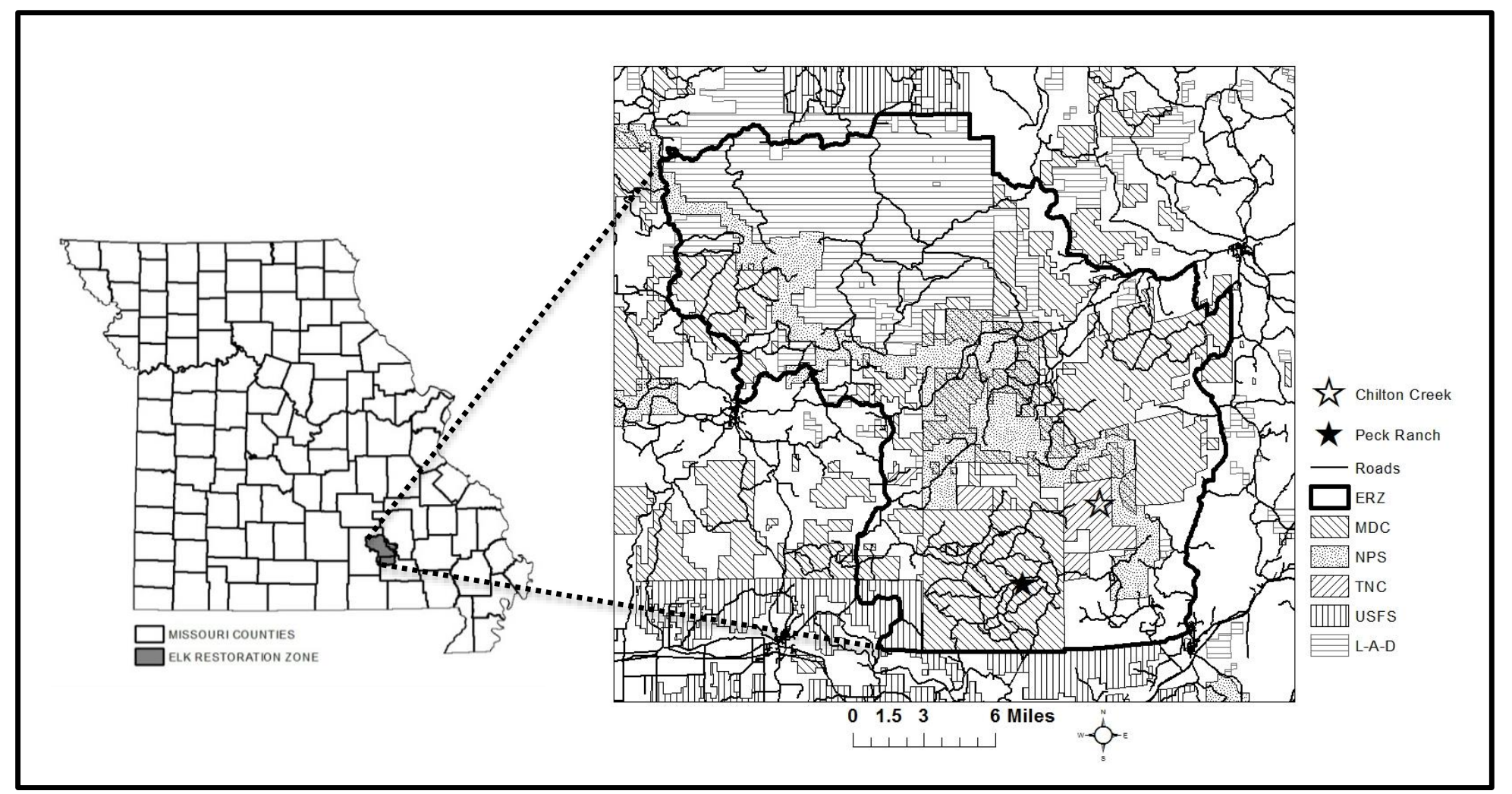

Figure 1. Missouri Elk Restoration Zone (ERZ) in parts of Carter, Reynolds, and Shannon Counties where elk were released in 2011-2013. Publicly accessible land in the ERZ belongs to the Missouri Department of Conservation (MDC), National Park Service (NPS), The Nature Conservancy (TNC), the United States Forest Service (USFS), and the L-A-D Foundation (L-A-D). Elk 
were released on the Missouri Department of Conservation's Peck Ranch Conservation Area and The Nature Conservancy's

Chilton Creek Preserve. 


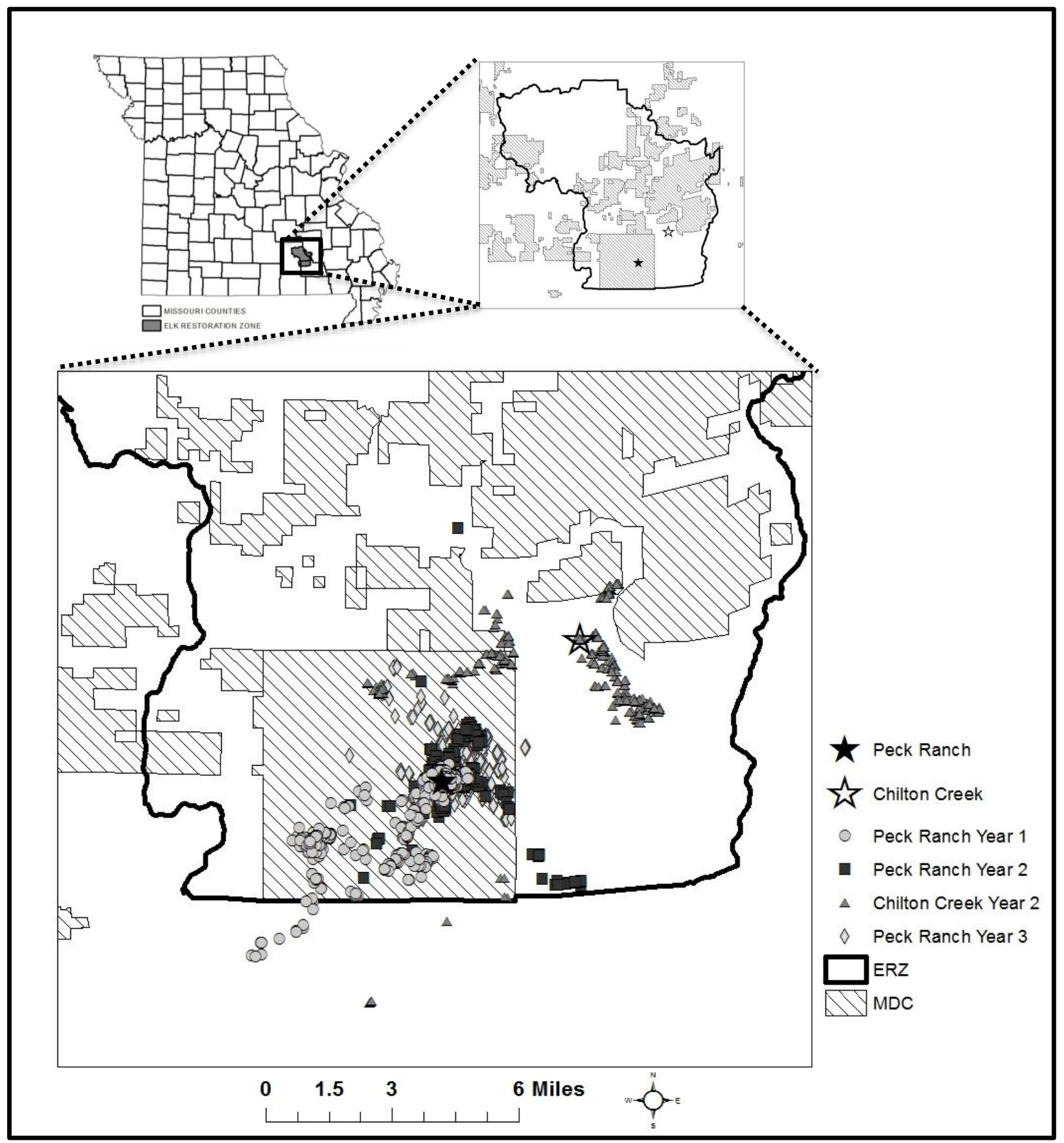

Figure 2. GPS locations collected during the first 10 days post-release for elk reintroduced to south-central Missouri. Elk were released on the Missouri Department of Conservation's Peck Ranch Conservation Area in 2011-2013 and The Nature Conservancy's Chilton Creek Preserve in 2012. 


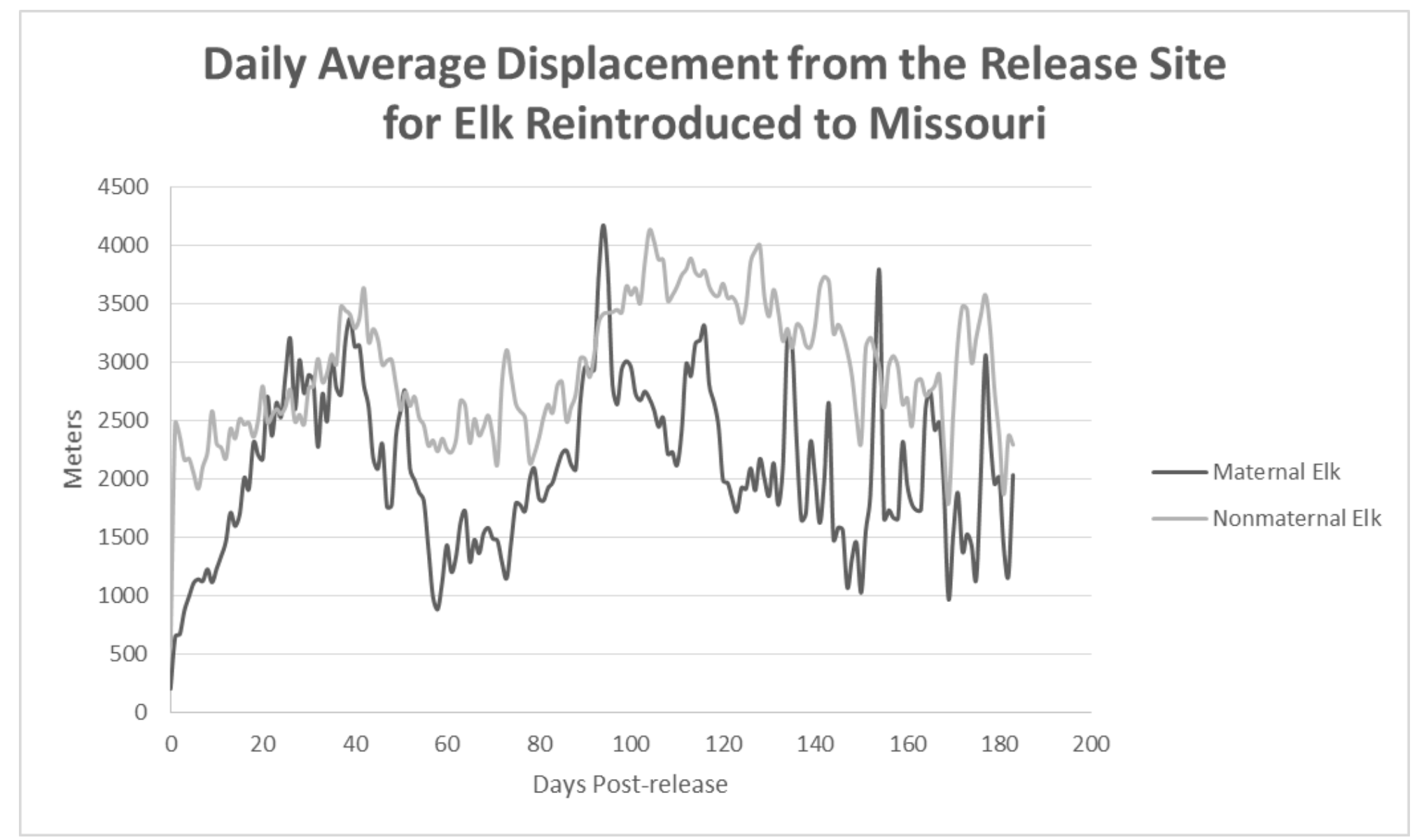

Figure 3. Daily average distance (m) from the release site for elk reintroduced to south-central Missouri 2011-2013. 

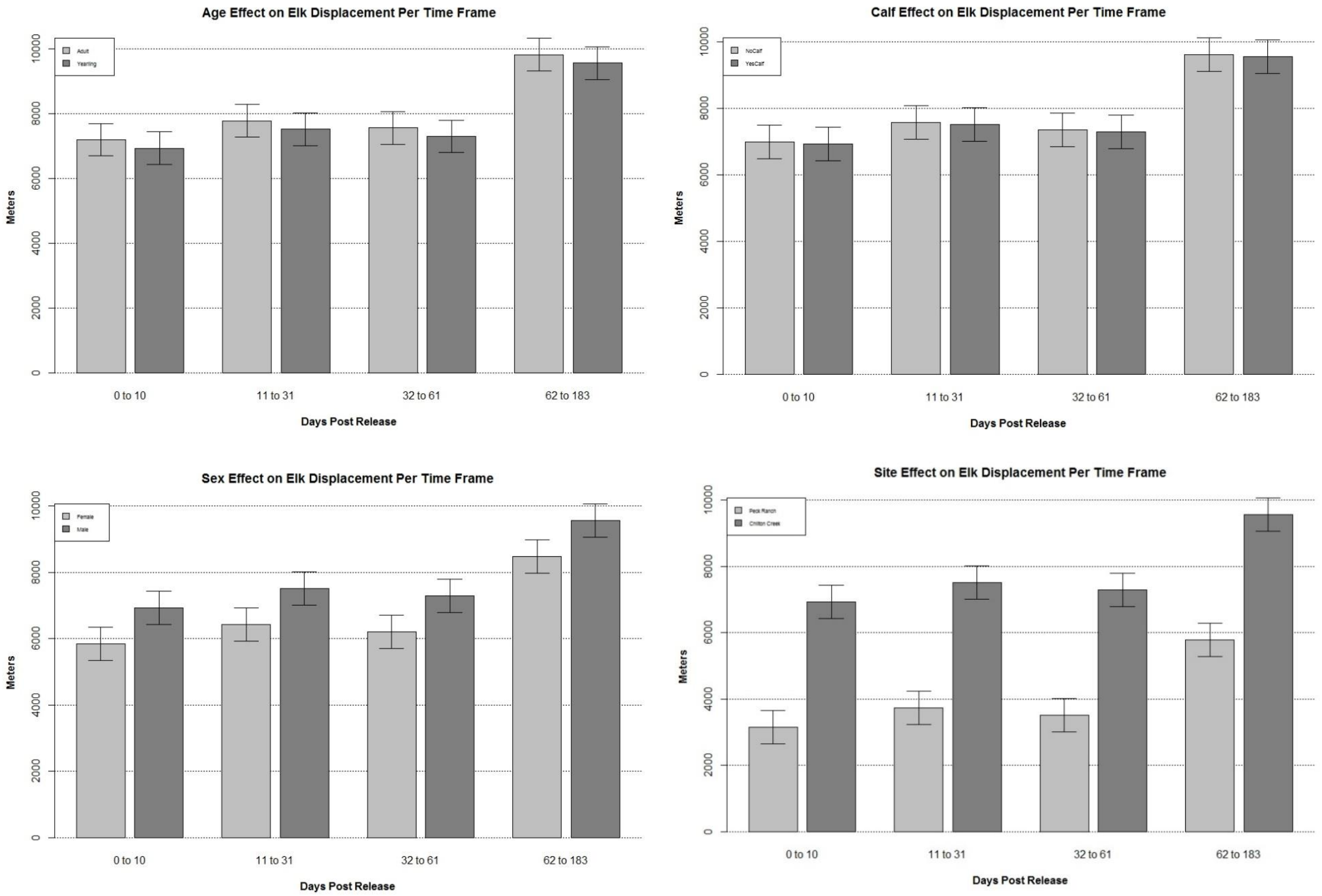
Year Effect on Elk Displacement Per Time Frame

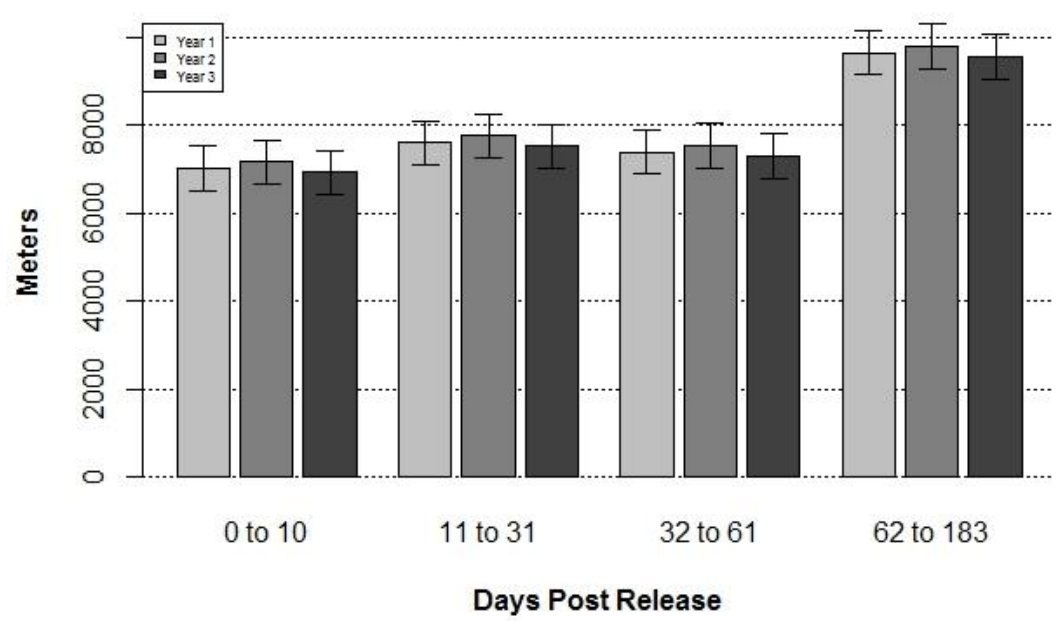

Figure 4. Model-averaged model predicted outcomes for each variable contributing to maximum displacement from the release site for elk reintroduced to south-central Missouri 2011-2013. Legends indicate age classes adult (light gray) and yearling (dark gray), calf-rearing status nonmaternal (light gray) and maternal (dark gray), sexes female (light gray) and male (dark gray), release sites Peck Ranch (light gray) and Chilton Creek (dark gray), and release years 1 (light gray), 2 (medium gray), and 3 (dark gray). 
Age Effect on Elk Speed Per Time Frame

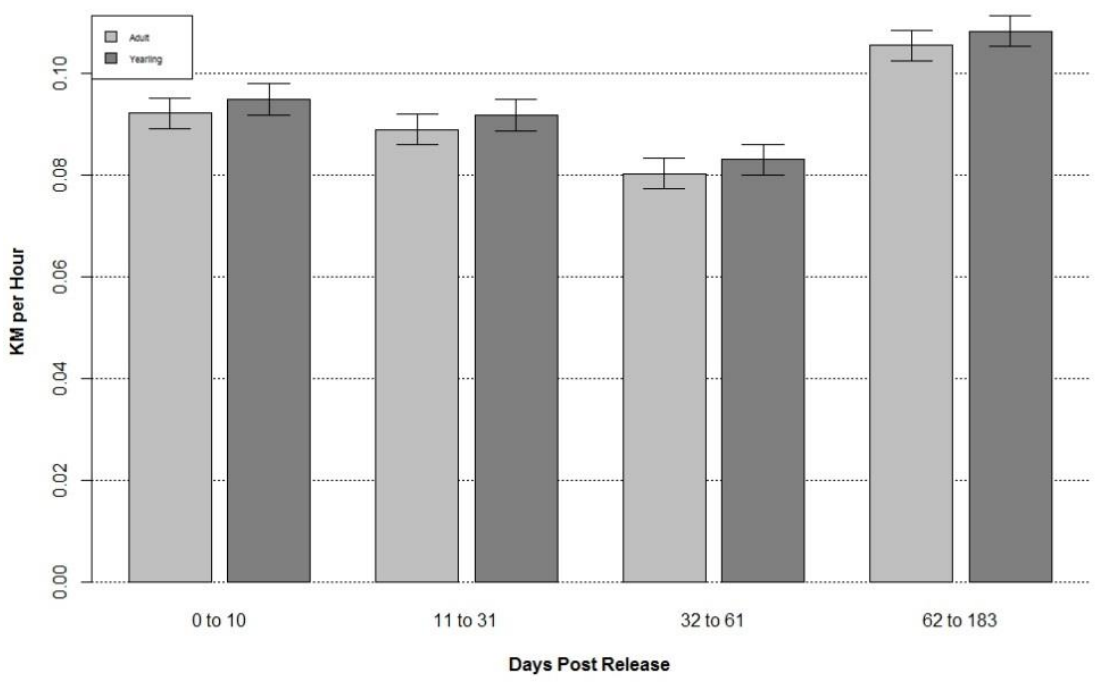

Sex Effect on Elk Speed Per Time Frame

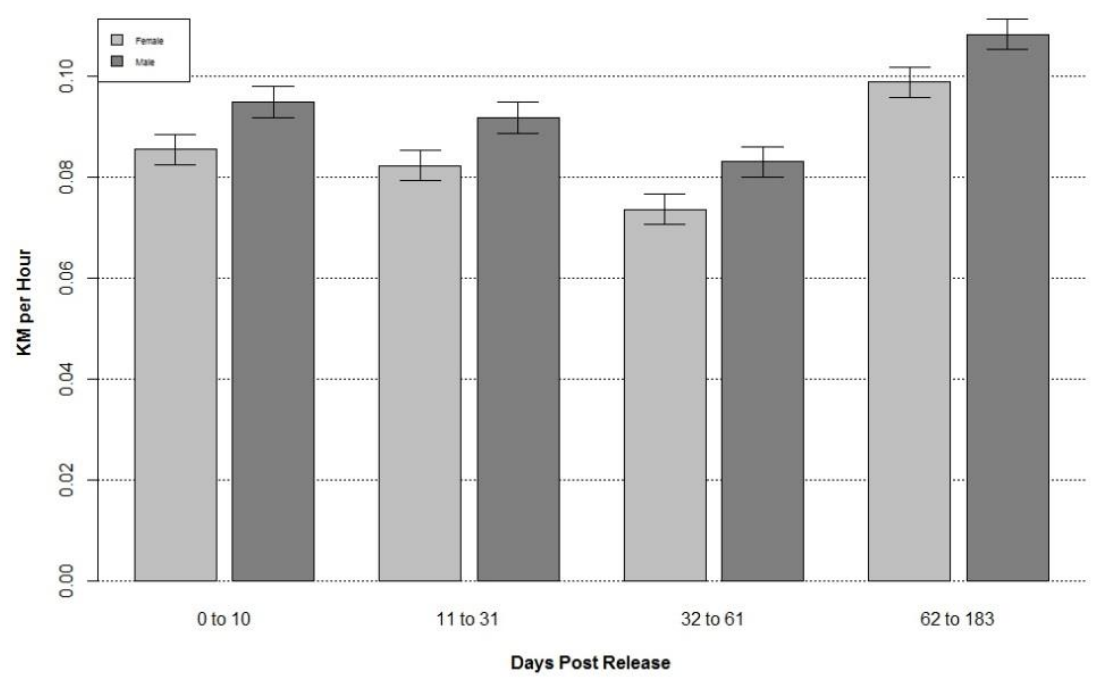

Calf Effect on Elk Speed Per Time Frame

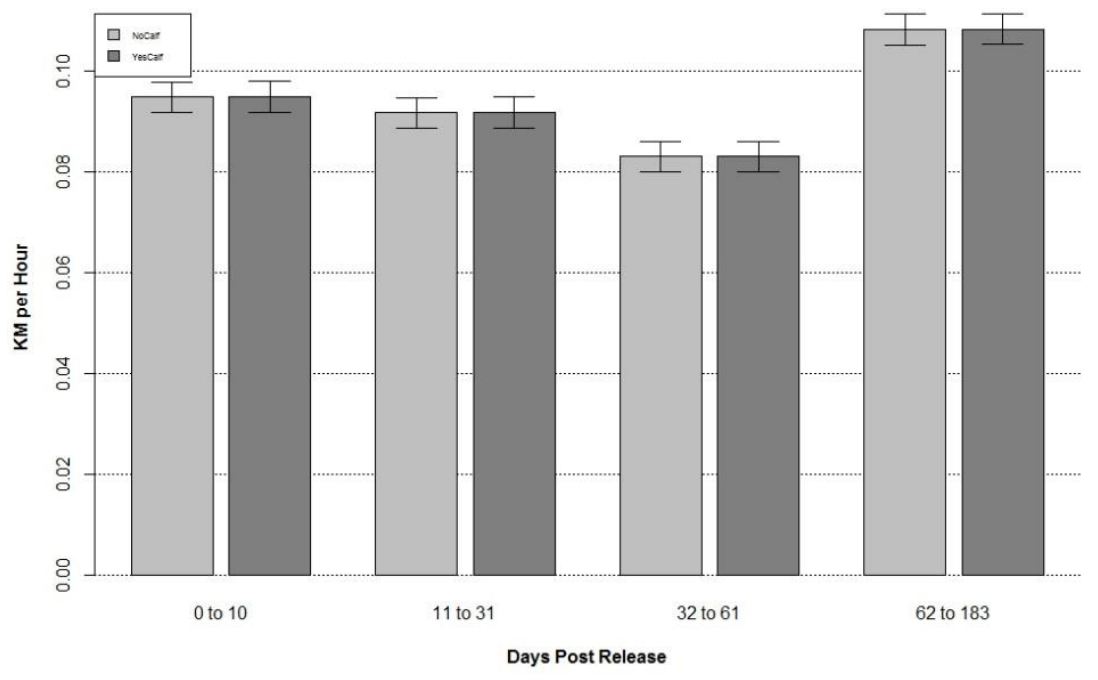

Site Effect on Elk Speed Per Time Frame

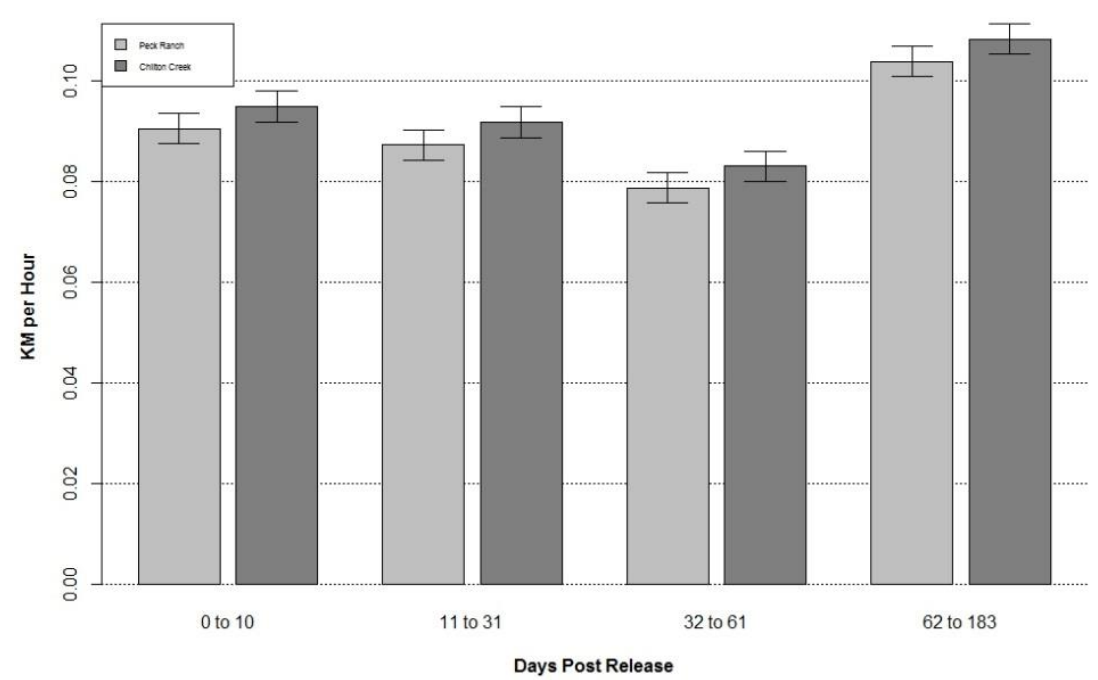




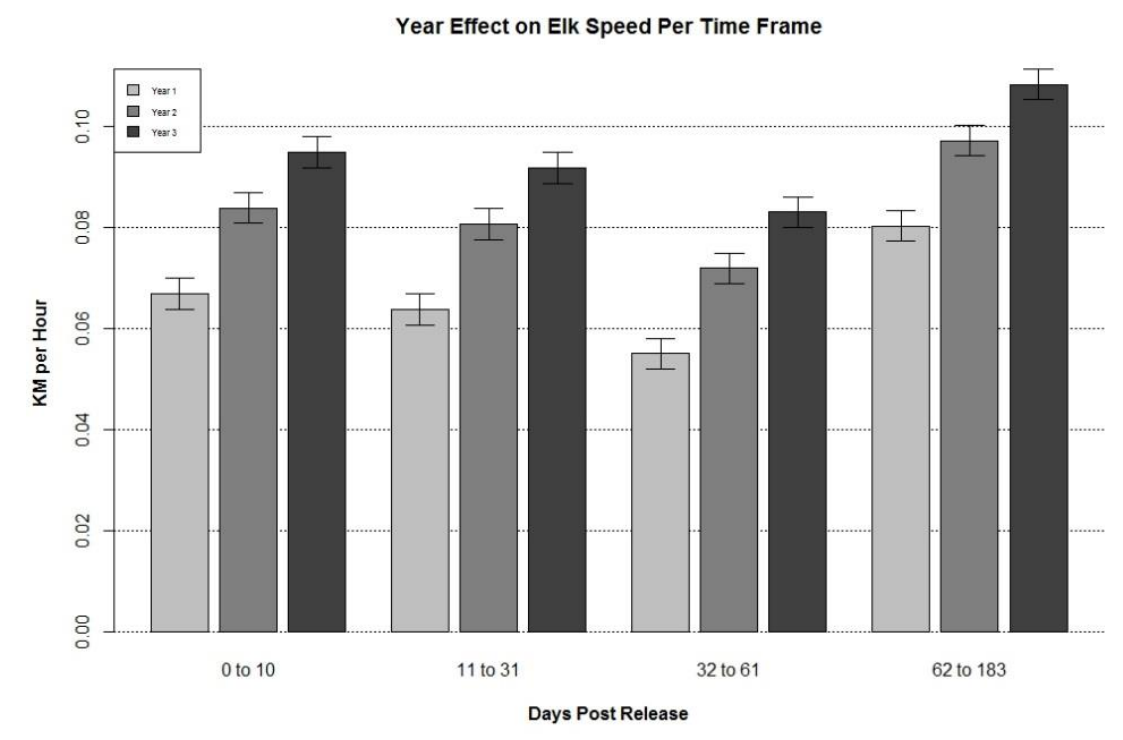

Figure 5. Model-averaged model predicted outcomes for each variable contributing to average movement rates for elk reintroduced to south-central Missouri 2011-2013. Legends indicate age classes adult (light gray) and yearling (dark gray), calf-rearing status nonmaternal (light gray) and maternal (dark gray), sexes female (light gray) and male (dark gray), release sites Peck Ranch (light gray) and Chilton Creek (dark gray), and release years 1 (light gray), 2 (medium gray), and 3 (dark gray). 
Age Effect on Elk Range Size Per Time Frame

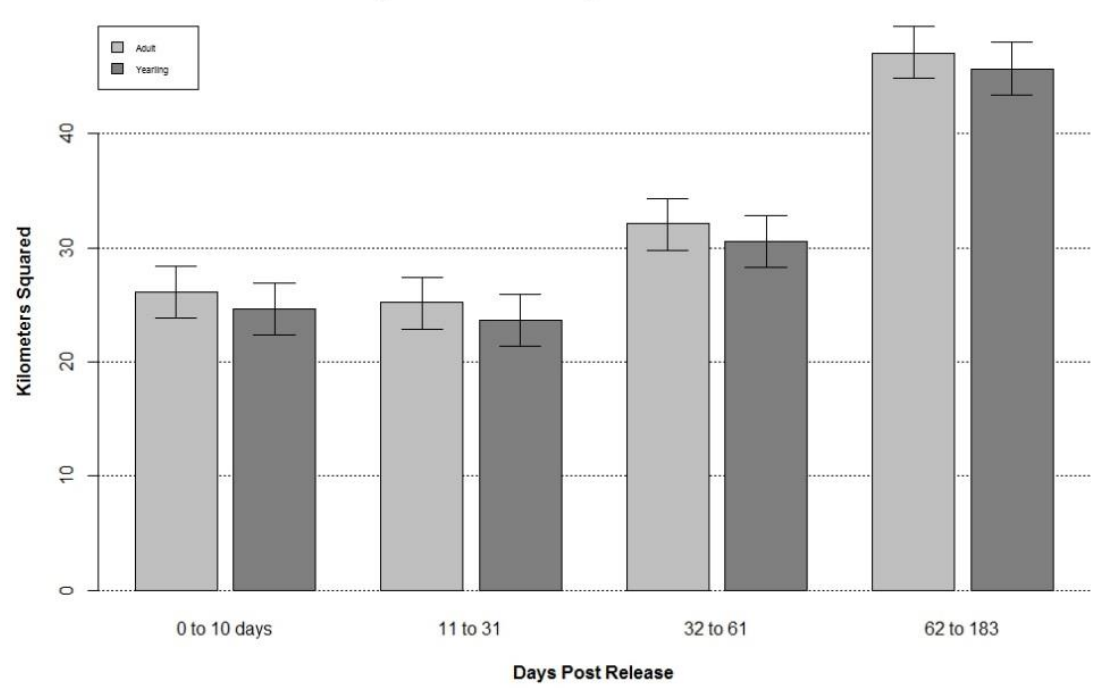

Sex Effect on Elk Range Size Per Time Frame

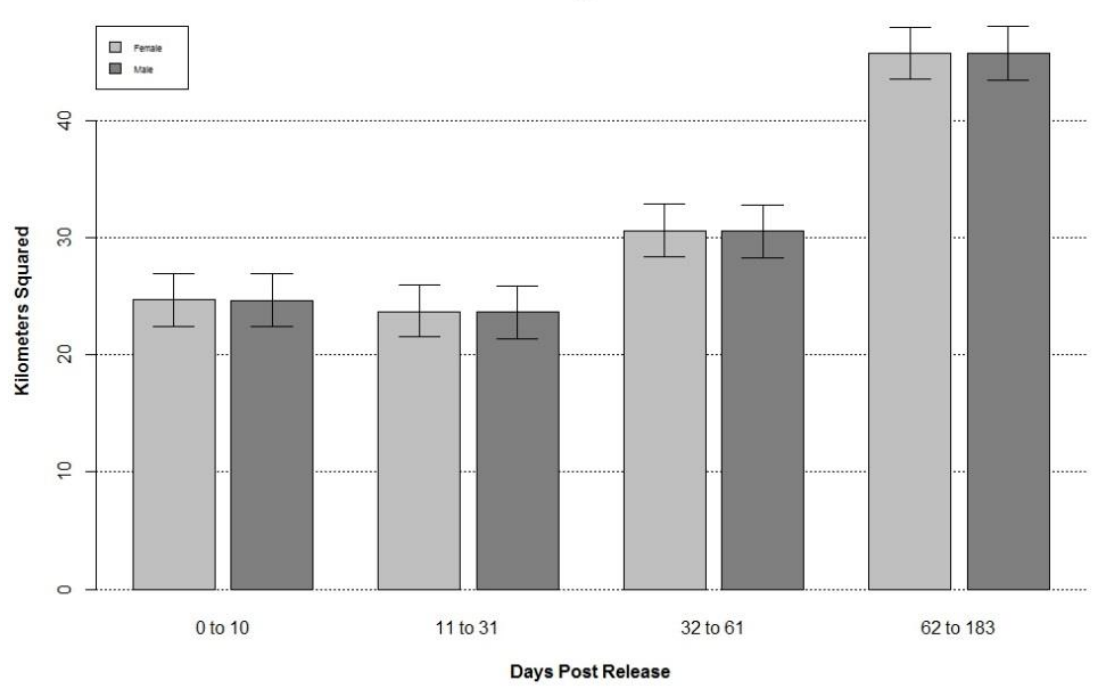

Effect of Calf Rearing on Elk Range Size Per Time Frame

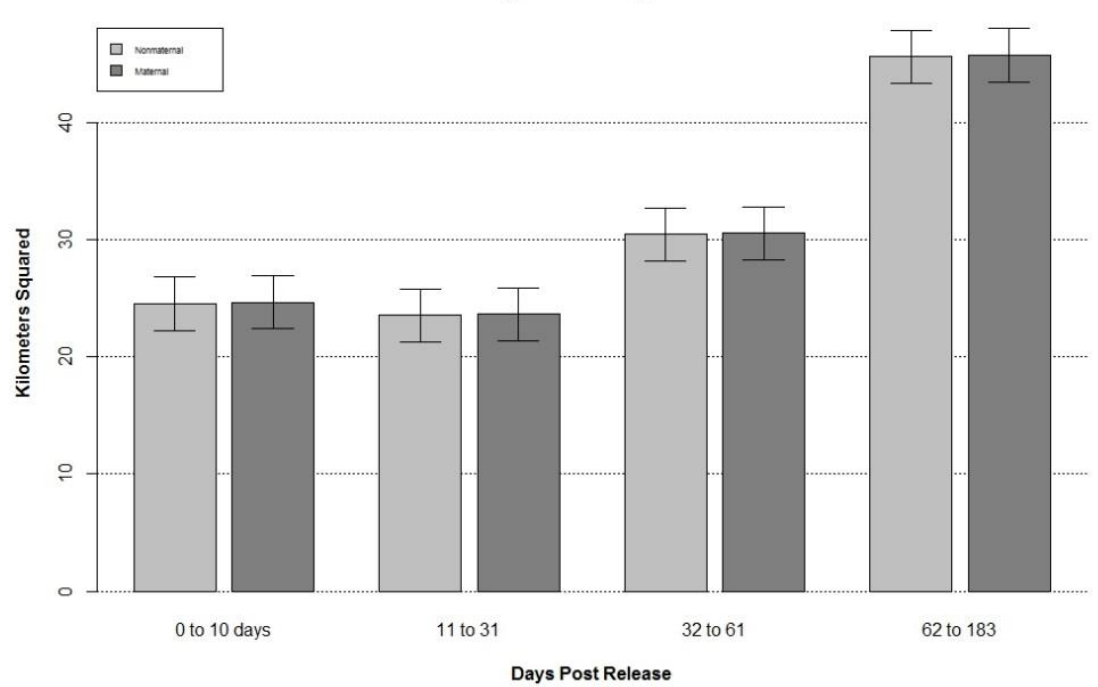

Site Effect on Elk Range Size Per Time Frame

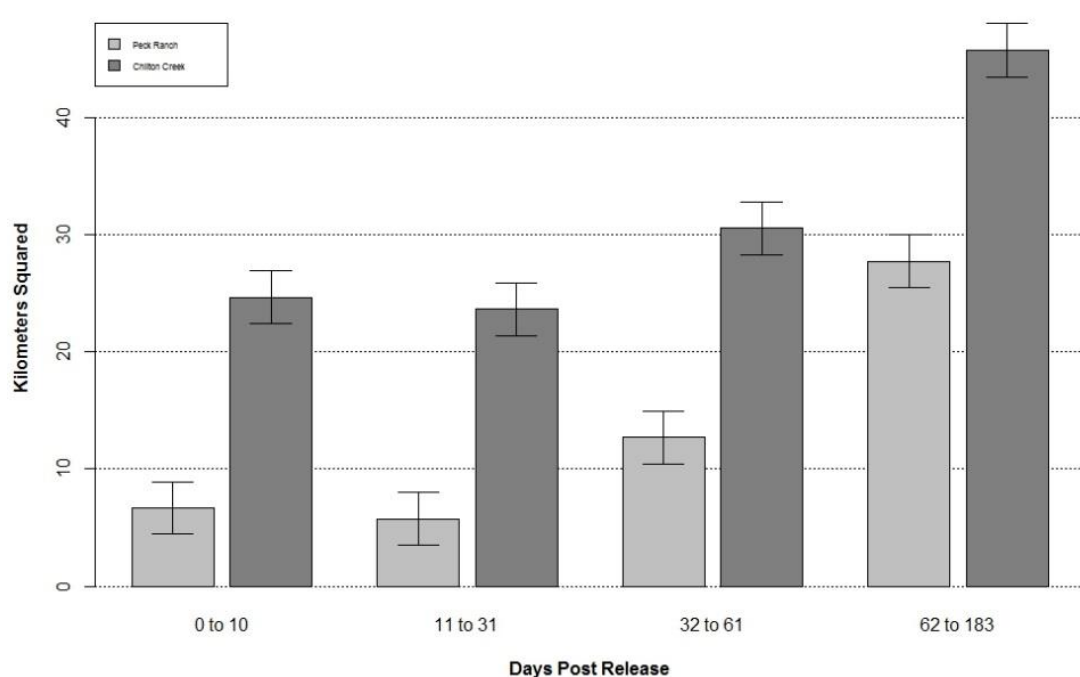




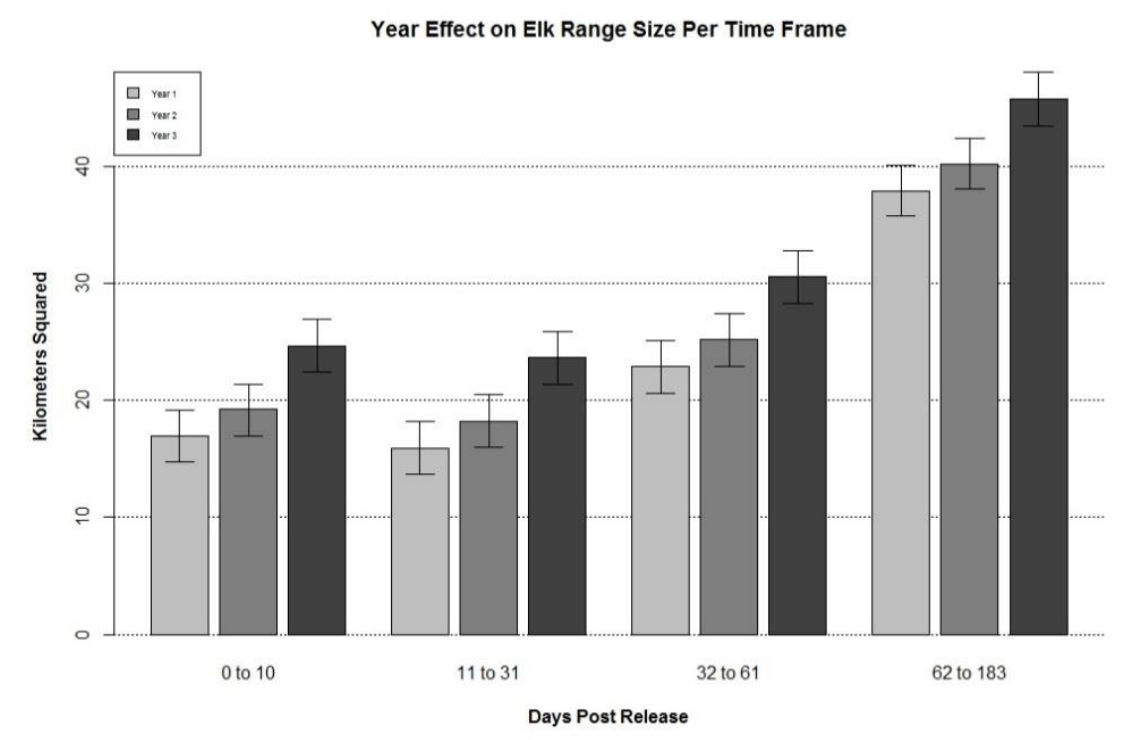

Figure 6. Model-averaged model predicted responses for each variable contributing to average range sizes 0-10, 11-31, 32-61, and 62-183 days post-release for elk reintroduced to south-central Missouri 2011-2013. Legends indicate age classes adult (light gray) and yearling (dark gray), sexes female (light gray) and male (dark gray), release sites Peck Ranch (light gray) and Chilton Creek (dark gray), and release years 1 (light gray), 2 (medium gray), and 3 (light gray). 
DISTURBANCE RESPONSE OF RECENTLY REINTRODUCED ELK IN THE MISSOURI OZARKS

\section{ABSTRACT}

Although wildlife reintroductions are often intended to provide the public with recreational opportunities, human disturbance at the release site may compromise the reintroduction effort. Animals that are disturbed may demonstrate reduced reproduction and survival. Further, if disturbance causes animals to abandon the release site, human-wildlife conflict may result. We studied the response of reintroduced Missouri elk (Cervus elaphus) to managed deer hunts in $2011(n=29), 2012(n=36)$, and 2013 (n=43). All elk were fitted with GPS collars that obtained fixes every 2-5 hours. We measured elk speeds, range shifts, and range sizes. We fit mixed-effects repeated measures models to determine the impact of hunter numbers, hunt type, hunt duration, hunt year, number of hunts an individual experienced, timing relative to the hunt, sex, age, release site, and release year on disturbance response. We asked deer hunters to carry GPS units during the hunts in order to assess spatiotemporal elk-hunter interactions and conducted a dynamic interaction analysis to assess whether elk were attracted to or avoided hunters. Elk responded to deer hunter disturbance by using refugia. Eleven elk left during the first hunt. After the first hunt, only one other hunt caused $>3$ elk to leave the conservation area. During the hunts, speeds increased, ranges shifted, and range sizes decreased. Speeds increased by $11 \%$ during each hunt compared to before the hunt. Elk used only $32.2 \%$ of their pre-hunt range post-hunt. Elk range sizes were 
$11 \%$ smaller during muzzleloader hunts than youth hunts. These behaviors may indicate that elk identified a fraction of their range to use as refugia and made more directed movements to leave the immediate vicinity of deer hunters. We observed neither attraction nor avoidance between deer hunters and elk, possibly due to availability of refugia within the spatial extent of the disturbance. This study provides evidence that elk are adaptable to human-wildlife disturbance even shortly (4 months) after reintroduction, and that animal reintroductions do not preclude recreational use of public lands where both are management priorities. 


\section{INTRODUCTION}

When managers consider wildlife reintroduction, public consumptive and nonconsumptive recreational opportunities are often cited as a potential benefit of the resource (Telesco 2007, Missouri Department of Conservation 2010, Virginia Department of Game and Inland Fisheries 2010); however, human disturbance and reintroduction success may conflict. As public demand for recreational opportunities on public lands grows (United States Geological Survey 2007, Naylor et al. 2009), managers must mitigate human disturbance of wildlife where the presence of a sustainable population is also a priority. As elk and other ungulates are commonly reintroduced (Seddon et al. 2005), and large mammals and reintroduced species may be susceptible to disturbance (Garcia Pereira et al. 2006, Teixeira et al 2007, Taylor and Knight 2003, Creel et al. 2002, Loehr et al. 2005), elk provide a valuable model system to evaluate the impacts of human disturbance on reintroduced populations. Under normal circumstances, elk can be adaptable to human disturbance, but they may demonstrate a more negative response shortly following translocation due to lack of established ranges or stress (Larkin et al. 2004, Dickens et al. 2007, Fryxell et al. 2008).

Extant populations of elk display a wide range of responses to human disturbance. Elk have been shown to alter their behavior in response to logging (Edge and Marcum 1985), cross-country skiing (Cassirer et al. 1992), all-terrain vehicle use, mountain biking, hiking, horseback riding (Naylor et al. 2009), and hunting (Vieira et al. 2003, Proffitt et al. 2010, Conner et al. 2001). Elk tolerance of human activity varies from regular use of residential areas to failure to recruit 
calves if elk are disturbed too much (Schultz and Bailey 1978, Phillips and Alldredge 2000). In some instances, displaced elk immediately return to a habitat after the disturbance is gone (Cassirer et al. 1992, Edge and Marcum 1985); other times, elk may be reluctant to return to certain areas even after the disturbance has subsided (Cole et al. 1997). This variation is likely explained by the mortality risk, frequency, and predictability of the disturbance (Cassirer et al. 1992, Knight 1980), with nonhunting, repetitive, and stationary disturbances being less disruptive (Edge and Marcum 1985, Cassirer et al. 1992). Although elk are typically tolerant of nonhunting disturbance, elk tend to seek refugia or vacate hunted areas during elk hunting seasons (Burcham et al. 1999, Conner et al. 2001, Millspaugh et al. 2000, Proffitt et al. 2010, Vieira et al. 2003). However, there is some evidence to suggest that elk can discern when human presence poses a mortality risk (Gude et al. 2006); if this is true, animals' spatial disturbance response may be lessened. Thus, elk are adaptable to different kinds of disturbance.

Although elk will adapt to disturbance, they may demonstrate a stronger aversion to human activity shortly after translocation, which may have repercussions for the reintroduction effort. Translocations are stressful for animals (Teixeira et al. 2007, Dickens et al. 2010, Jachowski et al. 2013), and additional stressors may cause reintroduced animals to move away from the release site as a coping mechanism (Dickens et al. 2007). Dispersal from the release site has been linked to failure to reproduce and increased mortality (Larkin et al. 2002, Yott et al. 2011). Additionally, movement away from the release site increases the risk of human-wildlife conflict with roadways or agrarian interests (Rosatte et al. 2007, 
Virginia Department of Game and Inland Fisheries 2010), which may decrease stakeholder support for the reintroduction.

Because human disturbance may negatively impact animals' ability to recruit young (Phillips and Alldredge 2000, Shively et al. 2005), decrease survival and reproduction, and prompt dispersal from the release site (Larkin et al. 2002, Dickens et al. 2010, Yott et al. 2011), it is important to understand which factors contribute to elk response to mitigate these effects. Hunter numbers, hunt type, hunt duration, hunt year, number of hunts an individual has experienced, and timing relative to the hunt may impact disturbance response (Cassirer et al. 1992, Bender et al. 1999, Burcham et al. 1999, Millspaugh et al. 2000, Vieira et al. 2003, Frair et al. 2007). Additionally, demographic and reintroduction variables sex, age, release site, and release year may alter an individual's response (Millspaugh et al. 2000, Loehr et al. 2005, Winnie and Creel 2006). Hunter numbers may or may not be an important predictor variable. There is some evidence that fewer hunters may cause less disturbance than more hunters (Burcham et al. 1999, Millspaugh et al. 2000). However, Vieira et al. (2003) reported that decreased elk hunter numbers did not reduce the number of elk moving to refugia, and Cassirer et al. (1992) found that elk disturbance response did not vary with numbers of skiers approaching. Hunt type may yield differing disturbance results, with elk tolerating archery hunts more than conspicuous firearm hunts (Millspaugh et al. 2000). Hunt duration has also been shown to affect disturbance response; short elk hunts have been successfully used to limit disturbance impacts and allow for elk viewing (Bender et al. 1999). Hunt year may help explain disturbance response patterns. If elk must balance 
disturbance response against adequate energy intake (Frid and Dill 2002), elk may be more reluctant to forfeit feeding time in favor of fleeing in response to a poor forage production year or other stochastic events. The number of hunts an individual has experienced likely helps explain elk disturbance response. Reintroduced elk must learn site-specific risk mitigation behaviors quickly to survive. One study indicated that translocated elk demonstrated similar survival rates to resident elk after just one year (Frair et al. 2007). Thus, after experiencing a year of managed hunts, elk may learn that deer hunters do not pose an immediate mortality threat and become more tolerant of deer hunter disturbance. Given that elk are susceptible to disturbance, their movement patterns will likely be different before, during, and after each hunt. Sex and age may also be important predictor variables due to differing anti-predator strategies (Millspaugh et al. 2000, Loehr et al. 2005, Winnie and Creel 2006). Finally, release site and release year may contribute to varying disturbance responses. Animals released at different sites might have varying experience with nonlethal human disturbance, and animals released in later years may benefit from the experience of those released in previous years.

To determine whether animals would be adaptable to a large-scale human disturbance shortly after translocation, we studied the effects of managed deer hunts on the movements of elk reintroduced to Missouri. Peck Ranch Conservation Area (Peck Ranch), where elk congregated post-release, held three managed hunts each fall. Whereas most disturbance was limited and predictable on Peck Ranch, each hunt was an intense, large-scale, unpredictable disturbance. Because elk have 
been shown to leave disturbed areas, managers were concerned about potential conflicts between deer management and providing recreational opportunities and elk reintroduction success. Our objectives were to characterize elk disturbance response spatially by measuring individual average speeds, individual range shifts, and population range size, as well as assess spatiotemporal elk-hunter interactions. Movement rates are used both as a proxy for transience (Turchin 1998) and as a measure of the flight response of disturbed animals (Schultz and Bailey 1978). When animals are disturbed, their movement rates increase (Cole et al. 1997, Conner et al. 2001). Although elk have been shown to expand their range to less preferred habitats during disturbance events, these responses are typically shortlived, with animals often returning to disturbed sites as soon as later the same day when these disturbances do not pose a mortality risk (Schultz and Bailey 1978, Knight 1980, Edge and Marcum 1985, Kuck et al. 1985, Cassirer et al. 1992, Cole et al. 1997, Burcham et al. 1999, Millspaugh et al. 2000, Conner et al. 2001, Vieira et al. 2003, Naylor et al. 2009, Proffitt et al. 2010, Dickens et al. 2010, Grignolio et al. 2011). Thus, we anticipated that elk would increase movement rates and expand or shift their ranges during each hunt, but return to pre-hunt spatial behavior after each hunt. We also expected that disturbance responses would lessen as elk learned that deer hunters were not a threat. We predicted that individual average speeds, individual range shifts, and population range sizes would vary based on hunter numbers, hunt type, hunt duration, hunt year, number of hunts an individual has experienced, and timing relative to the hunt, as well as sex, age, release site, and release year. Finally, we hypothesized that elk would not share space with deer 
hunters. Because the hunts were an intense and unpredictable disturbance, and elk were hunted in Kentucky prior to translocation, we expected that elk would temporarily vacate areas occupied by hunters.

\section{STUDY AREA}

We studied elk reintroduced to an $896 \mathrm{~km}^{2}$ restoration zone in the Ozark Highlands of south-central Missouri (Figure $1,91^{\circ} 24^{\prime}$ to $90^{\circ} 58^{\prime} \mathrm{W}$ and $37^{\circ} 0^{\prime}$ to $37^{\circ} 19^{\prime} \mathrm{N}$, Missouri Department of Conservation 2010, Keller et al. in press). Elk were released at the Missouri Department of Conservation's Peck Ranch Conservation Area (Peck Ranch, 2011-2013) and The Nature Conservancy's Chilton Creek Preserve (2012), located $2.5 \mathrm{~km}$ from Peck Ranch. Despite an alternate release location and post-release exploratory movements, nearly all elk were located on Peck Ranch during the study.

The 9,327 hectare Peck Ranch is located on the southern border of Missouri's elk restoration zone. Topography consists of rugged, narrow ridges ranging in elevation from 274-411 m above sea level (Missouri Department of Conservation 2009). The conservation area contains forest and woodland (90\%), savannah, wetlands, limestone and hyalite glades (7\%), and wildlife food plots (2\%) (Missouri Department of Conservation 2014). Primary tree species in the region include oak (Quercus alba, Q. stellata, Q. coccinea, Q. velutina), hickory (Carya tomentosa, C. texana, C. glabra), and shortleaf pine (Pinus echinata) (Brookshire and Dey 2000, Shifley et al. 2000). Peck Ranch offers 221 hectares of regionally rare open land; the majority is managed in 151 food plots seeded with agricultural crops and grasses. 
Many of these food plots lie along roadways. Locally present large mammals include white-tailed deer (Odocoileus virginianus), black bears (Ursus americanus), coyotes (Canis latrans), bobcats (Lynx rufus), and transient cougars (Puma concolor). Cougars are the only predators known to have killed elk in the study area.

Managed hunts were conducted within a 4,283 ha refuge in the center of Peck Ranch. The refuge perimeter was partially fenced with barbed wire; the fencing was in disrepair and served as a boundary marker for hunters but did not restrain elk movements. The largest food plots were located along roadways within the refuge. Hunters in the managed hunts were only allowed to hunt within the refuge, but public hunting was allowed outside of the refuge. Hunters were allowed to drive many roads and could access remaining refuge area on foot. Occasionally hunters were granted permission to drive closed roads and two-tracks in order to retrieve harvested deer.

Human-wildlife disturbance on Peck Ranch was limited. Although gravel roads and two-tracks permeated much of Peck Ranch, public vehicle access was restricted to some roads within the refuge. Select roadways were used to form an elk viewing route that was open year-round except elk calving season (April 1-July 1), managed hunts, and deer rifle season. Visitors were allowed to access the entirety of Peck Ranch on foot, but did not commonly do so. Vehicles on the driving tour, hikers on the Peck Ranch Nature Trail $(0.8 \mathrm{~km})$ and the Ozark Trail $(17.7 \mathrm{~km})$, hunters outside of the refuge, ecological researchers, and workers conducting management activities such as food plot management and logging comprised the 
majority of human disturbance within Peck Ranch outside of the managed deer hunts.

\section{METHODS}

\section{Field methods}

To assess the impact of human disturbance on the movements of reintroduced elk, we studied elk response to a managed deer hunt by observing changes in elk movement patterns and elk-hunter interactions. The Missouri Department of Conservation held 3 managed hunts at Peck Ranch Conservation Area each fall: modern firearms youth in October, archery in November, and muzzleloader in December. The hunts were a short but intense, unpredictable, and large-scale disturbance in that hunters were allowed to access roads normally closed to the public, were legally required to leave their trucks (and the roadways) to hunt, and achieved a much higher human density than the elk experience the rest of the year. The youth hunt allowed 60 tags; the archery and muzzleloader hunts each allowed 200. Hunters drawn for a tag were allowed to scout and erect stands the weekend prior to the hunt. They were also required to register before hunting, which began one day prior to the hunt. At registration, we asked hunters to voluntarily carry GPS units (eTrex Venture HC, Garmin International, Inc., Olathe, KS) with them while hunting in the refuge. We had GPS units available for all hunters in a hunt, and we incentivized participation with a gift card raffle. We positioned research staff at the only access gate during all hours of the hunt (5:0020:00) to remind hunters to power units on and off as they entered and left Peck 
Ranch and to provide replacement batteries as needed. We collected GPS units when hunters harvested a deer or reported that they were done hunting for the weekend.

We managed hunter GPS units to collect as much hunter location data as possible during the hunt within memory and battery constraints. We programmed GPS units to keep a track with fixes taken every 20 seconds to ensure that memory space would not be limited over the maximum duration of huntable hours. Fixes were recorded in the unit's Active Log with a time and date stamp and downloaded as points.

Elk locations were collected from animals reintroduced to Missouri in 2011 ( $n=34,15$ adult female, 6 adult male, 5 yearling female, 8 yearling male), 2012 ( $n=33,22$ adult female, 4 adult male, 3 yearling female, 4 yearling male), and 2013 ( $n=39,20$ adult female, 16 yearling female, 3 yearling male), as well as 2 female elk born in Missouri in 2011 and fitted with GPS collars as yearlings. All translocated elk were fitted with GPS-PPT/VHF collars prior to release (RASSL 3D cell collar, North Star Science and Technology, LLC, King George, VA; G2110E Iridium/GPS series model, Advanced Telemetry Systems, Isanti, MN). The Missouri-born elk were considered to be in the 2011 release-group. We obtained fixes from elk at 2.5 $(n=2), 3(n=43), 4(n=2)$, and 5 hour $(n=39)$ intervals. Elk were handled according to University of Missouri Animal Care and Use Committee protocol 6909.

We tested both hunter GPS units and elk GPS collars for accuracy. We randomly selected test points on Peck Ranch in meadow, mid- and high-density coniferous forest, and mid- and high-density deciduous forest habitats (Sager- 
Fradkin et al. 2006, Homer et al. 2007). For 2 weeks in November 2012, we deployed 10 hunter GPS units and 5 elk collars at those locations. We allowed elk collars to retrieve locations at the same 5-hour interval as the majority of collars on animals released in the first and second years; we programmed hunter GPS units to retrieve one location each hour. Finally, we marked each test location with a highaccuracy Trimble GPS unit and used this fix as our true location for comparison (Trimble GeoXT 3000, Trimble Navigation Limited, Sunnyvale, CA).

\section{Analytical methods}

To determine the effect of deer hunter activity on reintroduced elk movements, we evaluated individual elk average speeds and the elk population range size before, during, and after the hunts, determined the extent of individual range shifts before vs. after each hunt, and conducted a dynamic interaction analysis between elk and deer hunters during each hunt (Kenward et al. 2008). To increase relocation numbers while not using any given day more than once, we measured "before" and "after" the hunts in 9 day increments. We considered all hours (0:0023:59) of hunt days to be "during" the hunt, and used all elk locations collected in those hours. If an individual died during a series of hunts, we censored the animal.

We measured individual elk average speeds, individual range shifts, and population range size before, during, and after each managed deer hunt to assess the impact of deer hunter activity on elk movement patterns. We defined movement rates as the Euclidean distance between points traveled per hour $(\mathrm{km} / \mathrm{hr}$, White and Garrott 1990) and calculated average speeds for individuals with $\geq 3$ relocations per time period (before, during, after) using the Tracking Analyst function in ArcInfo 
10.2 (ESRI, Redlands, CA). To evaluate range shifts, we constructed fixed kernel utilization distributions (UDs) for elk with $\geq 30$ relocations per 9-day buffer period before and after each of the hunts in a given year (Van Winkle 1975, Seaman et al. 1999). We created UDs using packages KernSmooth, ks, and mvtnorm in program $R$ (R Version 2.10.0, www.r-project.org, Accessed 26 Jan 2012). We used plug-in methods to select bandwidths (Gitzen et al. 2006). To assess range shifts, we calculated a Volume of Intersection Index (V) between individual before- and afterhunt UD pairs, which yields a proportion volume overlap statistic ranging from 0 to 1 (Seidel 1992, Millspaugh et al. 2004b). We used 100\% volume UDs to catch range overlap at the edges of an elk's range. To measure the area of population-level ranges, we combined locations from all elk during each hunt to create $95 \%$ volume fixed kernel UDs for before, during, and after each hunt using the methods outlined above.

We developed candidate model sets to test hypotheses explaining patterns in elk average speeds, home range overlap, and population range size (Appendices 13). We included the variables hunter numbers (Cassirer et al. 1992, Burcham et al. 1999, Millspaugh et al. 2000, Vieira et al. 2003), hunt type (Millspaugh et al. 2000) or place in the hunt sequence (Millspaugh et al. 2000, Frair et al. 2007), hunt duration (Bender et al. 1999), and hunt year (Frair et al. 2007) in the range size models (Appendix 3). For individual-based average speed (Appendix 1) and home range shift models (Appendix 2), we used each of those variables as well as the number of hunts experienced by an individual elk (Frair et al. 2007), sex (Millspaugh et al. 2000), age (yearling or adult, Millspaugh et al. 2000, Loehr et al. 
2005), individual release site, and individual release year. We incorporated timing relative to each hunt into the range size and average speed model sets; this variable was implicitly included in the range shifts model. For the individual-based average speed model, timing relative to each hunt was categorized as "before," "during" or "after." Because the modeling procedure we used to fit the population-based elk range size models will not recognize more than 2 variants of a categorical variable, we coded two variables (during, after) and allowed the null for both to represent the remaining option (before). We followed the same protocol for coding the variables hunt type and hunt year for the range size models. We calculated hunter numbers based on the total number of registered hunters, rather than the number of hunters who volunteered to carry GPS units. Because youth, archery, and muzzleloader seasons were always in that order chronologically, we could not separate hunt type and place in the hunt sequence, and chose to include only one variable (hunt type) to represent both parameters. Hunt duration indicated whether the managed hunt lasted 2 or 3 days. We counted the number of hunts experienced by an individual elk cumulatively between years.

We ranked models using an information theoretic approach (Burnham and Anderson 2002). We fit mixed effects models for individually-based analyses and linear regression models for population-based analyses. We conducted individual analyses average speeds and range shifts in the MIXED procedure in SAS 9.3 (SAS Institute, Inc., Cary, NC); we used the REG procedure for the population-level range size analysis. We assessed support for each model using Akaike's Information Criterion corrected for small sample sizes (AICc) (Burnham and Anderson 2002). 
We determined the appropriate covariance structure for average speeds and range shifts models by modeling each response variable using restricted maximum likelihood methods and selecting the model with the lowest AICc. We tested 3 potential covariance structures for average speeds and range shifts: unstructured, compound symmetry, and autoregressive covariance, where unstructured assumes independence among data, compound symmetry accounts for dependence among data, and autoregressive accounts for potential temporal autocorrelation among data. An autoregressive covariance structure was the best fit for both average speeds and range shifts, so we fit subsequent mixed effects models using that structure. We also tested nonlinear forms of our only continuous variable, hunter numbers, for the average speeds, home range overlap, and population range size responses. We fit linear, quadratic, and psuedothreshold models for each response using restricted maximum likelihood methods (Franklin et al. 2000, Bonnot et al. 2011a). The best fit for the relationship between average speeds and range shifts and hunter numbers was quadratic; the best fit for the relationship between population range size and hunter numbers was linear. Thereafter we used the best fit form of the hunter number variable for each response.

We calculated parameter estimates for models using a two-step process (Bonnot et al. 2011b). First, in order to obtain analogous AICc values across models comprised of different fixed effects, we fit candidate models using maximum likelihood methods. We considered any model with $1 / 8^{\text {th }}$ or greater relative support of the top model in our confidence set (Burnham and Anderson 2002, Bonnot et al. 2011b). Second, we found parameter estimates and standard errors 
for fixed effects by refitting models using restricted maximum likelihood methods (Diggle et al. 1994, Bonnot et al. 2011b). If model uncertainty existed, we modelaveraged using the maximum-likelihood Akaike weights $w_{i}$, where $w_{i}$ indicates the probability that the candidate model provides the best fit of any model in the confidence set, and the equation (1):

$$
\widehat{\bar{\beta}}=\sum_{i=1}^{R} w_{i} \widehat{\beta}_{l},
$$

where $\widehat{\bar{\beta}}$ is the model averaged estimate of each coefficient, $w_{i}$ is the Akaike weight calculated from AIC values for $R$ models in the confidence set containing the predictor variable, and $\widehat{\beta}_{l}$ is the estimate of the coefficient for each variable in model $i$ (Burnham and Anderson 2002, Bonnot et al. 2008). We calculated the unconditional variance estimates for each predictor variable in the final model using the equation (2):

$$
\widehat{\operatorname{var}}(\widehat{\bar{\beta}})=\left[\sum_{i=1}^{R} w_{i} \sqrt{\left[\widehat{\operatorname{var}}\left(\widehat{\beta}_{l}\right)+\left(\widehat{\beta_{l}}-\widehat{\overline{\beta_{l}}}\right)^{2}\right]}\right]^{2}
$$

and used the unconditional variance estimates to construct confidence intervals (Burnham and Anderson 2002, Bonnot et al. 2011b, Bonnot et al. 2008).

To evaluate elk-hunter spatiotemporal interactions, we conducted Kenward's dynamic interaction analysis in program Ranges8 (Anatrack Ltd., Wareham, UK, Kenward 2001, Millspaugh 2004). A dynamic interaction analysis accounts for temporal overlap when comparing space use between two individuals by limiting comparisons of space use to simultaneous relocations. The result is a Jacobs' index score (Jacobs 1974), ranging from -1 to 1 , where -1 is complete avoidance, 0 represents indifference, and 1 is complete attraction between individuals. We 
calculated hunter and elk GPS location error by finding the average Euclidean distance between GPS locations and the true location for each test unit (SagerFradkin et al. 2006). We used $6 \mathrm{~m}$ as our tracking error input in the analysis based on our GPS accuracy test. We considered locations taken within 5 minutes of one another to be simultaneous. As Jacobs' Index scores may be unreliable with $<4$ location pairs, we limited our elk-hunter interaction analysis to individual elk with $\geq 5$ hunter location pairs (Kenward et al. 2008). We calculated geometric means for the Jacobs' index in order to obtain more consistent results (Walls and Kenward 2001).

RESULTS

We collected 31,122 locations on elk during the managed hunts, but sample sizes varied by analysis (Table 1). In year 1 , we censored elk due to mortality (2 adult female, 1 adult male). In year 2, we censored elk due to death (11 adult female, 1 yearling female, 1 yearling male) and extensive movements beyond Peck Ranch (1 adult female). In year 3, we censored additional elk due to death (7 adult female, 5 yearling female) and extensive movements outside of Peck Ranch (1 adult female). Finally, some collared elk were censored due to complete collar failure or activated blow-off devices ( $\left.n_{\text {year } 1}=2, n_{\text {year } 2}=10, n_{\text {year } 3}=19\right)$.

Although elk were observed to leave Peck Ranch during 5 of the 9 managed hunts (55.5\%), all elk returned to Peck Ranch within 3 days after the hunt (Table 2). During the first year deer hunt, elk left Peck Ranch, but did not leave in subsequent hunts. This behavior may indicate that elk adapted to the hunt disturbance after 
just one hunt. Following the first hunt post-release, no elk left during 4 of the remaining hunts, and 3 or fewer elk left during 3 of the remaining hunts. However, over half of the elk left Peck Ranch during the 2012 muzzleloader hunt. This may be due to decreasing tolerance during the 2012 hunt year, or it may have been an artifact of elk exploratory movements post-release and the herding nature of elk. When elk left Peck Ranch, they typically moved either in a large group ( $>11$ individuals) or as solitary individuals, rather than in small groups.

We deployed a total of 845 GPS units on deer hunters (Table 3). We were unable to deploy GPS units during the 2013 muzzleloader hunt due to inclement weather. We could not retrieve data from 10 GPS units that had been deployed (1\%). Total number of hunters registered per hunt ranged from 56 to 177 (Table 3). Participation rates were generally high, ranging from $76 \%$ to $100 \%$ and averaging 88.9\% (Table 3). Two hunter GPS units were broken during the hunts, and one was stolen.

Average speeds

Average speeds increased during hunts relative to before hunts and remained somewhat higher after hunts; they also increased with progressive hunts and hunt years. There was no model uncertainty, and the top model included all variables associated with timing: timing with respect to each hunt (before, during, after), place in the hunt sequence (or hunt type), and hunt year. Generally, as time went on, elk increased their average speeds as the hunt sequence progressed and with each subsequent year (Figures 2 and 3). Place in the hunt sequence had the greatest impact, contributing approximately $0.03 \mathrm{~km} / \mathrm{hr}$ per subsequent hunt. With 
respect to a given hunt, average speeds were lowest before, highest during, and intermediate after each hunt (Figures 2 and 3). Elk increased speeds by $11 \%$ during each hunt compared to before the hunt. Average speeds were not affected by hunter numbers, hunt duration, number of hunts experienced, demographics, or time or site of release.

Individual range shifts

Range overlap between before- and after-hunt periods was low, with elk using just $32.2 \%$ of their previous range on average, and varied with hunt type and hunt year. Range overlap was generally low, with average volume of intersection indexes ranging from 0.290 for youth hunts (min: 0 , max: 0.631 ) to 0.348 for archery hunts (min: 0, max: 0.712 ) and 0.327 for muzzleloader hunts (min:0, max: 0.640). Place in the hunt sequence (or hunt type) and hunt year explained the variation in individual range shifts (Figure 4). Range shifts were greatest for the first hunt of the series, the youth hunt, with only $17 \%$ overlap between ranges before and ranges after the hunt. For archery and muzzleloader hunts, range overlap increased to around $25 \%$ between ranges before and after each hunt. Range overlap steadily decreased for each hunt year, falling from 38\% overlap in 2011 to $30 \%$ in 2012 to $17 \%$ in 2013. There was no evidence that hunter numbers, hunt duration, number of hunts experienced, sex, age, release site, or release year impacted range shifts.

\section{Population range size}

Population range sizes decreased as time progressed within a hunt year and as a function of hunter numbers. Population range sizes varied from 304 ha during 
the 2011 muzzleloader hunt to 4434 ha before the 2013 youth hunt. Hunt type and hunter numbers explained range size patterns (Table 4). Generally, population range sizes decreased as the hunt sequence progressed from youth to archery to muzzleloader seasons, with muzzleloader season ranges being $11 \%$ lower than youth season ranges (Figure 5). The largest change in range size between hunt types was between the youth and archery hunts. Range sizes also decreased with increasing hunter numbers. The elk range size for the largest hunt was approximately halved compared to the smallest hunt. We did not observe population range sizes to change according to hunt duration, hunt year, number of hunts experienced, timing relative to the hunt (before, during, after), sex and age characteristics, release site, or release year.

\section{Dynamic interaction analysis}

We did not observe strong aversion or attraction between elk and deer hunters (Figure 6). We found the average GPS error for hunter GPS units to be 5.86 $\mathrm{m}(\mathrm{min} 2.00, \max 10.88)$ and the average GPS error for elk collars to be $5.99 \mathrm{~m}$ (min 3.00, max 11.35), and used $6 \mathrm{~m}$ as our error input. We observed an average of 14.5 hunter-elk location pairs per elk (min: 5, max: 23). We calculated average geometric mean Jacobs' index scores to be -0.007 for youth hunts $(2011=-0.001,2012=-0.007$, $2013=-0.009), 0.021$ for archery hunts $(2011=-0.005,2012=-0.021,2013=0.066)$, and 0.044 for muzzleloader hunts $(2011=0.002,2012=0.074)$. The strongest avoidance between elk and hunters was during the 2012 archery hunt $(-0.021)$; the strongest attraction was during the 2012 muzzleloader hunt (0.074). 


\section{DISCUSSION}

Our study shows that elk are highly adaptable; even shortly after translocation from a hunted population, elk will tolerate an unpredictable, largescale, high-intensity human disturbance event without abandoning the release site. Our predictions that managed hunts would lead to typical disturbance responses such as increased movement rates and range shifts were supported. However, contrary to our hypotheses, range shifts persisted 9 days post-hunt, range sizes decreased, and each of these responses appeared to strengthen over time. However, we did not observe elk avoidance of individual deer hunters. We believe elk used refugia to lower disturbance impacts. These results suggest that wildlife reintroductions do not preclude human recreation on lands managed for multiple uses, as long as the species does not experience hunting pressure.

Reintroduced elk responded to a managed deer hunt by using disturbance refugia. Decreasing range sizes coupled with increasing movement rates over subsequent hunts seem to indicate that elk used well-known areas and made more direct movements out of the immediate vicinity of individual deer hunters. This theory is supported by relatively low range overlap between 9 days pre- and 9 days post-hunt. If elk were using only a fraction of their previous range, but were not abandoning it, they may have been identifying patches of refugia within their original range. As a result, elk were able to remain within Peck Ranch rather than relocate (Table 2). Elk have been shown to use refugia such as dense vegetation or ridges in response to elk hunts and other disturbances (Cassirer et al. 1992, Millspaugh et al. 2000, Conner et al. 2001). Thus, if elk can mitigate disturbance 
through habitat structure, and past experience has shown that the disturbance is short-lived, they may choose to stay within the extent of the disturbed area rather than relocating to refugia outside of the disturbed area. The study area in Missouri is predominately forested and features abundant ridges. It therefore seems unlikely that Missouri elk will abandon public lands with sufficient refugia in favor of undisturbed private land, which has led to landowner conflicts in other places (Burcham et al. 1999, Proffitt et al. 2010). Notably, sex and age were not important predictor variables for disturbance response in our study. This may be due to hunts coinciding with the rut, when males and females are typically near one another, or to disproportionate collar failures limiting information on males.

Reintroduced elk appear to acclimatize to disturbance over time. Hunt type and hunt year were the only predictor variables to explain both individual average speeds and individual range shifts. We believe that the significance of hunt type was its place in the hunt sequence, as other hunt-type specific variables (hunt duration, hunter numbers) did not contribute to the models. Decreasing range overlap within-year may show that elk had previously identified refugia and immediately returned to these areas over subsequent hunts; increasing range overlap among years may indicate that elk felt more secure expanding their space use despite the disturbance. Thus, elk used similar mitigation strategies despite theoretically more disruptive disturbance (additional noise, hunters). This may indicate that elk learned that mortality risk from deer hunters was low or non-existent, and their spatial use reflected that. Interestingly, number of hunts experienced by an individual elk was not an important predictor variable. This may be due to the 
gregarious nature of elk, or limited sample sizes due to collar failures may have precluded us from detecting any effect.

Reintroduced elk in our study appeared to be ambivalent to the presence of deer hunters. Jacobs' index scores were nearly 0 , indicating neither attraction nor avoidance between deer hunters and elk. The slight attraction observed in some hunts (Figure 6) may be an artifact of habitat configuration in Peck Ranch. Because deer hunters commonly hunt along the edges of fields and food plots, and elk are associated with these habitats, elk may have remained near areas of high hunter concentration. Additionally, elk in our study area may associate human presence with food, as pre-release holding pens provided both cut hay and clover, and management activities around Peck Ranch during the study period yielded downed tree-tops. Elk were observed returning to the holding facilities and visiting active management sites after the disturbance subsided, as has been observed in other studies (Cassirer et al. 1992, Edge and Marcum 1985). Finally, although elk were hunted in Kentucky, elk did not experience poaching after release in Missouri to our knowledge. Thus, elk may have adapted to site-specific human mortality risk within a few months post-release.

\section{MANAGEMENT IMPLICATIONS}

For adaptable species such as elk, reintroductions do not preclude heterospecific hunts where both are management priorities. If landscapes provide refugia within the extent of the disturbance, animals will not be forced to seek refugia outside of the disturbance. This allows public land managers to mitigate 
disturbance impacts and limit animals' relocation to private land where they may not be wanted. Timing was the most important factor for elk disturbance response, with elk acclimating to managed deer hunts over time. Human density only affected one of our disturbance metrics: population range size decreased with hunter numbers. This may be because elk were restricting movements to undisturbed parts of their range. If disturbance limits habitat availability for elk, managers may need to limit duration of intensive disturbance events, or prevent them from occurring during more sensitive times of the year, such as calving season, to prevent reduction in population growth. However, previous studies have shown that mortality risk increases the degree of wildlife disturbance response. Thus, animal behavior may change after Missouri implements its elk hunting season, so future research is merited. 


\section{LITERATURE CITED}

Beale, C.M. and P. Monaghan. 2004. Human disturbance: people as predation-free predators? Journal of Applied Ecology 41:335-343.

Benson, J. F., and M. J. Chamberlain. 2007. Space use, survival, movements, and reproduction of reintroduced Louisiana black bears. The Journal of Wildlife Management 71(7):2393-2403.

Bonnot, T.W., M.L. Wildhaber, J.J. Millspaugh, A.J. DeLonay, R.B. Jacobson, and J.L Bryan. 2011a. Discrete choice modeling of shovelnose sturgeon habitat selection in the Lower Missouri River. Journal of Applied Ichthyology $27: 291-300$

Bonnot, T.W., J.H. Schulz, and J.J. Millspaugh. 2011b. Factors affecting mourning dove harvest in Missouri. Wildlife Society Bulletin 9999(xx):1—9.

Brookshire, B.L. and D.C. Dey. 2000. Establishment and data collection of vegetationrelated studies on the Missouri Ozark Ecosystem Project study sites. Pages 1-18 in S.R. Shifley and B.L. Brookshire, editors. Missouri Ozark Forest Ecosystem Project site history, soils, landforms, woody and herbaceous vegetation, down wood, and inventory methods for the landscape experiment.

Burcham, M., W.D. Edge, C.L. Marcum. 1999. Elk use of private land refuges. Wildlife Society Bulletin 27(3):833-839.

Burnham, K.P., and D.R. Anderson. 2002. Model selection and multi-model inference: a practical information-theoretic approach. Second edition. Springer, New York, New York, USA. 
Cassirer, E.F., D.J. Freddy, and E.D. Ables. 1992. Elk responses to disturbance by cross-country skiers in Yellowstone National Park. Wildlife Society Bulletin $20(4): 375-381$.

Cole, E.K., M.D. Pope, and R.G. Anthony. 1997. Effects of road management on movement and survival of Roosevelt elk. Journal of Wildlife Management 61(4):1115-1126.

Conner, M.M., G.C. White, D.J. Freddy. 2001. Elk movement in response to earlyseason hunting in northwest Colorado. Journal of Wildlife Management 65(4):926-940.

Creel, S., J.E. Fox, A. Hardy, J. Sands, B. Garrott, and R.O. Peterson. 2002. Snowmobile activity and glucocorticoid stress responses in wolves and elk. Conservation Biology 16(3):809-814.

Dickens, M. J., D. J. Delehanty, and L. Michael Romero. 2010. Stress: An inevitable component of animal translocation. Biological Conservation 143(6):1329— 1341.

Diggle, P., K.-Y. Liang, and S. L. Zeger. 1994. Analysis of longitudinal data. Oxford University Press, New York, New York, USA.

Edge, W.D., and C.L. Marcum. 1985. Movements of elk in relation to logging disturbance. Journal of Wildlife Management, 49(4):926-930.

Franklin, A.B., D.R. Anderson, R.J. Gutierrez, and K.P. Burnham. 2000. Climate, habitat quality, and fitness in Northern Spotted Owl populations in Northwestern California. Ecological Monographs 70(4):539_590. 
Frair, J.L., E.H. Merrill, J.R. Allen, and M.S. Boyce. 2007. Know thy enemy: Experience affects elk translocation success in risky landscapes. Journal of Wildlife Management 71(2):541-554.

Frid , A. and L. Dill. 2002. Human-caused disturbance stimuli as a form of predation risk. Conservation Ecology 6(1):11.

Garcia Pereira, R.J., J.M. Barbanti Duarte, J.A. Negrao. 2006. Effects of environmental conditions, human activity, reproduction, antler cycle, and grouping on fecal glucocorticoids of free-ranging Pampas deer stags (Ozotoceros bezoarticus bezoarticus). Hormones and Behavior 49:114-122.

Gitzen, R.A., J.J. Millspaugh, and B.J. Kernohan. 2006. Bandwidth selection for fixedkernel analysis of animal utilization distributions. Journal of Wildlife Management 70(5):1334-1344.

Grignolio, S., E. Merli, P. Bongi, S. Cuiti, and M. Apollonio. 2011. Effects of hunting with hounds on a non-target species living on the edge of a protected area. Biological Conservation 144:641-649.

Gude, J.A., R.A. Garrot, J.J. Borkowski, and F. King. 2006. Prey risk allocation in a grazing ecosystem. Ecological Applications 16(1): 285-298.

Haydon, D.T., J.M. Morales, A. Yott, D.A. Jenkins, R. Rosatte, and J.M. Fryxell. 2008. Socially informed random walks: incorporating group dynamics into models of population spread and growth. Proceedings of the Royal Society B 275:1101-1109.

Homer, C., J. Dewitz, J. Fry, M. Coan, N. Hossain, C. Larson, N. Herold, A. McKerrow, J.N. VanDriel, and J. Wickham. 2007. Completion of the 2001 National Land 
Cover Database for the conterminous United States. Photogrammetric Engineering and Remote Sensing, Vol. 73(4):337-341.

Jachowski, D.S., R. Slotow, and J.J. Millspaugh. 2013. Delayed physiological acclimatization by African elephants following reintroduction. Animal Conservation 16:575-583.

Jacobs, J. 1974. Quantitative measurement of food selection: A modification of the forage ratio and Ivlev's electivity index. Oecologia 14(4):413—417.

Kenward, R.E. 2001. A manual for wildlife radio tagging. Academic Press, London, England, United Kingdom.

Kenward, R.E., S.S. Walls, A.B. South, and N.M. Casey. 2008. Ranges8: For the analysis of tracking and location data. Anatrack Ltd., Wareham, United Kingdom.

Knight, J.E. 1980. Effect of hydrocarbon development on elk movements and distribution in northern Michigan. Ph.D. University of Michigan.

Kuck, L., G.L. Hompland, and E.H. Merrill. 1985. Elk calf response to simulated mine disturbance in southeast Idaho. Journal of Wildlife Management 49(3):751757.

Larkin, J.L., D.S. Maehr, J.J. Cox, M.W. Wichrowski, and R.D. Crank. 2002. Factors affecting reproduction and population growth in a restored elk Cervus elaphus nelsoni population. Wildlife Biology 8:49-54.

Loehr, J., M. Kovanen, J. Carey, H. Hogmander, C. Jurasz, S. Karkkainen, J. Suhonen, and H. Ylonen. 2005. Gender- and age-class-specific reactions to human disturbance in a sexually dimorphic ungulate. Canadian Journal of Zoology 83:1602-1607. 
Millspaugh, J.J., G.C. Brundige, R.A. Gitzen, and K.J. Raedeke. 2000. Elk and hunter space-use sharing in South Dakota. Journal of Wildlife Management 64(4):994-1003.

Millspaugh, J.J., G.C. Brundige, R.A. Gitzen, and K.J. Raedeke. 2004. Herd organization of cow elk in Custer State Park, South Dakota. Wildlife Society Bulletin 32(2):506-514.

Missouri Department of Conservation. 2010. Elk restoration in Missouri.

Missouri Department of Conservation. 2009. Peck Ranch Conservation Area

Brochure. <http://extra.mdc.mo.gov/documents/area_brochures/5203.pdf>

Missouri Department of Conservation. 2014. Peck Ranch Conservation Area Summary. <http://mdc4.mdc.mo.gov/applications/moatlas/AreaSummaryPage.aspx?tx tAreaID $=5203>$

Naylor, L.M., M.J. Wisdom, and R.G. Anthony. 2009. Behavioral responses of North American elk to recreational activity. Journal of Wildlife Management 73(3):328-338.

Phillips, G.E. and A.W. Alldredge. 2000. Reproductive success of elk following disturbance by humans during calving season. Journal of Wildlife Management 64(2):521-530.

Proffitt, K.M., J.L. Grigg, K.S. Hamlin, J. Cunningham, J.A. Gude, and C. Jourdonnais. 2010. Changes in elk resource selection and distributions associated with a late-season elk hunt. Journal of Wildlife Management 74(2):210—218. 
Ruth, T. K., K. A. Logan, L. L. Sweanor, M. G. Hornocker, and L. J. Temple. 1998. Evaluating cougar translocation in New Mexico. The Journal of Wildlife Management 62(4):1264-1275.

Sager-Fradkin, K.A., K.J. Jenkins, R.A. Hoffman, P.J. Happe, J.J. Beecham, and R.G. Wright. 2006. Fix success and accuracy of global positioning system collars in old-growth temperate coniferous forests. Journal of Wildlife Management 71(4):1298-1308.

Schultz, R.D. and J.A. Bailey. 1978. Responses of National Park elk to human activity. Journal of Wildlife Management 42(1):91-100.

Seaman, D.E., J.J. Millspaugh, B.J. Kernohan, G.C. Brundige. 1999. Effects of sample size on kernel home range estimates. Journal of Wildlife Management 63(2): $739-747$.

Seddon, P.J., P.S. Soorae, and F. Launay. 2005. Taxonomic bias in reintroduction projects. Animal Conservation 8:51-58.

Seidel, K.D. 1992. Statistical properties and applications of a new measure of joint space use for wildlife. Thesis, University of Washington, Seattle, USA.

Shifley, S.R., L.M. Roovers, R.G. Jensen, and D.R. Larsen. 2000. Composition and structure of woody forest vegetation in the Missouri Ozarks. Pages 71-106 in S.R. Shifley and B.L. Brookshire, editors. Missouri Ozark Forest Ecosystem Project site history, soils, landforms, woody and herbaceous vegetation, down wood, and inventory methods for the landscape experiment. 
Shively, K.J., A.W. Alldredge, and G.E. Phillips. 2005. Elk reproductive response to removal of calving season disturbance by humans. Journal of Wildlife Management 69(3):1073-1080.

Stedman, R., D.R. Diefenbach, C.B. Swope, J.C. Finley, A.E. Luloff, H.C. Zinn, G.J. San Julian, and G.A. Wang. 2004. Integrating wildlife and human-dimensions research methods to study hunters. Journal of Wildlife Management 68(4):762-773.

Taylor, A.R. and R.L. Knight. 2003. Wildlife responses to recreation and associated visitor perceptions. Ecological Applications 13(4):951—963.

Teixeira, C. P., C. S. de Azevedo, M. Mendl, C. F. Cipreste, and R. J. Young. 2007(1). Revisiting translocation and reintroduction programmes: the importance of considering stress. Animal Behaviour 73:1-13.

Telesco, R.L, F.T. Van Manen, J.D. Clark, and M.E. Cartwright. 2007. Identifying sites for elk restoration in Arkansas. Journal of Wildlife Management 71(5):1393-1403.

Turchin, P. 1998. Quantitative analysis of movement: measuring and modeling population redistribution in animals and plants. Sinauer Associates, Sunderland, Massachusetts.

United States Geological Survey. 2007. A human-dimensions review of humanwildlife disturbance: a literature review of impacts, frameworks, and management solutions.

<https://www.fort.usgs.gov/sites/default/files/products/publications/2156 7/21567.pdf > 
Van Winkle, W. 1975. Comparison of several probabilistic home-range models. Journal of Wildlife Management. 39(1):118-123.

Vieira, M.E.P., M.M. Connor, G.C. White, D.J. Freddy. 2003. Effects of archery hunter numbers and opening dates on elk movement.

Virginia Department of Game and Inland Fisheries. 2010. Elk restoration and management options for southwest Virginia.

Walls, S.S., and R.E. Kenward. 2001. Spatial consequences of relatedness and age in buzzards. Animal Behaviro 61:1069-1078.

White, G.C. and R.A. Garrott. 1990. Analysis of wildlife radio-tracking data. Academy Press Inc., San Diego, California.

Yott, A., R. Rosatte, J. A. Schaefer, J. Hamr, and J. Fryxell. 2011. Movement and spread of a founding population of reintroduced elk (Cervus elaphus) in Ontario, Canada. Restoration Ecology 19:70-77. 


\section{TABLES}

Table 1. Sample sizes for each analysis to assess disturbance response of reintroduced elk to managed deer hunts on Peck Ranch Conservation Area in south-central Missouri 20112013. Year 2 included animals released in year1 and year 2 . Year 3 included animals released in year 1 , year 2 , and year 3 .

\begin{tabular}{llll}
\hline & Year 1 & Year 2 & Year 3 \\
\hline All Elk & 29 & 36 & 43 \\
Average Speed & 26 & 28 & 34 \\
Range Shifts & 23 & 17 & 32 \\
Range Size & 29 & 36 & 43 \\
Interaction Analysis & 26 & 32 & 40 \\
\hline
\end{tabular}


Table 2. Numbers of reintroduced elk that left Peck Ranch Conservation Area at any point during 3 annual managed deer hunts in south-central Missouri 2011-2013.

\begin{tabular}{|c|c|c|c|c|}
\hline Hunt & $\begin{array}{l}\text { Elk Leaving } \\
\text { Peck Ranch }\end{array}$ & $\begin{array}{l}\text { Total Elk } \\
\text { Observed }\end{array}$ & $\begin{array}{l}\text { Percent Elk Leaving } \\
\text { Peck Ranch }\end{array}$ & $\begin{array}{l}\text { Maximum Duration Off } \\
\text { Peck Ranch Post-Hunt }\end{array}$ \\
\hline 2011 Youth & 11 & 29 & $40.7 \%$ & 1 Day \\
\hline 2011 Archery & 0 & 29 & - & - \\
\hline 2011 Muzzleloader & 0 & 29 & - & - \\
\hline 2012 Youth & 0 & 36 & - & - \\
\hline 2012 Archery & 2 & 36 & $5.6 \%$ & 3 Days \\
\hline 2012 Muzzleloader & 20 & 36 & $55.6 \%$ & 0 Days \\
\hline 2013 Youth & 1 & 43 & $2.3 \%$ & 0 Days \\
\hline 2013 Archery & 0 & 43 & - & - \\
\hline 2013 Muzzleloader & 3 & 43 & $7.0 \%$ & 3 Days \\
\hline
\end{tabular}


Table 3. Hunter registration and GPS study participation rates for youth, archery, and muzzleloader deer hunts 2011-2012 on Peck Ranch Conservation Area in south-central Missouri.

\begin{tabular}{lllll}
\hline Hunt Type & Year & Hunters & Hunters & Participation \\
& & Registered & Participating & Rate (\%) \\
\hline Youth & 2011 & 56 & 53 & 94.6 \\
Archery & 2011 & 150 & 133 & 88.7 \\
Muzzleloader & 2011 & 175 & 148 & 84.6 \\
Youth & 2012 & 57 & 57 & 100 \\
Archery & 2012 & 139 & 131 & 94.2 \\
Muzzleloader & 2012 & 177 & 154 & 88.7 \\
Youth & 2013 & 57 & 48 & 84.2 \\
Archery & 2013 & 159 & 121 & 76.1 \\
Muzzleloader & 2013 & 81 & - & - \\
\hline Total & - & 1051 & 845 & - \\
Average & - & 116.8 & 105.6 & 88.9 \\
\hline
\end{tabular}


Table 4. Model selection results for factors contributing to elk population range size during managed deer hunts for elk reintroduced to south-central Missouri 2011-2012. We report log likelihood (LL), number of parameters (K), Akaike Information Criterion (AIC), AIC corrected for small sample sizes (AICc), and the difference in AICc from the most supported model $\left(\triangle \mathrm{AIC}_{\mathrm{C}}\right)$.

\begin{tabular}{|c|c|c|c|c|c|c|c|c|}
\hline Rank & Model No. & Model & LL & $\mathbf{K}$ & AIC & AICC & $\Delta \mathrm{AIC}_{\mathrm{C}}$ & $w_{i}$ \\
\hline 1 & 1 & Hunter Numbers & $1.0036 \mathrm{E}-186$ & 2 & 860.555 & 861.055 & 0 & 0.797 \\
\hline \multirow[t]{2}{*}{2} & 2 & Hunt Type or Place in the Hunt & $6.4932 \mathrm{E}-187$ & 3 & 863.425 & 864.469 & 3.414 & 0.145 \\
\hline & & Sequence & & & & & & \\
\hline 3 & 6 & Hunt Type, Timing Relative to Hunt & $1.4488 \mathrm{E}-186$ & 5 & 865.82 & 868.677 & 7.623 & 0.018 \\
\hline 4 & 4 & Hunt Year & $1.5091 \mathrm{E}-187$ & 3 & 866.344 & 867.387 & 6.333 & 0.034 \\
\hline 5 & 3 & Hunt Duration & $6.1835 \mathrm{E}-189$ & 2 & 870.733 & 871.233 & 10.179 & 0.005 \\
\hline 6 & 5 & Timing Relative to Hunt & 8.9346E-189 & 3 & 871.997 & 873.041 & 11.986 & 0.002 \\
\hline
\end{tabular}




\section{FIGURES}

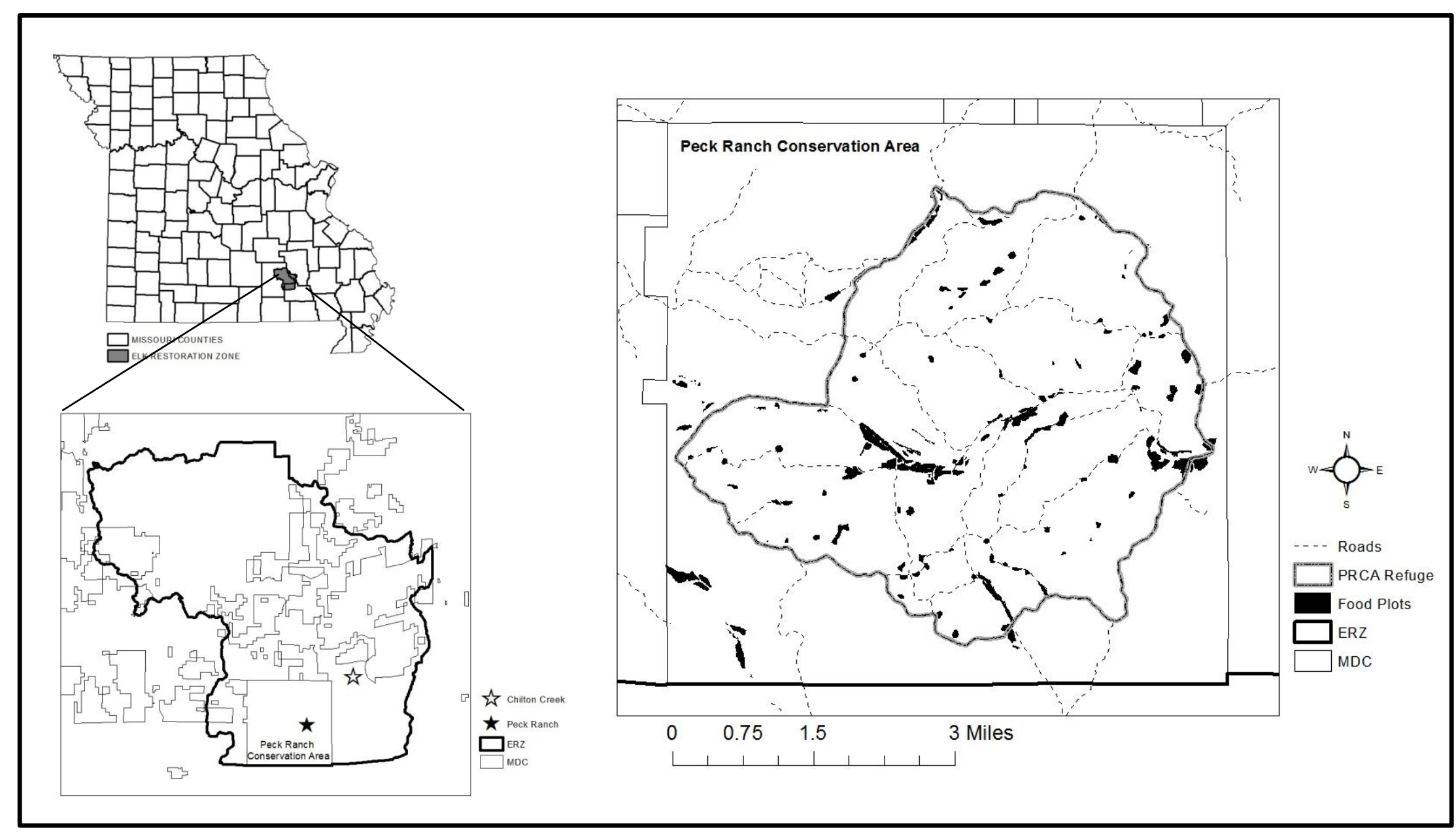

Figure 1. We studied elk reintroduced to an Elk Restoration Zone (ERZ) in south-central Missouri 2011-2013. Elk were

released at the Missouri Department of Conservation's Peck Ranch Conservation Area (Peck Ranch, filled star) and The Nature 
Conservancy's Chilton Creek Preserve (hollow star). We assessed elk disturbance response to a managed deer hunt occurring within the refuge area of Peck Ranch. Hunters were allowed to access the majority of the roads within the Peck Ranch refuge (dashed lines). 


\section{Hunt Type Effect on Elk Speed Before, During, and After Managed Hunts}

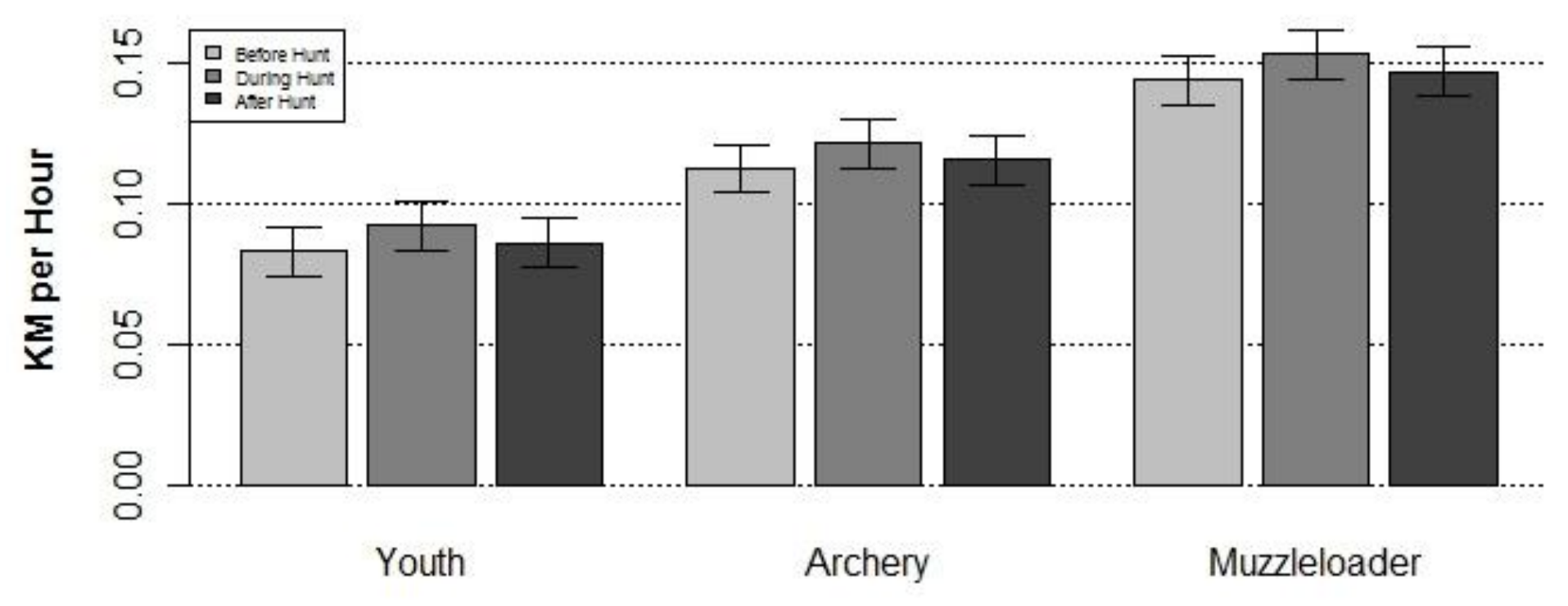

Hunt Type

Figure 2. Predicted effects of hunt type or place in the hunt sequence on individual elk average speeds before, during, and after managed deer hunts in south-central Missouri, 2011-2013. Legend denotes before (light gray), during (medium gray), and after (dark gray) hunts. 


\section{Year Effect on Elk Speed Before, During, and After Hunts}

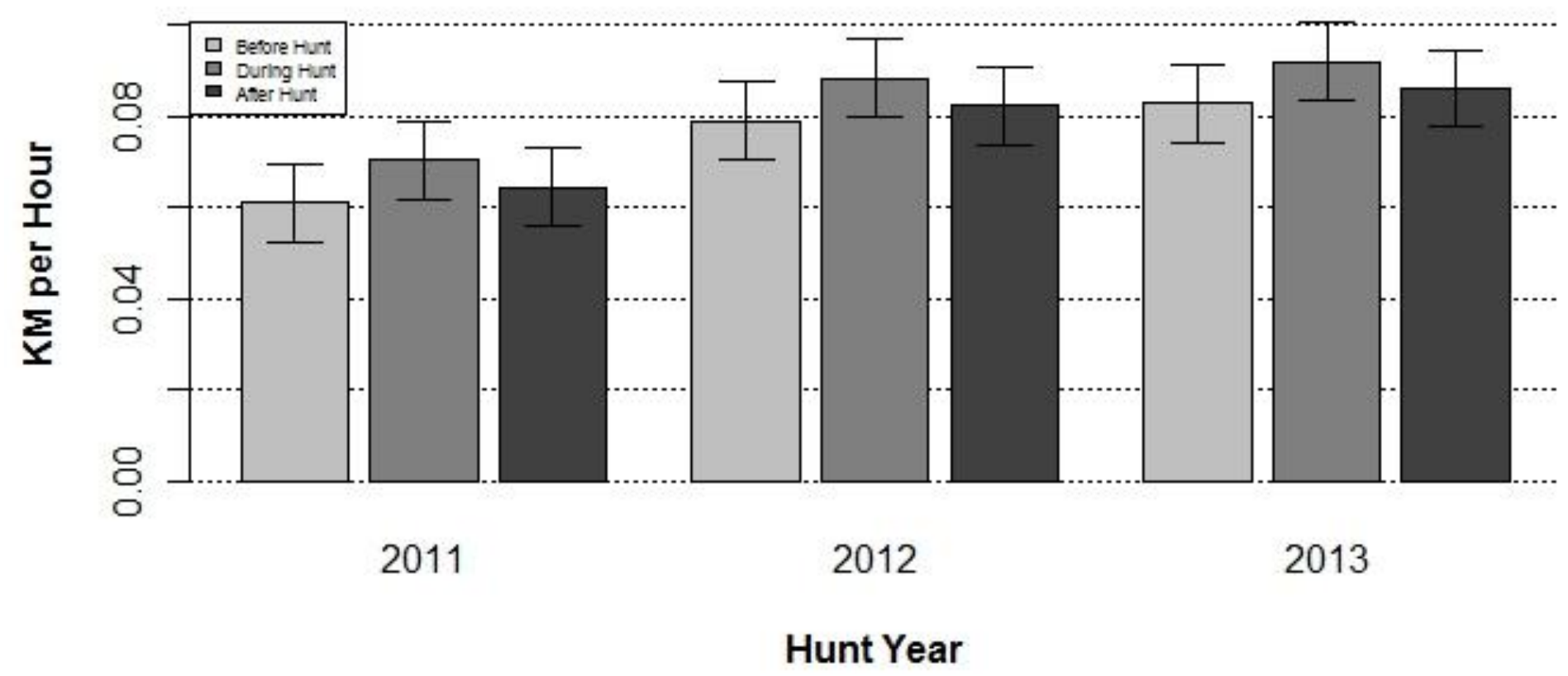

Figure 3. Predicted responses for the impact of year on individual elk average speeds before, during, and after managed deer hunts in south-central Missouri, 2011-2013. Legend indicates before (light gray), during (medium gray), and after (dark gray) hunts. 


\section{Year and Hunt Type Effect on Elk Range Shifts Before vs. After Hunts}

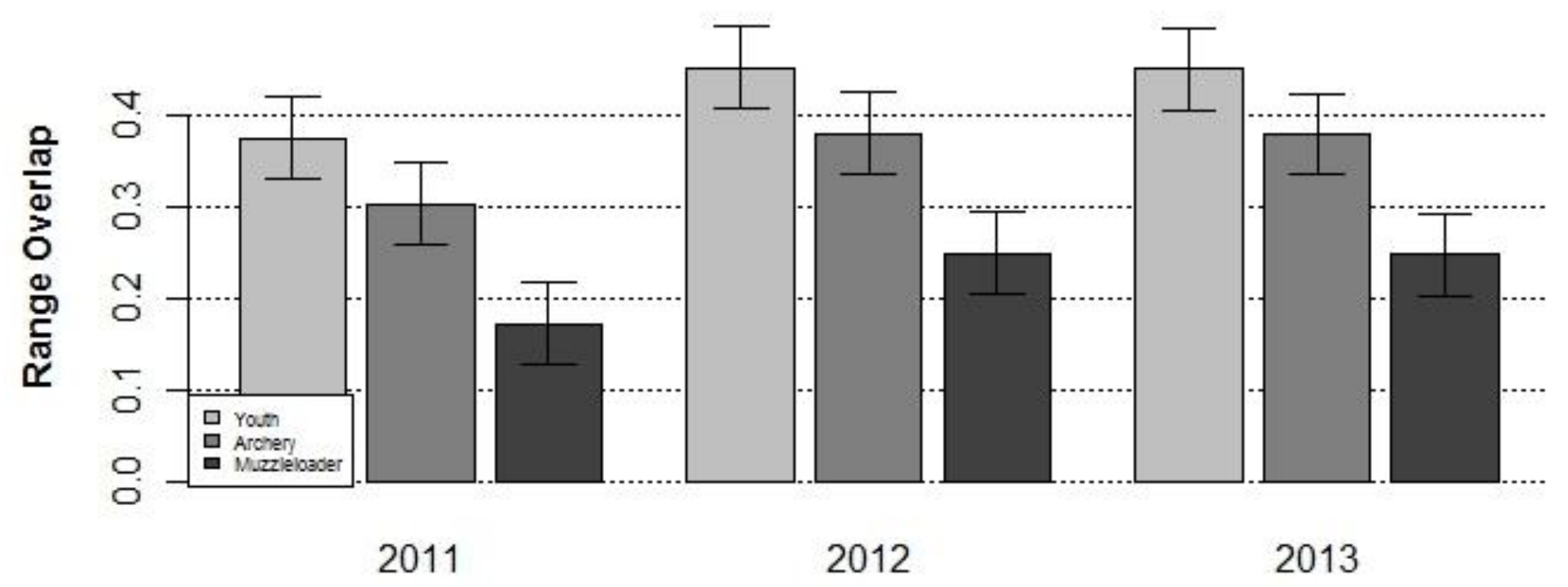

Hunt Type and Hunt Year

Figure 4. Predicted outcomes for the impact of hunt type and hunt year on before vs. after hunt range shifts for individual elk in south-central Missouri 2011-2013. Legend indicates youth (light gray), archery (medium gray), and muzzleloader (dark gray) hunts. 
Hunter Numbers Effect on Elk Range Size

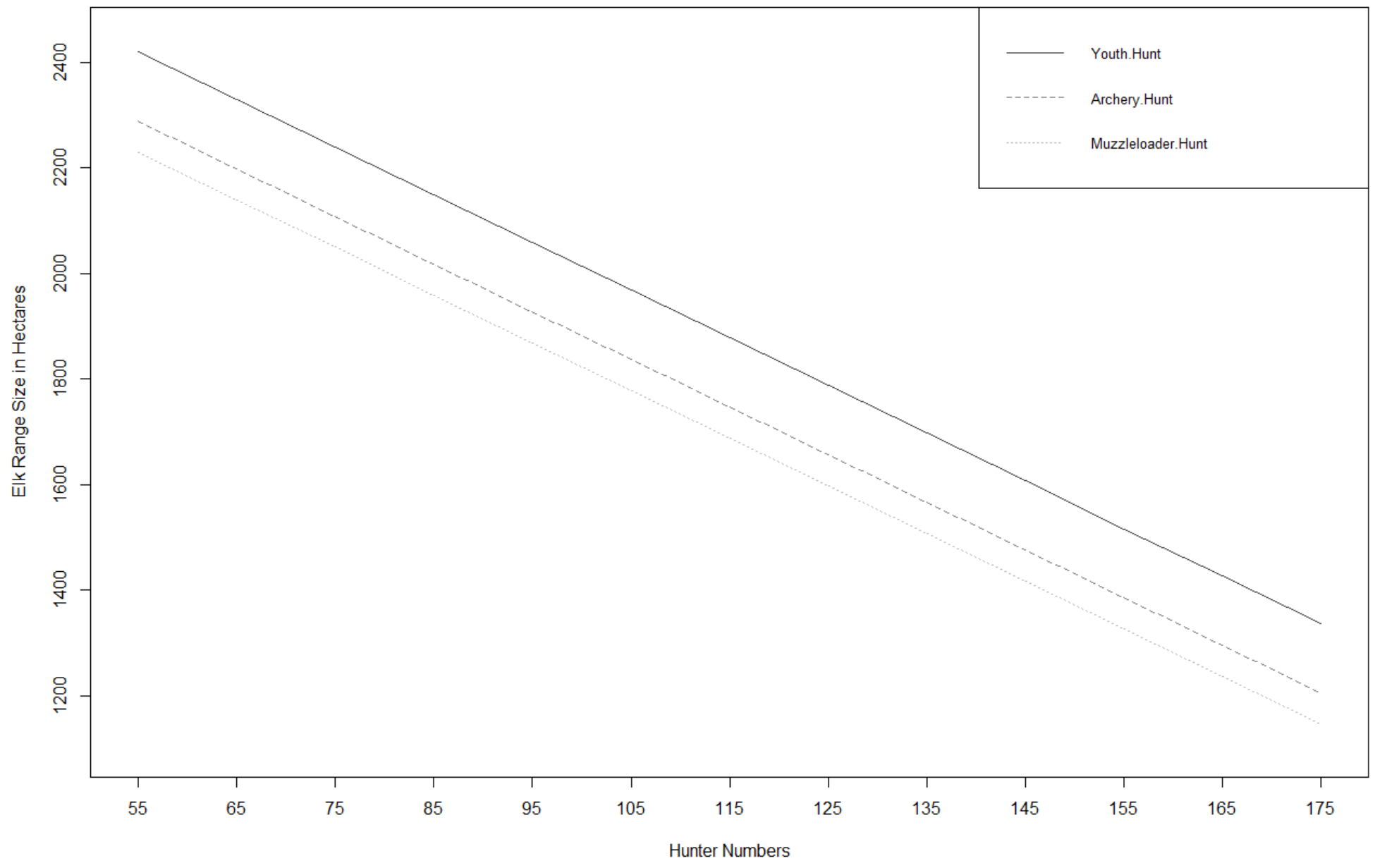

Figure 5. Effect of hunter numbers on population range size for elk reintroduced to south-central Missouri during youth, archery, and muzzleloader managed deer hunts (2011-2013). 
Elk-Hunter Interactions During Managed Deer Hunts

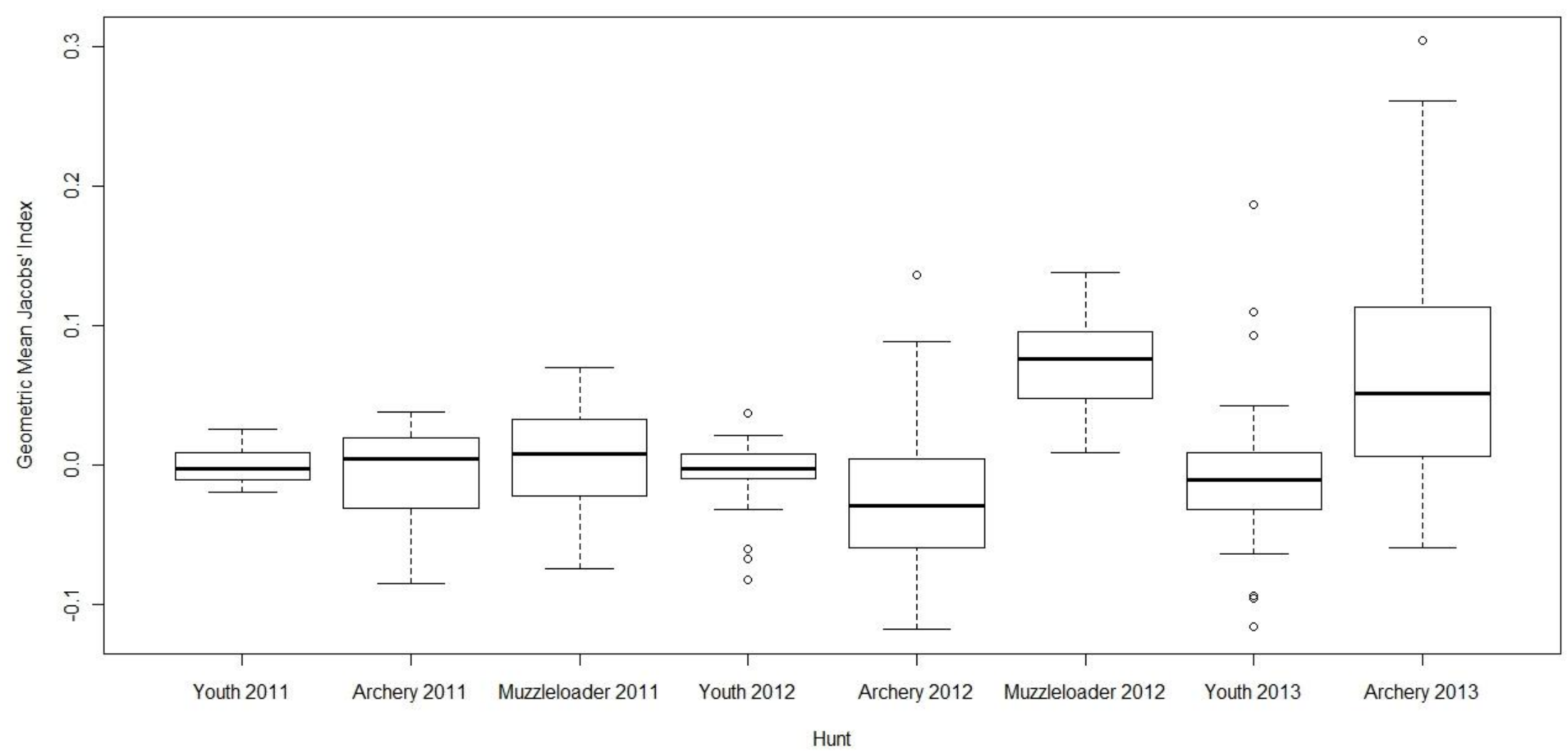

Figure 6. Average individual elk geometric mean Jacobs' Index scores between simultaneous elk-hunter location pairs. Elkhunter interactions were examined during managed youth, archery, and muzzleloader deer hunts in south-central Missouri 2011-2013. 


\section{APPENDICES}

Appendix 1. Candidate model set used to assess the relative importance of hunter numbers, hunt type, place in the hunt sequence, hunt duration, hunt year, number of hunts experienced by an individual elk, time period relative to hunt, hunter days, noise potential, sex, age, release site, and release year on individual elk average speeds during managed deer hunts in south-central Missouri in 2011, 2012, and 2013.

\section{Hypothesis}

Only hunter numbers influences response

Only hunt type or place in the hunt

sequence influences response

Only hunt duration influences response

Only hunt year influences response

Only number of hunts experienced influences response

Only timing relative to the hunt (before during, after) influences response

Non-hunt factors influence response

Only sex influences response

Only age influences response

Only release site influence response

Only release year influences response

\section{Model Structure}

$\beta_{0}+\beta_{1}$ (Hunter Numbers)

$$
\beta_{0}+\beta_{2} \text { (Hunt Type) }
$$

$$
\beta_{0}+\beta_{3} \text { (Hunt Duration) }
$$

$\beta_{0}+\beta_{4}$ (Hunt Year)

$\beta_{0}+\beta_{5}$ (Number of Hunts Experienced)

$\beta_{0}+\beta_{6}$ (Timing Relative to Hunt)

$$
\begin{aligned}
& \beta_{0}+\beta_{7}(\text { Sex })+\beta_{8}(\text { Age })+\beta_{9}(\text { Release Site })+ \\
& \beta_{10}(\text { Release Year }) \\
& \beta_{0}+\beta_{7}(\text { Sex }) \\
& \beta_{0}+\beta_{8}(\text { Age }) \\
& \beta_{0}+\beta_{9}(\text { Release Site }) \\
& \beta_{0}+\beta_{10}(\text { Release Year })
\end{aligned}
$$




$\begin{array}{ll}\text { Release factors (site and year) influence } & \beta_{0}+\beta_{9} \text { (Release Site) }+\beta_{10} \text { (Release Year) } \\ \text { response } & \beta_{0}+\beta_{7}(\text { Sex })+\beta_{8} \text { (Age) } \\ \text { Demographic factors (sex and age) } & \\ \text { influence response } & \beta_{0}+\beta_{6} \text { (Timing Relative to Hunt) }+\beta_{2}(\text { Hunt } \\ \text { Specific hunt and timing relative to each } & \text { Type) }+\beta_{4} \text { (Hunt Year) } \\ \text { hunt influence response } & \end{array}$


Appendix 2. Candidate models used to determine the relative importance of hunter numbers, hunt type, place in the hunt sequence, hunt duration, hunt year, number of hunts experienced by an individual elk, hunter days, noise potential, sex, age, release site, and release year on individual elk range shifts around managed deer hunts in south-central Missouri in 2011, 2012, and 2013.

\section{Hypothesis}

Model Structure

Only hunter numbers influences response

$\beta_{0}+\beta_{1}$ (Hunter Numbers)

Only hunt type or place in the hunt

$\beta_{0}+\beta_{2}$ (Hunt Type)

sequence influences response

Only hunt duration influences response

$\beta_{0}+\beta_{3}$ (Hunt Duration)

Only hunt year influences response

$\beta_{0}+\beta_{4}$ (Hunt Year)

Only number of hunts experienced

$\beta_{0}+\beta_{5}$ (Number of Hunts Experienced)

influences response

Non-hunt factors influence response

$\beta_{0}+\beta_{6}($ Sex $)+\beta_{7}($ Age $)+\beta_{8}($ Release Site $)+$

$\beta_{9}$ (Release Year)

Only sex influences response

$\beta_{0}+\beta_{6}($ Sex $)$

Only age influences response

$\beta_{0}+\beta_{7}$ (Age)

Only release site influence response

$\beta_{0}+\beta_{8}$ (Release Site)

Only release year influences response

$\beta_{0}+\beta_{9}$ (Release Year)

Release factors (site and year) influence

$\beta_{0}+\beta_{8}$ (Release Site) $+\beta_{9}$ (Release Year) response 
Demographic factors (sex and age) $\quad \beta_{0}+\beta_{6}($ Sex $)+\beta_{7}$ (Age)

influence response

A specific hunt is the main influence on $\quad \beta_{0}+\beta_{2}$ (Hunt Type) $+\beta_{4}$ (Hunt Year) response 
Appendix 3. Candidate models used to determine the relative importance of hunter numbers, hunt type, place in the hunt sequence, hunt duration, hunt year, and timing in relation to each hunt on elk population range size during managed deer hunts in southcentral Missouri in 2011, 2012, and 2013.

\section{Hypothesis Model Structure}

Only hunter numbers influences response $\beta_{0}+\beta_{1}$ (Hunter Numbers)

Only hunt type or place in the hunt $\beta_{0}+\beta_{2}$ (Archery) $+\beta_{3}$ (Muzzleloader) sequence influences response

Only hunt duration influences response $\beta_{0}+\beta_{4}$ (Hunt Duration)

Only hunt year influences response $\beta_{0}+\beta_{5}($ Hunt Year 1$)+\beta_{6}($ Hunt Year 2$)$

Only timing relative to each hunt influences

$\beta_{0}+\beta_{7}$ (During) $+\beta_{8}$ (After) response

Specific hunt and timing relative to each $\beta_{0}+\beta_{2}$ (Archery) $+\beta_{3}($ Muzzleloader $)+$ hunt influence response $\beta_{7}$ (During) $+\beta_{8}$ (After) 